San Jose State University

SJSU ScholarWorks

Master's Theses

Master's Theses and Graduate Research

1994

\title{
The synthesis, characterization, and reactivity of a new zirconocene compound, and examination of an organometallic alkylation reaction
}

Robert William Towne

San Jose State University

Follow this and additional works at: https://scholarworks.sjsu.edu/etd_theses

\section{Recommended Citation}

Towne, Robert William, "The synthesis, characterization, and reactivity of a new zirconocene compound, and examination of an organometallic alkylation reaction" (1994). Master's Theses. 876.

DOI: https://doi.org/10.31979/etd.28d6-cn5d

https://scholarworks.sjsu.edu/etd_theses/876

This Thesis is brought to you for free and open access by the Master's Theses and Graduate Research at SJSU ScholarWorks. It has been accepted for inclusion in Master's Theses by an authorized administrator of SJSU ScholarWorks. For more information, please contact scholarworks@sjsu.edu. 


\section{INFORMATION TO USERS}

This manuscript has been reproduced from the microfilm master. ÜMI films the text directly from the original or copy submitted. Thus, some thesis and dissertation copies are in typewriter face, while others may be from any type of computer printer.

The quality of this reproduction is dependent upon the quality of the copy submitted. Broken or indistinct print, colored or poor quality illustrations and photographs, print bleedthrough, substandard margins, and improper alignment can adversely affect reproduction.

In the unlikely, event that the author did not send UMI a complete manuscript and there are missing pages, these will be noted. Also, if unauthorized copyright material had to be removed, a note will indicate the deletion.

Oversize materials (e.g., maps, drawings, charts) are reproduced by sectioning the original, beginning at the upper left-hand corner and continuing from left to right in equal sections with small overlaps. Each original is also photographed in one exposure and is included in reduced form at the back of the book.

Photographs included in the original manuscript have been reproduced xerographically in this copy. Higher quality 6 " $x$ 9" black and white photographic prints are available for any photographs or illustrations appearing in this copy for an additional charge. Contact UMI directly to order.

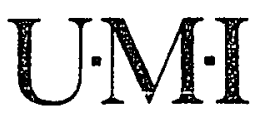



Order Number 1959059

The synthesis, characterization, and reactivity of a new zirconocene compound, and examination of an organometallic alkylation reaction

Towne, Robert William, M.S.

San Jose State University, 1994

Copyright (C1994 by Towne, Robert William. All rights reserved.

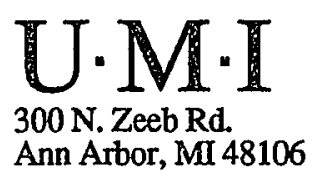



THE SYNTHESIS, CHARACTERIZATION, AND REACTIVITY

OF A NEW ZIRCONOCENE COMPOUND, AND

EXAMINATIONN OF AN ORGANOMETALLIC

ALKYLATION REACTION

\author{
A Thesis \\ Presented to \\ The Faculty of the Department of Chemistry \\ San Jose State University
}

\author{
In Partial Fulfillment \\ of the Requirements for the Degree \\ Master of Science
}

By

Robert William Towne

August, 1994 
(C) 1994

Robert William Towne

ALL RIGHTS RESERVED 
APPROVED FOR THE DEPARTMENT OF CHEMISTRY
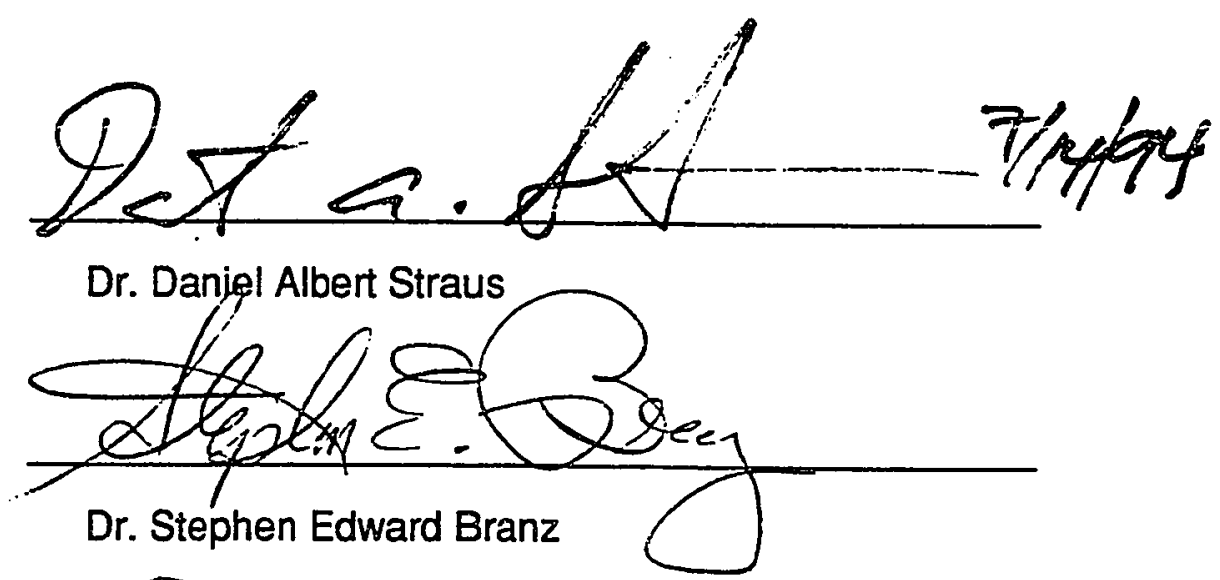

Sars become

Dr. Sam P. Prone

APPROVED FOR THE UNIVERSITY

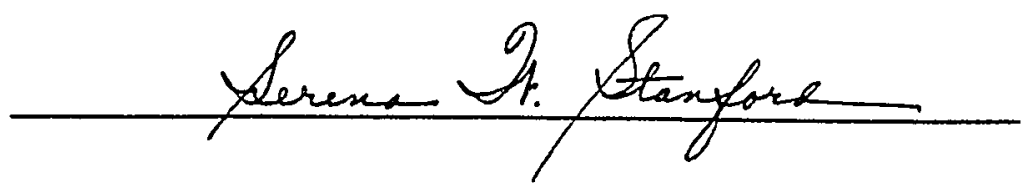




\begin{abstract}
THE SYNTHESIS, CHARACTERIZATION, AND REACTIVITY

OF THE FIRST OXIMATO-ZIRCONOCENE COMPLEXES, AND

EXAMINATION OF AN ORGANOMETALLIC

ALKYLATION REACTION

by Robert $\mathrm{W}$. Towne
\end{abstract}

Syntheses and characterization of the first zirconocene-oximato complexes, $\left(\eta^{5}-\mathrm{C}_{5} \mathrm{H}_{5}\right)_{2} \mathrm{Zr}(\mathrm{X}) \mathrm{ON}=\mathrm{CRR}^{\prime}\left(\mathrm{X}=\mathrm{CH}_{3}, \mathrm{Cl} ; \mathrm{R}=p-\mathrm{C}_{6} \mathrm{H}_{4} \mathrm{CH}_{3}, \mathrm{R}^{\prime}=\mathrm{H}\right.$; $\mathbf{R}, \mathbf{R}^{\prime}=\mathrm{CH}_{3}$ ) are discussed. Their properties are compared to those of known titanocene-oximates. Preliminary reactivity studies for these compounds with acid, base, and hydridozirconocenes remain inconclusive.

The Grignard-like activity of alkylzirconocenes in the presence of excess base is examined. Products of the addition of different stoichiometric amounts of potassium tert-butoxide to $\left(\eta^{5}-\mathrm{C}_{5} \mathrm{H}_{5}\right)_{2} \mathrm{ZrXR}\left(\mathrm{X}, \mathrm{R}=\mathrm{CH}_{3} ; \mathrm{X}=\mathrm{Cl}, \mathrm{R}=\mathrm{CH}_{3}\right.$; $\left.X, \mathrm{R}=\mathrm{CH}_{2} \mathrm{C}_{6} \mathrm{H}_{5}\right)$ and $\mathrm{NaN}\left(\mathrm{Si}\left(\mathrm{CH}_{3}\right)_{3}\right)_{2}$ to $\left(\eta^{5}-\mathrm{C}_{5} \mathrm{H}_{5}\right)_{2} \mathrm{Zr}\left(\mathrm{CH}_{3}\right)_{2}$ in various solvents are examined by NMR-spectroscopy. The selectivity of $\left(\eta^{5}-\mathrm{C}_{5} \mathrm{H}_{5}\right)_{2} \mathrm{Zr}\left(\mathrm{CH}_{3}\right)_{2}$ or $\left(\eta^{5}-\mathrm{C}_{5} \mathrm{H}_{5}\right)_{2} \mathrm{Zr}\left(\mathrm{CH}_{3}\right) \mathrm{Cl}$ in the presence of excess potassium tert-butoxide as methylating agents for aldehydes and benzophenone is compared with Grignards and zirconium and titanium alkoxyalkyls. 
To my wife,

Linda 


\section{ACKNOWLEDGEMENTS}

I would like to thank Dan Straus for his encouragement and support beginning in my undergraduate years at San Jose State and for his contagious. enthusiasm for teaching and particularly for organometallic chemistry. Thanks, also, to Steve Branz and Sam Perone, my committee members, and to Gerry Selter and Roy Okuda. All of you made the study of chemistry here a joy. Dan, thanks, too, for helping me to "crank-out" this thesis through our discussions and a lot of heavy proof-reading on your part. Steve, thanks for the many helpful suggestions, too.

Thanks to my employer, Syntex, for financial support and supplying the work environment that so greatly values education. Thanks to my supervisors, $\mathrm{Al}$ Holstein and Tom Alfredson for putting up with my strange work schedules, and my friends and collegues, there, who've given me "moral support" and whose friendship I value. Thanks, also, for the encouragement of Dave Robertson, lan Massey, and Lew Throop.

Thanks to several fellow students, two whose camaraderie and friendship I continue to enjoy at work, John Chiang and Steve Ferla. They, Jean Wren, and Gary Borges set high standards for themselves in their educational pursuits, the latter two particularly in their oral presentations, that I used as an example for myself.

I am fortunate to have a wonderful supportive family. I am proud of my two sons, Bill and Braden, who have grown into fine young men despite my absence while attending to school or work these last few years. I am most grateful for my best friend, my wife, Linda, whose sacrifice was very great during these years and whose support and belief in me keeps me going. 


\section{TABLE OF CONTENTS}

\section{Page}

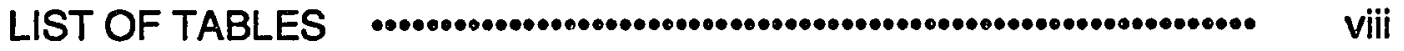

LIST OF FIGURES AND SCHEMES $\quad \cdots \cdots \cdots$

CHAPTER 1. The Synthesis, Characterization, and Reactivity of the First Oximato-Zirconocene Complexes $\quad \cdots \quad 1$

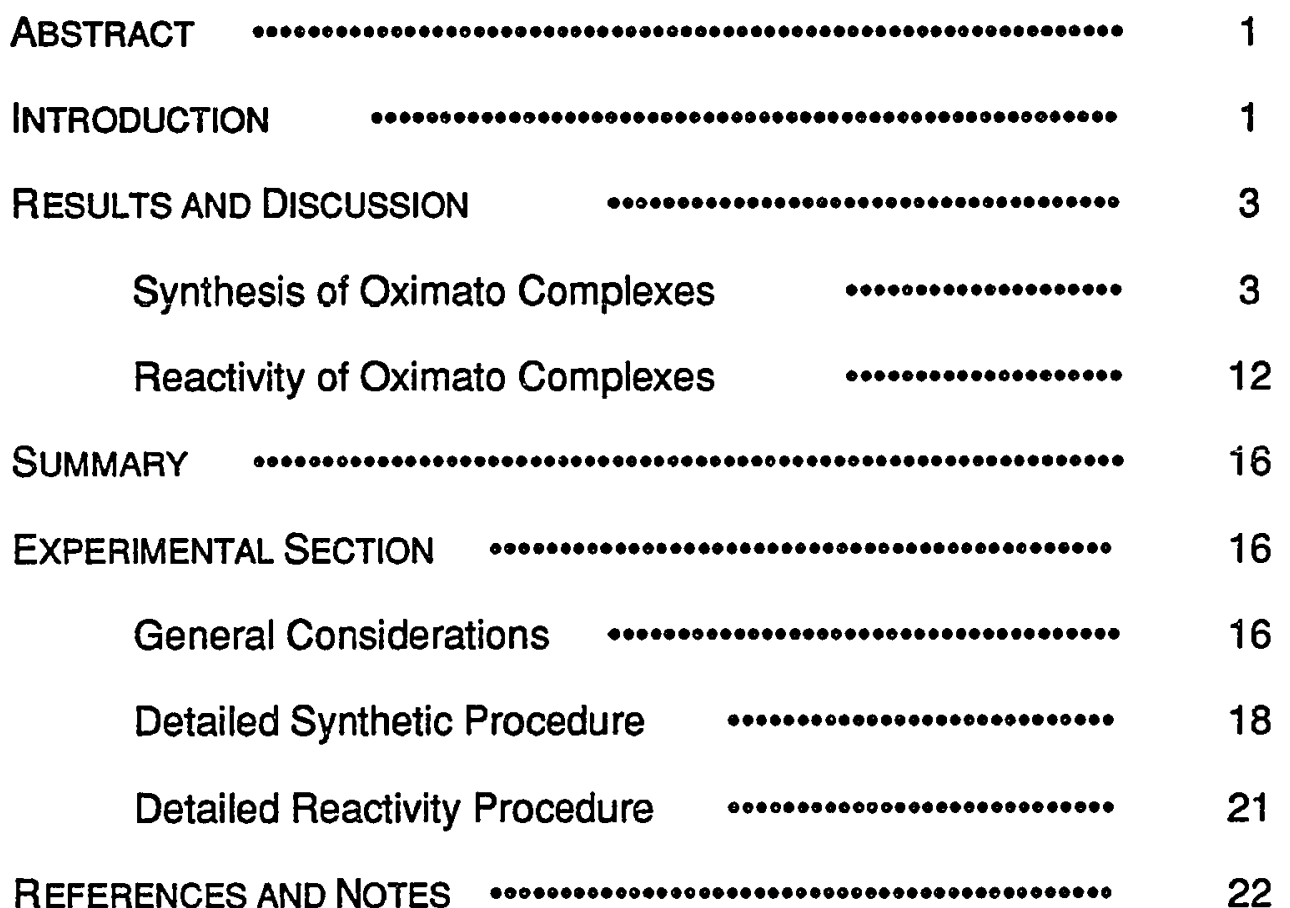

CHAPTER 2. An Examination of the Reaction of Some Zirconocenes With Potassium tert-Butoxide in Different Solvents and Some Related Experiments Using Nuclear Magnetic Resonance Spectroscopy

ABSTRACT

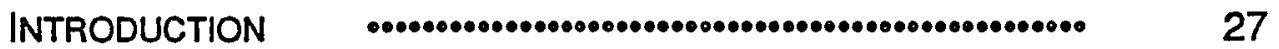

RESULTS AND DISCUSSION

SUMMARY 


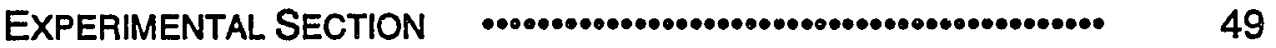

General Considerations $\quad$....................................... 49

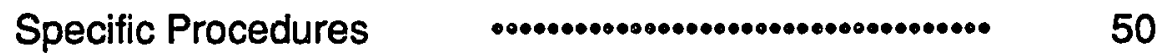

REFERENCES AND NOTES $\quad$

CHAPTER 3. An Indirect Examination of the Methylation of Aldehydes and Ketones Using Zirconocenes in the Presence of Excess

Base $\quad 00000000000000000000000000000000000000000000000000000000000$

ABSTRACT $\quad 0.000000000000000000000000000000000000000000000000000000061$

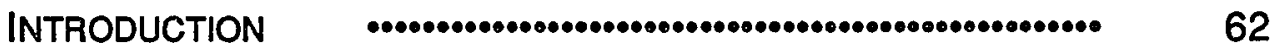

RESULTS AND DISCUSSION $\quad$

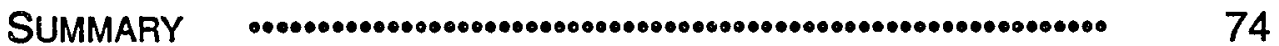

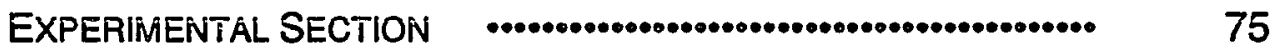

General Considerations $\quad$

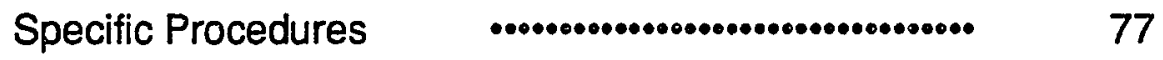

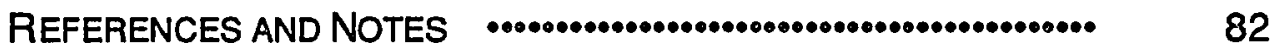

APPENDIX 1. Zirconocene-Oximato Complex Preparation and

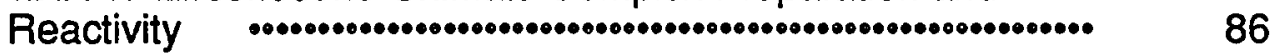

APPENDIX 2. Competition Reactions (Benzaldehyde vs "Compound") Zirconocene/Base Reaction $\quad$...0...0.0.0...................0.....0.......

APPENDIX 3. Competition Reactions (Benzaldehyde vs "Compound") Seebach Conditions 


\section{LIST OF TABLES}

Page

CHAPTER 1 (Zirconocene-oximato Complexes)

Table 1. Results of further reactions

11

CHAPTER 2 (NMR Experiments)

Table 1. NMR Spectral Shifts (ס) of Starting Materials and Reaction Products

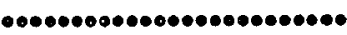

31

CHAPTER 3 (Indirect Probes of the Alkylation Reaction)

Table 1. Selected Competition Experiments

61

Table 2. Competition Experiments

71

viii 


\section{LIST OF FIGURES AND SCHEMES}

Page

CHAPTER 1 (Zirconocene-oximato Complexes)

Figure 1. 1H-NMR Analysis of $p$-Tolualdoxime in

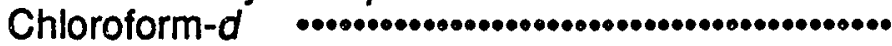

Figure 2. $1 \mathrm{H}$-NMR Analysis of $p$-Tolualdoxime

Complex 1 in Benzene- $d_{6}$

Figure 3. IR Analysis of 1 (nujol mull)

Figure 4. IR Analysis of p-Tolualdoxime (nujol mull) ••••... 6

Figure 5. $\mathrm{E}$ and $\mathrm{Z}$ isomers of $p$-Tolualdoxime

Figure 6. ${ }^{13} \mathrm{C}-\mathrm{NMR}$ Analysis (with APT) of $p$-Tolualdoxime in Chloroform-d

Figure 7. ${ }^{13} \mathrm{C}-\mathrm{NMR}$ Analysis (with APT) of 1 in Benzene- $d_{6}$

Figure 8. COSY Analysis of 1 in Benzene- $d_{6}$

Figure 9. Possible Isomeric Structures of $1 \quad$ *.............. 10

Scheme I. Proposed Nitrene Synthesis ....................... 12

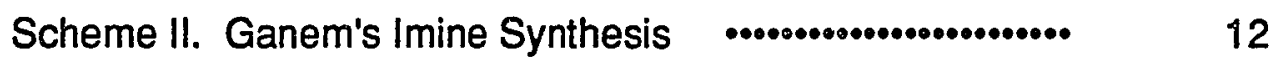

CHAPTER 2 (NMR Experiments)

Figure 1. Some Possible Structures of Intermediates •......• 28

Figure 2. ${ }^{1} \mathrm{H}-\mathrm{NMR}$ Spectrum of 1 in thf-d8 $\quad$.................. 30

Figure 3. $1 \mathrm{H}-\mathrm{NMR}$ Spectrum of 2 in thf- $\alpha_{8}$

Figure 4. The Addition of Potassium tert-Butoxide (KOt-Bu) to Dibenzylzirconocene

Figure 5. $1 \mathrm{H}-\mathrm{NMR}$ Spectrum for the Addition of 4 Equivalents of $\mathrm{KO} t-\mathrm{Bu}$ to 1 in thf- $d_{8}$

$\bullet \bullet \bullet \bullet \bullet \bullet \bullet$

Figure 5. ${ }^{13} \mathrm{C}$-NMR Spectrum for the Addition of 4 Equivalents of KOt-Bu to 1 in thf- $d_{8}$ 
Figure 7. ${ }^{1} \mathrm{H}-\mathrm{NMR}$ Spectrum for the Addition of 4 Equivalents of $\mathrm{KO}$ - $\mathrm{Bu}$ to 1 in thf- $\mathrm{d}_{8}$ (Degraded at Room Temperature in the dark $\quad$ •• 41

Figure 8. ${ }^{1} \mathrm{H}-\mathrm{NMR}$ Spectrum for the Addition of 2 Equivalents of $\mathrm{KO} t-\mathrm{Bu}$ to 1 in thf-d8

Figure 9. ${ }^{13} \mathrm{C}$-NMR Spectrum for the Addition of 2 Equivalents of KOt-Bu to 1 in thf-d8

Figure 10. ${ }^{1} \mathrm{H}-\mathrm{NMR}$ Spectrum for the Addition of 4.9 Equivalents of KOt-Bu to 2 in thf-cb

Figure 11. ${ }^{13} \mathrm{C}-\mathrm{NMR}$ Spectrum for the Addition of 4.9 Equivalents of KOt-Bu to 2 in thf-ds

Figure 12. ${ }^{1} \mathrm{H}-\mathrm{NMR}$ Spectrum for the Addition of 3.5 Equivalents of KOt-Bu to 2 in thf-dB

Figure 13. ${ }^{13} \mathrm{C}$-NMR Spectrum for the Addition of 3.5 Equivalents of KOt-Bu to 2 in thf-ds

CHAPTER 3 (Indirect Probes of the Alkylation Reaction)

Figure 1. Some Possible Structures of Intermediates .......... 62

Figure 2. The Addition of KOt-Bu to Dibenzylzirconocene $\quad • \bullet 63$

Figure 3. Enhanced Nucleophilicity of Zr-Alkyls in the Presence of KOt-Bu

Figure 4. Some Carbonyl Compounds Alkylated by the Zirconocene Reaction

Figure 5. Competition Experiments to Compare Selectivities of 2 Reactions 


\section{Chapter 1 \\ The Synthesis, Characterization, and Reactivity \\ of the First Oximato-Zirconocene Complexes}

\section{ABSTRACT}

The synthesis of the first zirconocene-aldoximates and zirconoceneketoximates, and their characterization by infrared spectroscopy, elemental analysis, and proton and carbon nuclear magnetic resonance spectroscopy is described. The new compounds are $\mathrm{Cp}_{2} \mathrm{Zr}\left(\mathrm{CH}_{3}\right) \mathrm{ON}=\mathrm{CH}\left(p-\mathrm{C}_{6} \mathrm{H}_{4} \mathrm{CH}_{3}\right)$ (1), $\mathrm{Cp}_{2} \mathrm{Zr}(\mathrm{Cl}) \mathrm{ON}=\mathrm{CH}\left(p-\mathrm{C}_{6} \mathrm{H}_{4} \mathrm{CH}_{3}\right)$-thf $(\underline{2}), \mathrm{Cp}_{2} \mathrm{Zr}(\mathrm{Cl}) \mathrm{ON}=\mathrm{CH}\left(p-\mathrm{C}_{6} \mathrm{H}_{4} \mathrm{CH}_{3}\right)$ (3) $)$, $\mathrm{Cp}_{2} \mathrm{Zr}(\mathrm{Cl}) \mathrm{ON}=\mathrm{C}\left(\mathrm{CH}_{3}\right)_{2}(4)$, and $\mathrm{Cp}_{2} \mathrm{Zr}\left(\mathrm{CH}_{3}\right) \mathrm{ON}=\mathrm{C}\left(\mathrm{CH}_{3}\right)_{2}$ (5) $\left(\mathrm{Cp}=\eta^{5}-\mathrm{C}_{5} \mathrm{H}_{5}\right)$. The reactivity of these compounds was investigated in the presence of acid, base, and zirconocene hydrides, although the outcome of these reactions is still unclear. Their properties are compared to that of known titanocene-oximates.

\section{INTRODUCTION}

Oxime chemistry is a rich field. ${ }^{1}$ Today we find that oximes are catalysts in alkylation and polymerization reactions, ${ }^{2}$ in the oxidation of unsaturated compounds, ${ }^{3}$ and, recently, in the synthesis of peptides. ${ }^{4}$ Oximes have long been used in the detection of nickel, ${ }^{5}$ uranium, 6 bismuth and lead, 7 palladium, 8 in the most economical production of copper with its separation from iron in aqueous solution, and in extraction of cobalt, manganese, zinc, and iron. ${ }^{9}$ Oximes act as fungicides, ${ }^{10}$ pesticides, ${ }^{11}$ rocket propellant enhancers, ${ }^{12}$ antidotes for chemical warfare agents, ${ }^{13}$ antioxidants and antiskinning agents for paints and varnishes, ${ }^{14}$ fireproofing agents and whitening inhibitors for 
polyolefins, ${ }^{15}$ and masking agents for polyesters containing residual metal catalysts. ${ }^{16}$ Dioximes have been used to vulcanize urethane rubber. ${ }^{17}$

Metal oxime derivatives are used as thickening agents for lubricating grease, 18 UV stabilizers for cellulose esters, ${ }^{19}$ color developers for pressure and heat sensitive copying and recording paper, 20 and are used in color photography. 21 Group IV transition metal-oxime compounds have been documented in the literature. 22 2-Hydroxy-1-naphthaldoxime is used as an analytical reagent for titanium (IV). ${ }^{23}$ Titanium oximes are useful as polymerization catalysts and "end blockers" in silicone chemistry.24 Since oximes can be synthesized from non-carbonyl compounds and are used for protection or activation of a carbonyl group, deoximation conditions and reagents have been of interest.25,26 Beckmann rearrangement to form substituted amides from oximes is a good example. 27 Reductive cleavage of oximes under mild conditions has been obtained with a low-valent titanium reagent. ${ }^{26}$ Tetrachlorotitanium acts as a catalyst in the transformation of oximes to amides, but its tetraalkoxides do not. 5 Metal carbonyls have been made to induce $\mathrm{N}-\mathrm{O}$ bond cleavage of the oxime group. 28

Titanocene polyoximes and dioximes and bis-indenyl titanium dioximes have been prepared and characterized 29 from the corresponding titanium dichloride and dioximes in the first instance, monooximes in the latter two. Historically Group IV metallocene-oximato complexes have been prepared in a two-phase (chloroform/aqueous base) system to give the complexes mentioned above and ionic complexes that are air and water stable. ${ }^{30}$ Titanocene dichloride complexes with dioximes or o-hydroxyaryloximes in thf/benzene facilitated by the addition of base to neutralize the $\mathrm{HCl}$ formed. ${ }^{31}$ Copolymers of 
titanocene with two kinds of dioximes have been prepared in both aqueous and two-phase systems. ${ }^{32}$ The only zirconocene-oxime complexes prepared to date have been polyamidoximes. 33

A search of the literature revealed that only dichlorides had been used as the Group IV metallocene reagent in these complexing reactions. We thought that some interesting chemistry might be found by using Schwartz reagent $\left(\mathrm{Cp}_{2} \mathrm{ZrHCl}\right)$ and/or dimethylzirconocene as precursors.

\section{RESULTS AND DISCUSSION}

\section{Synthesis of Oximato Complexes}

Trial syntheses were performed in NMR tubes with benzene-d $d_{6}$ as solvent (eq 1). $p$-Tolualdoximato methyl zirconocene 1 was first prepared in this way and characterized by ${ }^{1} \mathrm{H}$-NMR. Evidence of the formation of the new compound was the disappearance of the oxime $(\mathrm{C}=\mathrm{NOH})$ proton peak at $\delta 8.77$ and the integration as three protons of the peak at $\delta 0.67$ representing the metal-bound methyl group (Figures $1 \& 2$ ).

$$
\begin{aligned}
\mathrm{Cp}_{2} \mathrm{Zr}\left(\mathrm{CH}_{3}\right)_{2}+\mathrm{HON}=\mathrm{CH}\left(p-\mathrm{C}_{6} \mathrm{H}_{4} \mathrm{CH}_{3}\right) \stackrel{\mathrm{C}_{6} \mathrm{D}_{6}, \mathrm{RT}}{\mathrm{Cp}} \underset{\mathrm{Zr}\left(\mathrm{CH}_{3}\right) \mathrm{ON}={ }_{1}^{\mathrm{CH}}\left(p-\mathrm{C}_{6} \mathrm{H}_{4} \mathrm{CH}_{3}\right)+\mathrm{CH}_{4}}{\longrightarrow} \\
\qquad
\end{aligned}
$$



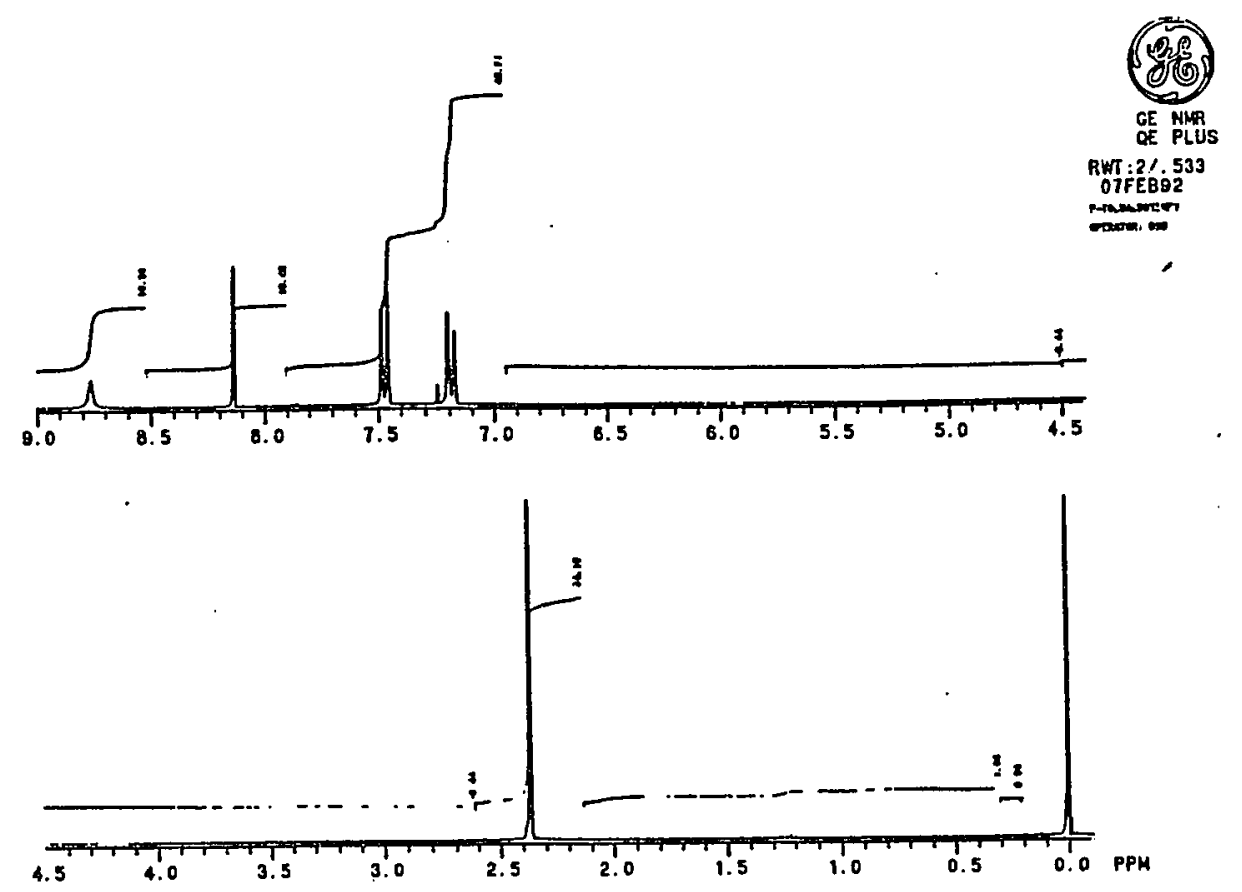

Figure 4 . ${ }^{1} \mathrm{H}$-NMViR Ânalysis of $p$-Tolualdoxime in Chioroiorm- $d$.

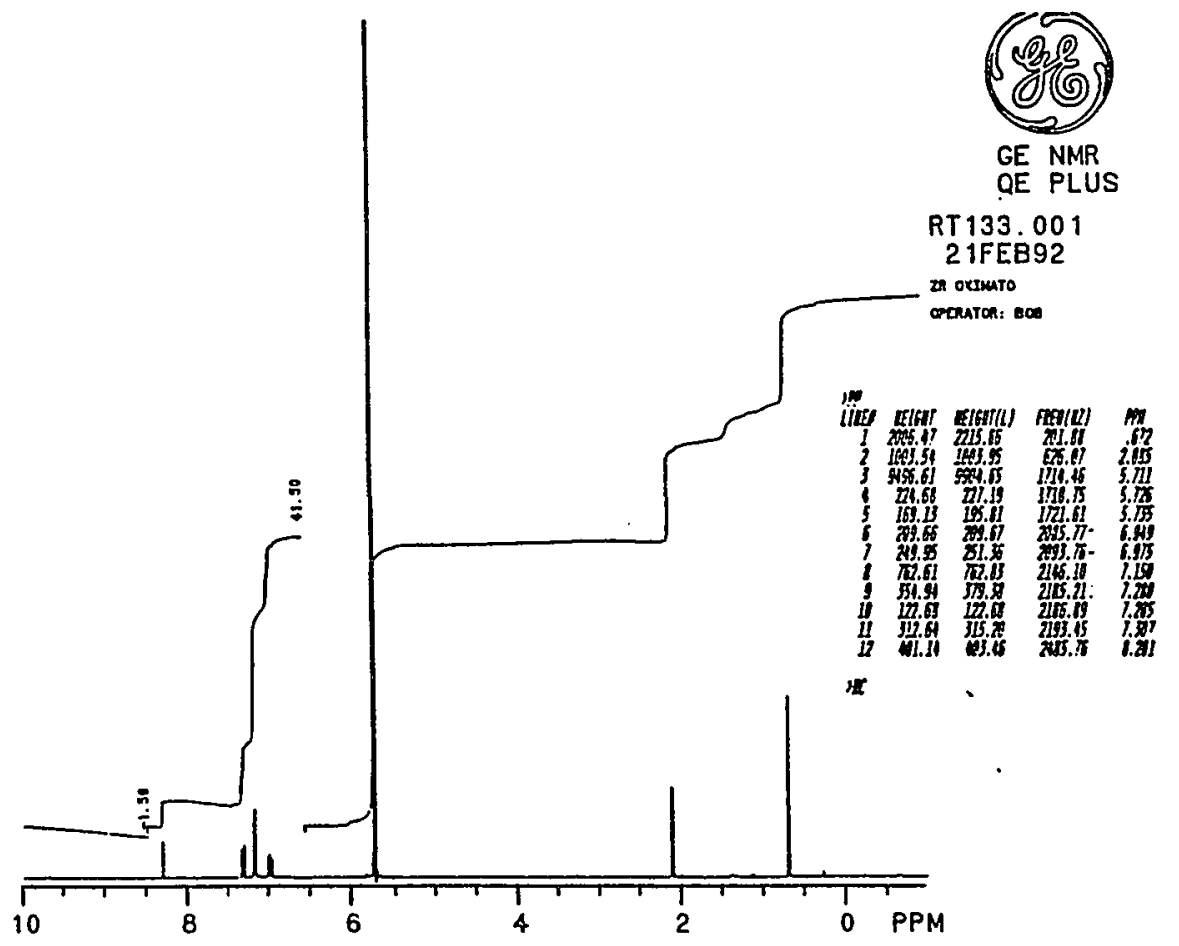

Figure 2. ${ }^{1} \mathrm{H}-\mathrm{NMR}$ Analysis of $p$-Tolualdoxime Complex 1 in Benzene- $d_{6}$. 
Millimolar quantities of $\mathbf{1}$ have been prepared at room temperature in diethyl ether in moderate yield ( $>70 \%$, eq 2 ). The product has been characterized by IR, mp, elemental analysis, ${ }^{1} \mathrm{H}-\mathrm{NMR},{ }^{13} \mathrm{C}-\mathrm{NMR}, \mathrm{APT}$, and COSY.

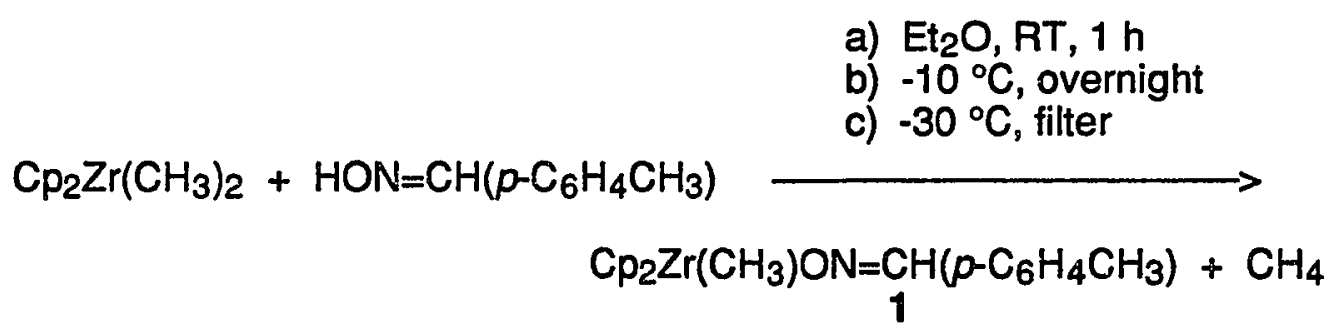

Both 1 and $p$-tolualdoxime are isolated as white crystals. The oximato complex 1 differs in its IR spectrum (Figure 3) from the starting oxime (Figure 4). The oxime has a broad $\mathrm{H}$-bonding $\mathrm{OH}$ peak $\left(3300 \mathrm{~cm}^{-1}\right)$ that is not present in the oximato, but is replaced by a weak but sharp peak at $3100 \mathrm{~cm}^{-1}$ representing the cyclopentadienyl $\mathrm{CH}$ stretch. ${ }^{34}$ The weak peak at $1620 \mathrm{~cm}^{-1}$ indicating $\mathrm{C}=\mathrm{N}$ stretch in the oxime has nearly disappeared in the oximato. The presence of this band in the oxime has been cited as evidence of the $\mathbf{Z}$ isomer ${ }^{35}$ (Figure 5), although the presence, also, of the $E$ isomer cannot be ruled out by IR alone, as bands at 945 and $805 \mathrm{~cm}^{-1}$ for the former and bands at 957 and $807 \mathrm{~cm}^{-1}$ for the latter both appear to be present. However, the proton NMR spectrum (Figure 1) shows only one isomer, and that is interpreted as E. ${ }^{36}$ The proton spectrum of the complex 1 (Figure 2) is also unambiguous and shows only one isomer is present; the $E$, if there is retention of stereochemistry, the $\mathbf{Z}$, if there is inversion. X-ray analysis would clarify this. The peak at $955 \mathrm{~cm}^{-1}$ attributable to $\mathrm{N}-\mathrm{O}$ bending in the oxime disappears in the oximato complex. 
This is, perhaps also, indicative of electron donation from the nitrogen to the metal giving a rigidity to the $\mathrm{Zr}-\mathrm{O}-\mathrm{N}-\mathrm{Zr}$ portion of the molecule.

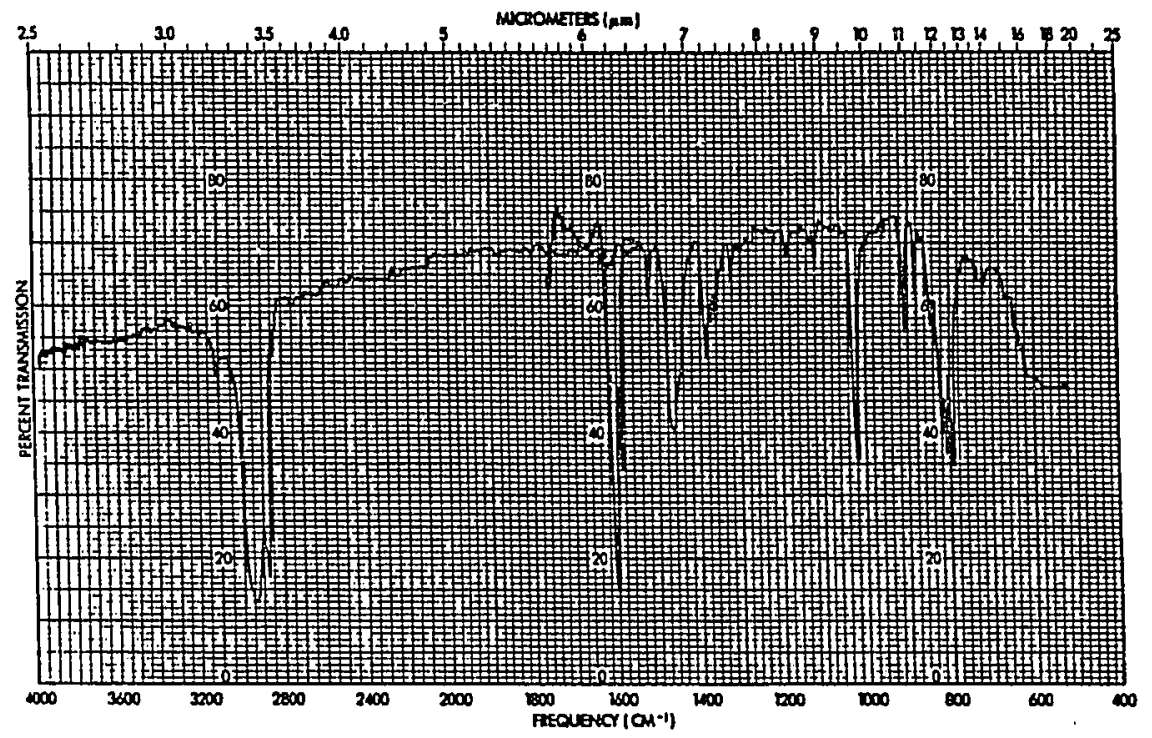

Figure 3. IR Analysis of 1 (nujol mull).

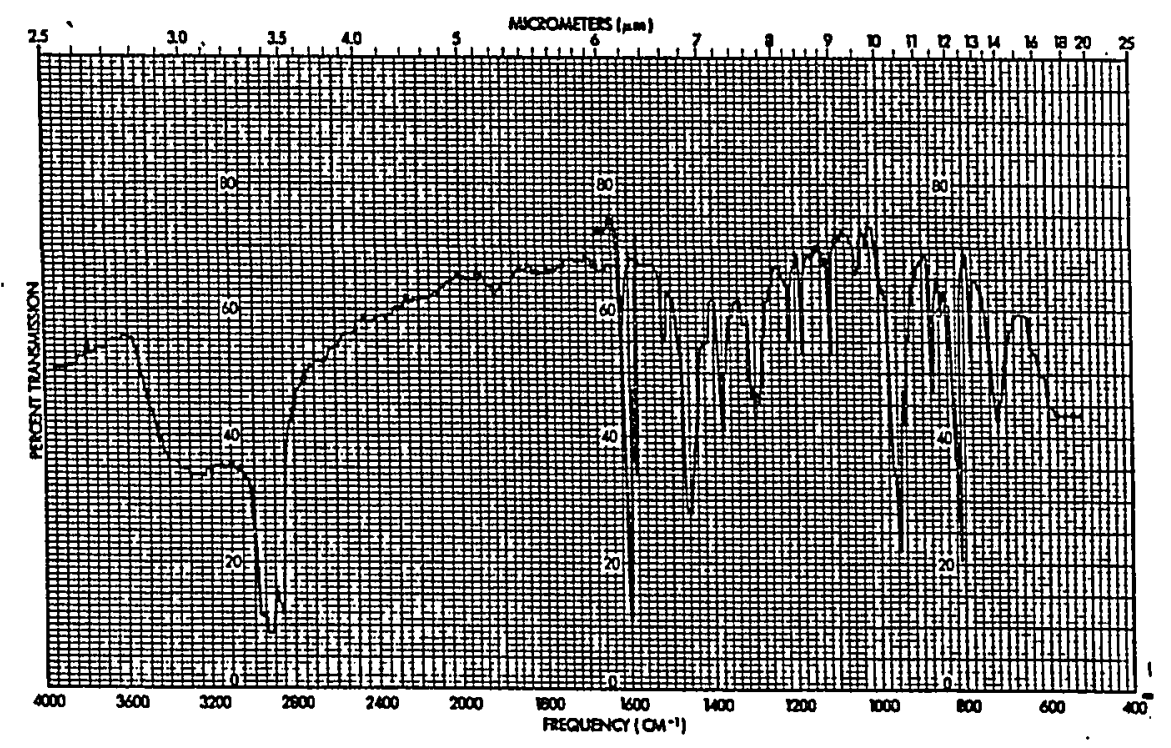

Figure 4. IR Analysis of $p$-Tolualdoxime (nujol mull). 
$\mathbf{E}$

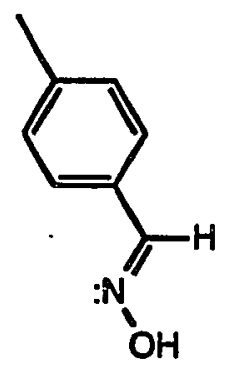

$\mathbf{Z}$

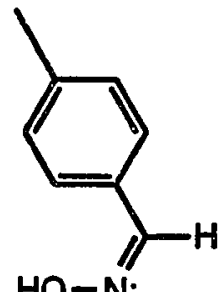

HO-N:

Figure 5. $E$ and $Z$ isomers of $p$-Tolualdoxime.

Figures 6 and 7 represent ${ }^{13} \mathrm{C}$-NMR analysis with APT of $p$-tolualdoxime and 1, respectively. As expected, the ${ }^{13} \mathrm{C}$-NMR spectrum of $p$-tolualdoxime displays six different carbons; that of 1 , eight.

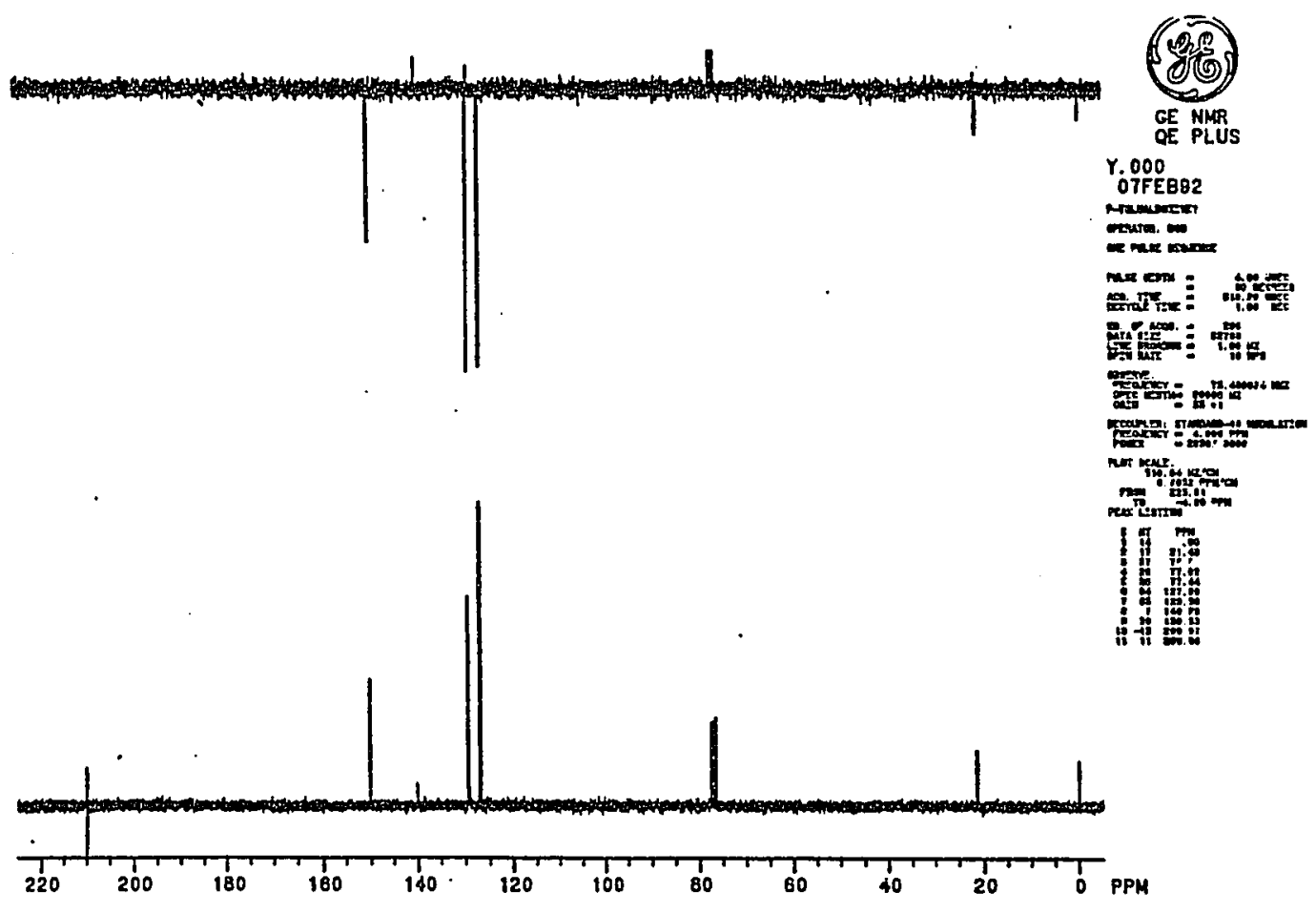

Figure 6. ${ }^{13} \mathrm{C}$-NMR Analysis (with APT) of p-Tolualdoxirne in Chloroform-d. 


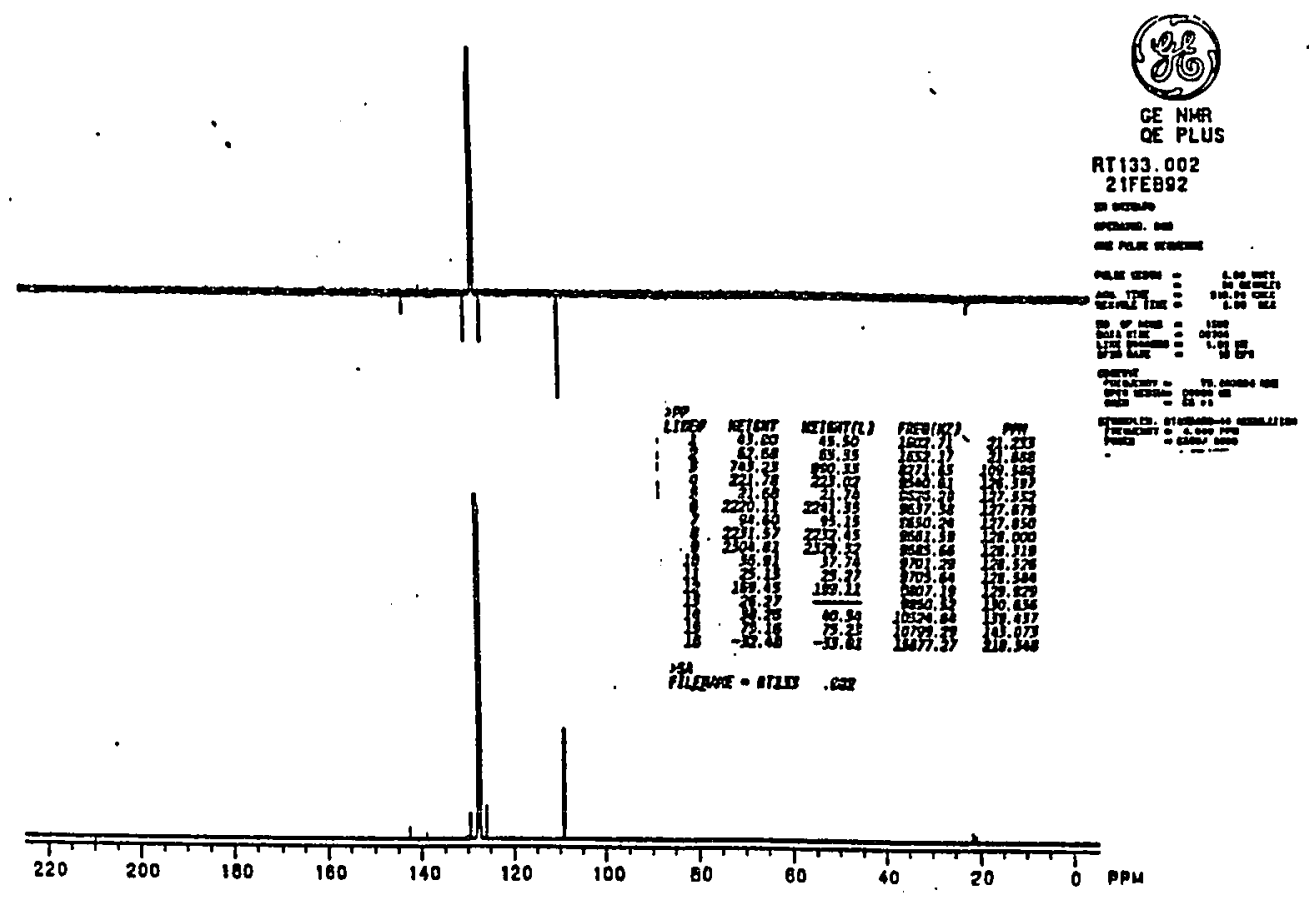

Figure 7. ${ }^{13} \mathrm{C}-N M R$ Analysis (with APT) of 1 in Benzene- $d_{6}$.

Figure 8 represents a COSY analysis of 1 with a labeled structural representation of the molecule. This structure is intended only for discussion of the 2D spectrum and is not meant to represent an $X$-ray structure. The analysis demonstrates that the different kinds of protons correlate to each other in the following way. Benzylic protons (b) correlate to protons (d) and less to protons (e). Protons (c) correlate to protons (a) and less to protons (e). Protons (e) correlate to protons (d). Protons (a) correlate to protons (c) and they appear to correlate to proton (f). We feel that isomer A or B (Figure 9) is the most probable in solution. There is precedent in the literature for the dative bond in the center of the ligands as in A or B rather than in the lateral position as in $C$ or D. 37 If we are to believe the NMR data for the starting oxime, an A product would imply inversion of stereochemistry in the complexing reaction, a B product, retention of stereochemistry. The NMR evidence presented here, 
however, does not allow us to distinguish between the isomers shown in Figure 9. The steric bulk of the ligand attached to the donor nitrogen is a good reason for a product with stereochemistry as in A;38 however, absolute proof will have to wait until we are able to grow a crystal suitable for $X$-ray analysis. ${ }^{39}$ Implied in this structural assignment is the assumption of retention of stereochemistry about the $\mathrm{C}=\mathrm{N}$ bond.

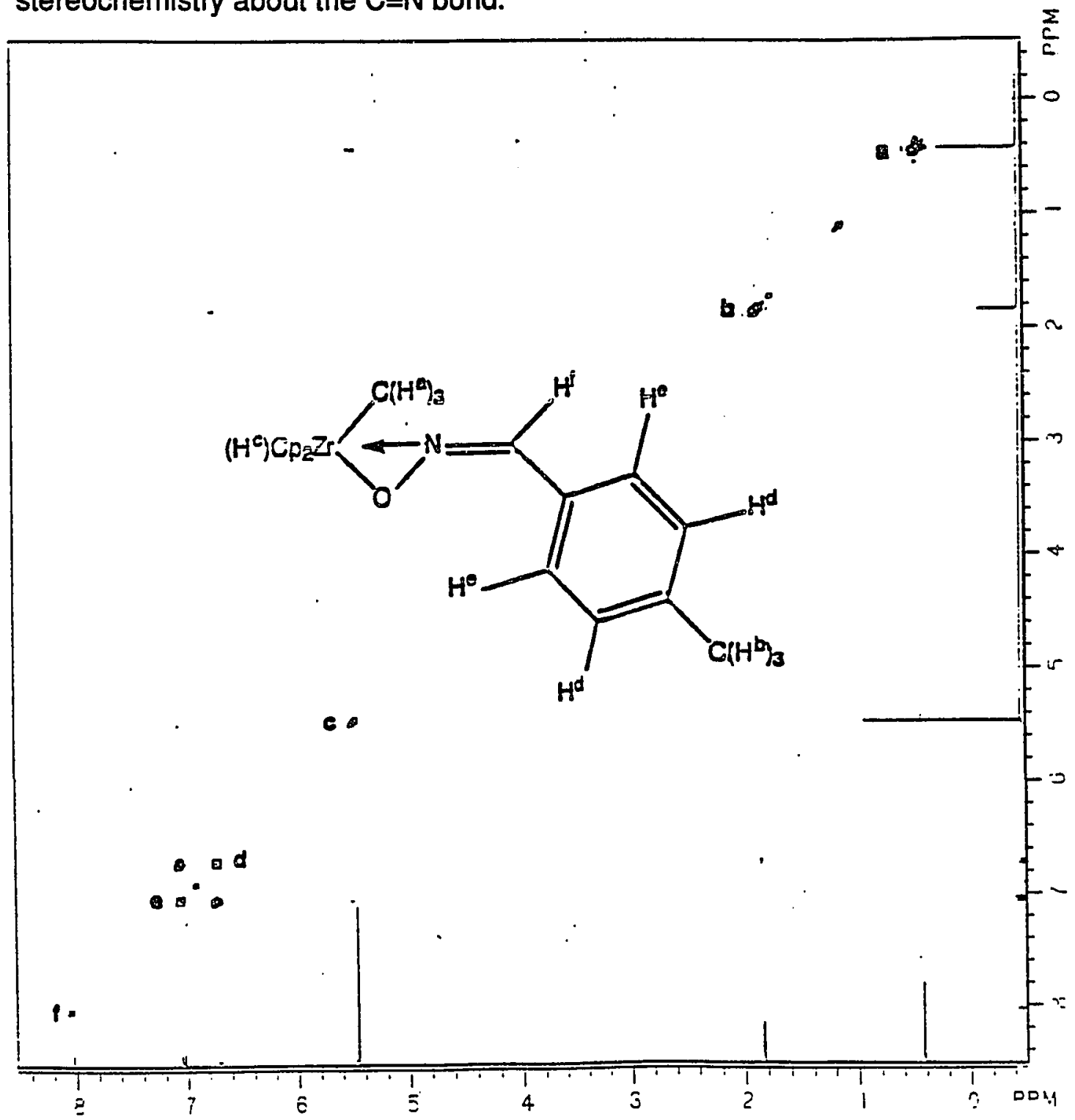

Figure 8. COSY Analysis of 1 in Benzene-d6. 


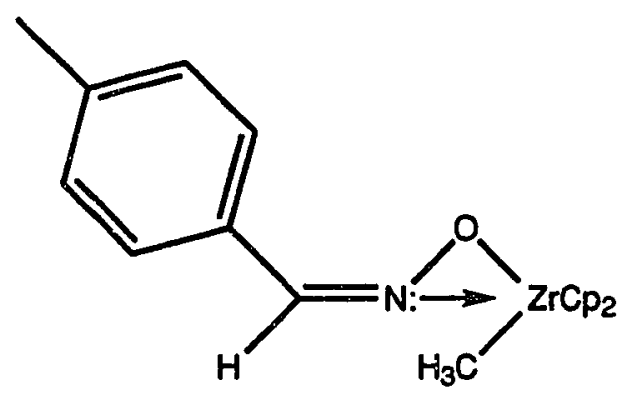

Isomer A

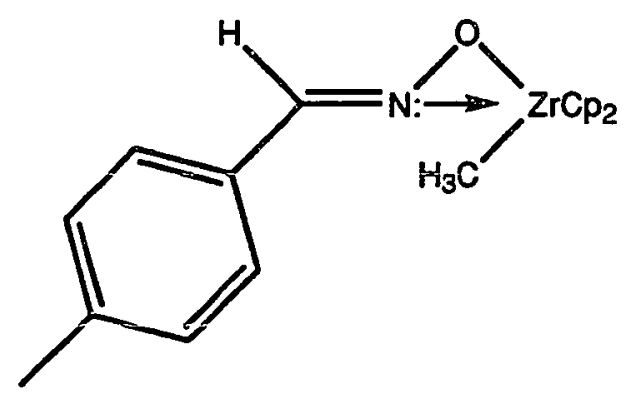

Isomer B

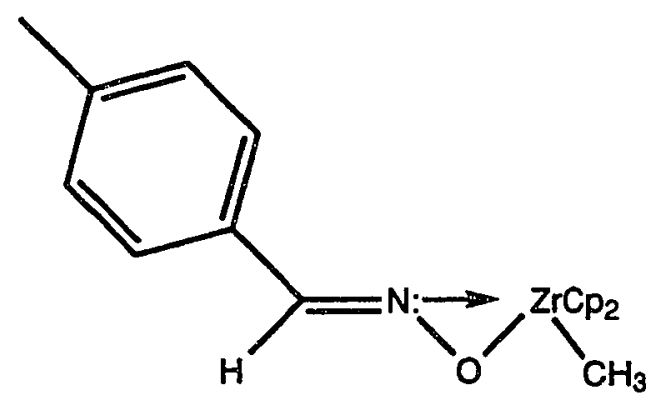

Isomer C

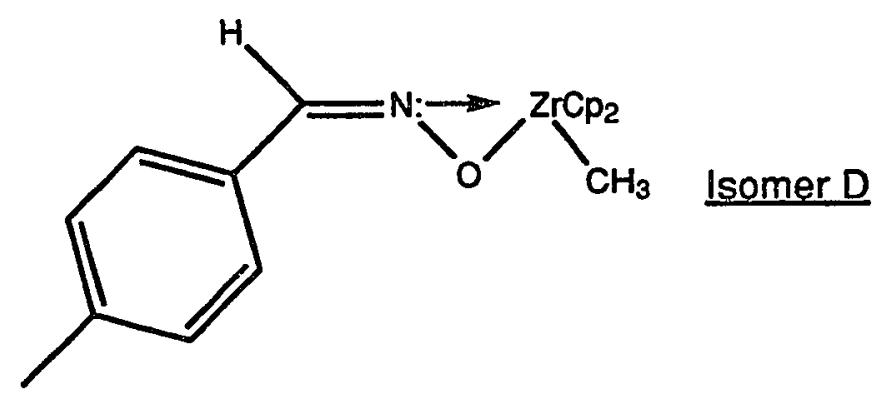

Figure 9. Possible Isomeric Structures of 1. 
Attempts at producing analogs of 1 have met with some success. Table 1 displays the results.

Table 1. Results of further reactions

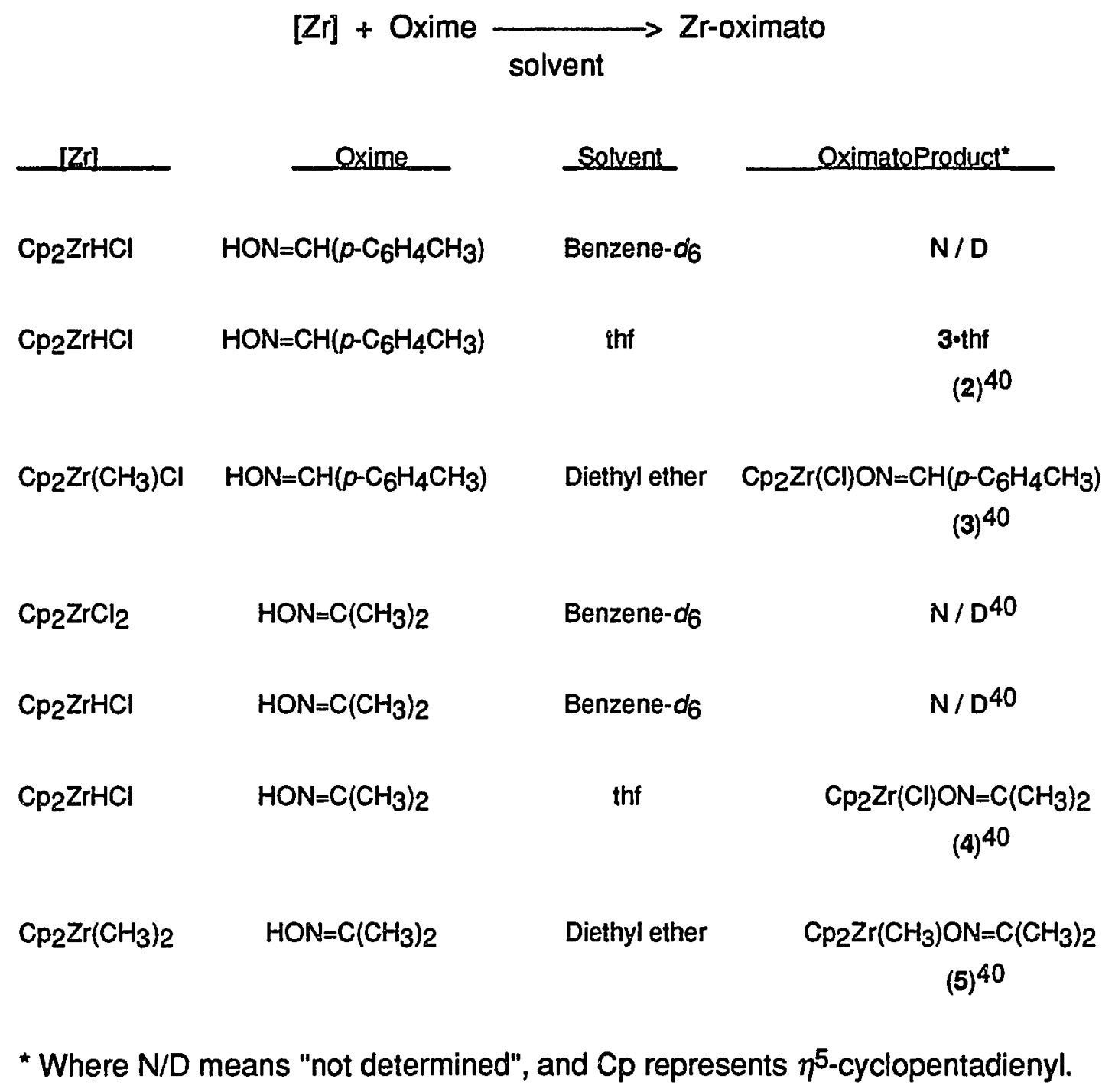

The $1 \mathrm{H}$-NMR spectrum of the complex 4 exhibits different chemical shifts for two kinds of methyl protons at $\delta 1.99$ and 2.13 in acetonitrile- $d_{3}$. The starting oxime has one singlet integrating to six protons at $\delta 1.85 .36$ It is of interest to 
note that 2 and 4 were produced under the same reaction conditions, but that while the former contains a co-crystallized tetrahydrofuran (thf), the latter does not.

\section{Reactivity of Oximato Complexes}

One goal of this exercise was to learn what happens with the addition of base to an oximato compound. Also of interest were conditions that might produce a nitrene (Scheme I) from the oxime in a reductive deoxygenation much the same as Ganem et al. in their recent production of imines from amides via "zirconation/hydrozirconation" (Scheme II). 41

\section{Scheme I}
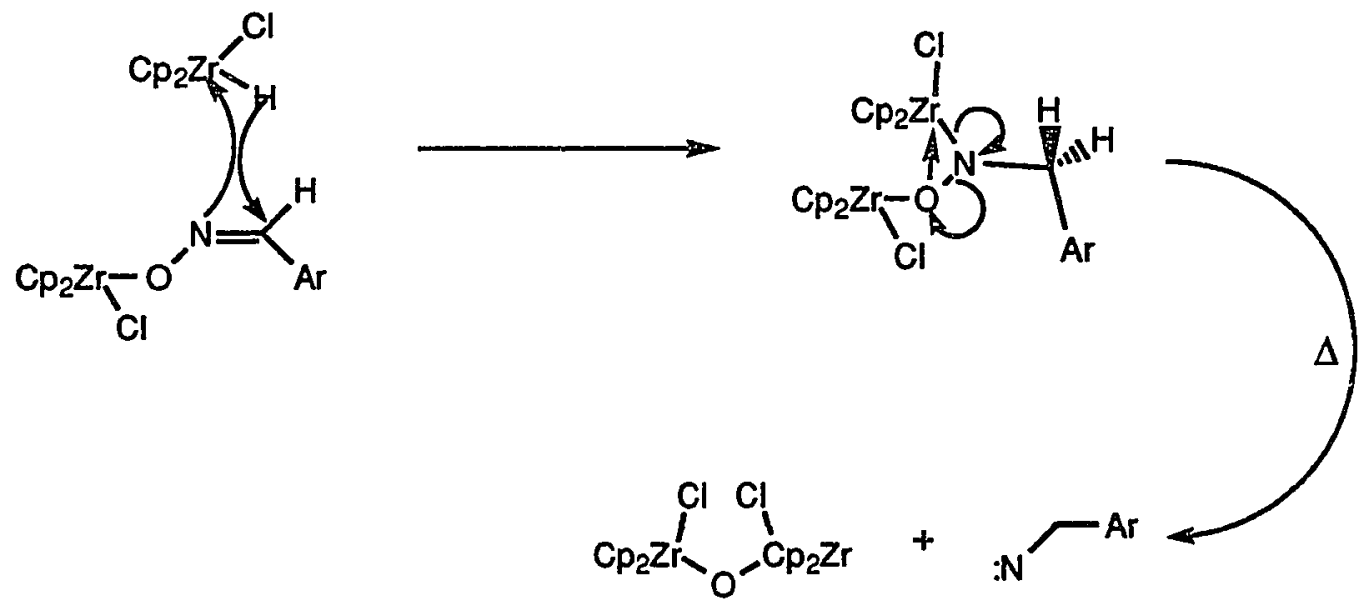

\section{Scheme II}

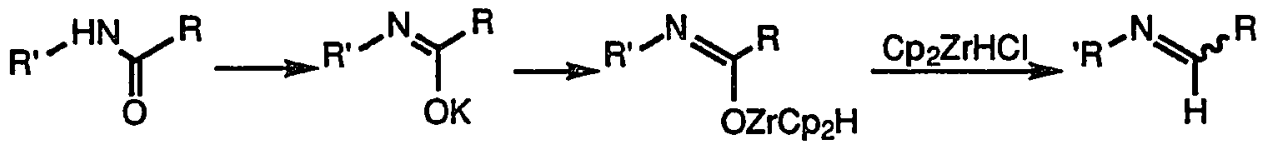


There is precedent for the second step in Scheme 2 based on the thermolysis of bridging aldehyde complexes. 42 The reactivity of 1 was investigated in the presence of zirconocene hydride complexes, $[\mathrm{Zr}]-\mathrm{H}$, and in various solvents (eq 3). The reaction of 1 with $\mathrm{Cp}_{2} \mathrm{ZrHCl}$ (a white insoluble solid) in benzene produced some bubbles, a white precipitate, and a yellow solution.

$$
1+[\mathrm{Zr}]-\mathrm{H} \underset{\text { (solvent) }}{\longrightarrow}
$$

The solution was assayed by ${ }^{1} \mathrm{H}-\mathrm{NMR}$, which indicated nearly all starting material. The reaction mixture was carefully heated for a couple of minutes over a steam bath to give a deep orange solution. The $1 \mathrm{H}-\mathrm{NMR}$ spectrum showed reduced presence of 1 and additional peaks as follows: a multiplet at $\delta 5.98$ and singlets at $\delta 8.34,5.81,2.69,2.21$, and 0.39 . The addition of methylene chloride (a test for zirconium hydrides) produced no further change in the ${ }^{1} \mathrm{H}-\mathrm{NMR}$. On a preparative scale the same reactants in toluene solvent (eq 3 ) give a clear yellow solution which can be stripped to an oil that is not soluble in pentane and gives an even more complex ${ }^{1} \mathrm{H}$-NMR spectrum than the previous reaction. The ${ }^{13} \mathrm{C}-\mathrm{NMR}$ shows stariing material and many additional, unidentifiable peaks. 40

Dihydridozirconocene and 1 in toluene at room temperature for 24 hours in the dark afforded, when filtered, a clear, yellow supernatant that yielded a pale yellow solid, on drying. ${ }^{1} \mathrm{H}$-NMR analysis of the solid revealed only starting material.

The reactivity of 2 , which has the more electronegative chloride on the metal in place of the methyl, in the presence of hydridozirconocene chloride in 
toluene was investigated. The product was a clear, yellow solution that, when stripped and redissolved in benzene- $d_{6}$ gave a complex ${ }^{1} \mathrm{H}-\mathrm{NMR}$ spectrum that could not be interpreted.

The reaction of 4 with hydridozirconocene chloride in benzene- $d_{6}$ gave, after heating at about $80^{\circ} \mathrm{C}$ for ten minutes, a clear, yellow solution with white solid. The complicated ${ }^{1} \mathrm{H}$-NMR spectrum showed some starting material but with an upfield shift of the cyclopentadienyl protons. The remainder of the spectrum was uninterpretable. The same reaction in toluene was also inconclusive, as it was in thf. The reaction of 1 with diisobutyl aluminum hydride in hexane gave a clear solution and fine, white precipitate that remained heterogeneous at $50^{\circ} \mathrm{C}$. Stripping of solvent gave a bubbly, yellow, glassy solid. The ${ }^{1} \mathrm{H}$-NMR spectrum was unintelligible. 40 The addition of lithium tritert-butoxyaluminum hydride in thf to a solution of 4 in thf gave no reaction. 40

Future work with this hydride chemistry might include the addition of 5 with hydridozirconocene chloride.

Reactivity toward various bases was investigated. The reaction of 1 with sodium bis(trimethylsilyl)amide in benzene- $d_{6}$ produced some gas evolution and a clear, intense yellow orange solution with some precipitate. The ${ }^{1} \mathrm{H}-\mathrm{NMR}$ spectrum, in benzene- $d_{6}$, of the supernatant showed the $C p$ peak downfield and the methyl and tolyl peaks upfield of those for the starting material. The same reaction in dimethylsulfoxide- $d_{6}$ gave a "blood-red" solution with mixing. The ${ }^{1} \mathrm{H}$-NMR spectrum showed $\mathrm{Cp}$ proions upfield of those for the starting material and no other protons downfield of $\delta 2.49$. In diethyl ether, the reaction of 2 with sodium bis(trimethylsilyl)amide gave, after 20 minutes and drying in vacuo, an orange-yellow solid. The ${ }^{1}$ H-NMR spectrum, compared with the starting 
materials, shows the disappearance of peaks at $\delta 8.45(\mathrm{~s}, 1 \mathrm{H})$ and $3.6(\mathrm{~m}$, tht?), and the appearance of new peaks at $\delta 6.4$ (s) and 6.5(s). The tolyl aromatic and methyl protons have moved downfield, and the Cp signals, which integrate at about $56 \%$ when compared to the tolyl peaks, have moved slightly upfield.

Some of this base chemistry was attempted on oximato complex $\mathbf{4 . 4 0}$ Sodium bis(trimethylsilyl)amide in thf with 4 produced a yellow solution, slightly opaque, almost immediately. This was stripped to a pale, yellow solid that was not soluble in toluene, even with warming or the addition of 2 equivalents of pyridine. The same reactants in diethyl ether, left overnight at room temperature, gave no apparent reaction. However, the white solid remaining after stripping the solvent in vacuo, although not very soluble in benzene- $d_{6}$, shows only two substrate peaks $(\delta 6.1(s)$ and $1.4(s))$ in its proton spectrum. These do not appear to be starting material.

A mixture of potassium hydride and 18-crown-6 in thf with 1 gave slow gas evolution, that increased with heating, and a yellow paste with some crystalline matter. The proton spectrum in benzene- $d_{6}$ gave mostly 18 -crown-6 with some starting material, but in acetonitrile- $d_{3}$ more gas evolved, perhaps attributable to unreacted potassium hydride, and the spectrum, again, showed mostly 18-crown-6 with some starting material.

The reaction of 1 with water (a 41 -fold excess) in benzene-d $d_{6}$ also produced an uninterpretable $1 \mathrm{H}-\mathrm{NMR}$ spectrum, although it revealed some remaining starting material, and the reaction mixture appeared homogeneous. The addition of $30 \% \mathrm{HCl}$ produced gas evolution and a two-phase system. The $1 \mathrm{H}$-NMR spectrum of the organic phase showed an impurity in mostly starting material. 


\section{SUMMARY}

The zirconocene-oximato complexes $1,2,3$, and 4 have been prepared and characterized. Complexes 1, 2, and 4 are reactive to hydridozirconocene chloride, but we have been unable to characterize the products by ${ }^{1} \mathrm{H}$-NMR or to isolate crystalline products. Complex 1 is also reactive to diisobutyl aluminum hydride, but the product mixture is complex. Complex 4 is unreactive to lithium tri-tert-butoxy aluminum hydride in thf. Complexes 1,2 , and 4 are reactive to base in the form of sodium bis(trimethylsilyl)amide, but further investigation is needed to characterize the products of these reactions. Complex 1, however, appears to be less reactive to potassium hydride, although a different solvent, thf, was used. Complex 1 is relatively unreactive toward acid in the form of water, and even with the addition of hydrochloric acid. We cannot say, however, that we have not produced a water-chelated cationic oximato species, 30 as the aqueous phase was not analyzed. We have experienced little problem with the solubility of zirconocene-oximato complexes, in direct contrast to Carraher, who cites low solubility as being characteristic of his titanocene polyoximes as well as his model compound titanocene dioximes and monooximes. 33

\section{EXPERINIENTAL SECTION}

\section{General Considerations}

All operations involving air sensitive compounds were performed under inert atmosphere by Schlenk, vacuum line, and glove box techniques. 
Zirconocene dichloride was purchased from Boulder Scientific. The diethyl ether, thf, toluene, pentane, hexane, and the benzene- $d_{6}$ and acetonitrile- $d_{3}$ were distilled under nitrogen from sodium benzophenone ketyl and transferred to storage flasks sealed with Teflon screw valves (deuterated solvents to screwtop bottles which were stored in an inert atmosphere). Pyridine and methyl sulfoxide used with air sensitive reagents were freeze-degassed and stored over $3 \AA$ molecular sieves. $18-C r o w n-6$ was recrystallized from acetonitrile that had been dried over $3 \AA$ sieves freshly activated by drying in vacuo, 24 hours. Melting points of oximes were determined using an Electrothermal ${ }^{\circledR}$ Melting point apparatus. Melting point and elemental analysis of metal-oxime complexes were performed by an independent laboratory. 43 IR spectra were collected on a Perkin Elmer Model 710B IR spectrometer. The ${ }^{1} \mathrm{H}-\mathrm{NMR}$ spectra were acquired, as noted, on a $60 \mathrm{MHz}$ Varian T $60 \mathrm{NMR}$ spectrometer, a 90 $\mathrm{MHz}$ Varian EM 390 NMR spectrometer, or a GE QE Plus $300 \mathrm{MHz}$ Spectrometer, and ${ }^{13} \mathrm{C}-\mathrm{NMR}$ spectra were collected on the GE QE Plus spectrometer. Proton and carbon shifts were adjusted to the deuterated solvent standard.

The oxime of $p$-tolualdehyde was prepared by the general method of Shriner et al. 44 The following starting materials were used as received from their manufacturers: p-tolualdehyde from Aldrich Chemical Co.; pyridine from Fisher Scientific Co.; and hydroxylamine hydrochloride from J. T. Baker. The oxime product was characterized by $\mathrm{mp}, 74.5-76^{\circ} \mathrm{C}$ (lit., $79-80^{\circ} \mathrm{C}$ ), 6 IR (nujol mull) $3300 \mathrm{~m}, \mathrm{~b}(\mathrm{H}$-bonded $\mathrm{OH}), 71620 \mathrm{w}(\mathrm{C}=\mathrm{N}), 1520 \mathrm{w}, 1310 \mathrm{~m}, 1300 \mathrm{~m}, 1290 \mathrm{~m}$,

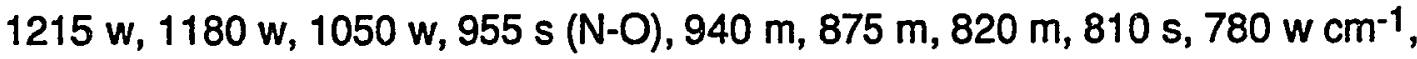
and ${ }^{1} \mathrm{H}-\mathrm{NMR}\left(90 \mathrm{MHz}, \mathrm{CCl}_{4}\right): \delta 2.30\left(\mathrm{~s}, 3 \mathrm{H}, \mathrm{CH}_{3}\right) ; 7.08(\mathrm{~d}, 2 \mathrm{H}, \mathrm{CH}, \mathrm{J}=8 \mathrm{~Hz})$; 
$\mathrm{J}=8 \mathrm{~Hz}) ; 7.39(\mathrm{~d}, 2 \mathrm{H}, \mathrm{CH}, \mathrm{J}=8 \mathrm{~Hz}) ; 8.03(\mathrm{~s}, 1 \mathrm{H}, \mathrm{ArHC}=\mathrm{N}){ }^{41} ; 9.00(\mathrm{~s}$, broad, $1 \mathrm{H}, \mathrm{C}=\mathrm{NOH}$.

The oxime of 2-propanone was recrystallized from petroleum ether and characterized by ${ }^{1} \mathrm{H}-\mathrm{NMR}\left(60 \mathrm{MHz}\right.$, chloroform- $d$ ): $\delta 1.4\left(\mathrm{~s}, 6 \mathrm{H}, \mathrm{CH}_{3}\right), 9.8$ (s, $1 \mathrm{H}, \mathrm{HON}) .40$

Dimethylzirconocene was prepared from dichlorozirconocene and methyllithium (1:2) in diethyl ether, sublimed, and stored under nitrogen. 31 The methyllithium was received from Aldrich, an aliquot was dissolved in diethyl ether and the molarity determined by titration to the phenolphthalein endpoint. Argon, nitrogen, oxygen, and liquid nitrogen were used as received from Air Products. The dimethylzirconocene was characterized by ${ }^{1} \mathrm{H}-\mathrm{NMR}(60 \mathrm{MHz}$, benzene- $\left.d_{s}\right): \delta-0.16\left(s, 6 \mathrm{H}, \mathrm{CH}_{3}\right), 5.71(\mathrm{~s}, 10 \mathrm{H}, \mathrm{Cp})$, and ${ }^{13} \mathrm{C}-\mathrm{NMR}(300 \mathrm{MHz}$, benzene- $\left.d_{6}\right): \quad \delta 30.2\left(s, \mathrm{CH}_{3}\right), 110.3(\mathrm{~s}, \mathrm{Cp})$.

\section{Detailed Synthetic Procedures}

The synthesis of zirconocene oximato complexes has been attempted under a variety of conditions which are described in the results section. The following are representative detailed procedures.

$\mathrm{Cp}_{2} \mathrm{Zr}\left(\mathrm{CH}_{3}\right) \mathrm{ON}=\mathrm{C}\left(\mathrm{p}_{-} \mathrm{C}_{6} \mathrm{H}_{4} \mathrm{CH}_{3}\right)$ (1). Dimethyl zirconocene $(520 \mathrm{mg}$, 2.16 mmoles) was dissolved in $4 \mathrm{~mL}$ diethyl ether. $p$-Tolualdoxime $(312 \mathrm{mg}$, 1.79 mmoles) was dissolved in $4 \mathrm{~mL}$ diethyl ether. The second solution was slowly cannulated into the first with stirring at $0^{\circ} \mathrm{C}$ to immediately give white crystals. After about 15 minutes the reaction mixture was brought to room temperature in a water bath, then cooled to $-10^{\circ} \mathrm{C}$ overnight in an acetone bath in a freezer. The mixture was then cooled to $-30^{\circ} \mathrm{C}$ in an acetone bath with dry 
ice, cold filtered, washed twice with cold pentane, and dried under high vacuum (50 millitorr) for two hours to give 1 (479 $\mathrm{mg}, 1.29 \mathrm{mmol}$, yield $=72.3 \%$, $M W=371$ ) as very fine, white needle-like crystals: $m p 120-123^{\circ} \mathrm{C}, \quad I R$ (nujol muli) $3100 \mathrm{w}(\mathrm{CH}, \mathrm{Cp})^{31}, 1620 \mathrm{ww}, 1520 \mathrm{w}, 1370 \mathrm{~m}, 1360 \mathrm{~m}, 1320 \mathrm{w}, 1190 \mathrm{w}$, $1120 \mathrm{w}\left(\delta_{\mathrm{s}}, \mathrm{CH}, \mathrm{Cp}\right), 1020 \mathrm{~s}(\mathrm{CH}, \mathrm{Cp}), 910 \mathrm{~m}(\mathrm{CC}, \mathrm{Cp}), 880 \mathrm{~m}, 845 \mathrm{~m}, 820 \mathrm{~s}$ $(\mathrm{CH}, \mathrm{Cp}), 805 \mathrm{~s}(\mathrm{CH}, \mathrm{Cp}), 795 \mathrm{~s} \mathrm{~cm}^{-1}$. ${ }^{1} \mathrm{H}-\mathrm{NMR}$ (300 MHz, benzene- $\left.d_{6}\right)$ : $\delta 0.67\left(\mathrm{~s}, 3 \mathrm{H}, \mathrm{Zr}-\mathrm{CH}_{3}\right.$ ), $2.08\left(\mathrm{~s}, 3 \mathrm{H}, \mathrm{CH}_{3}\right), 5.71$ (s, 10H, 2Cp), 6.96 (d, 2H, $J=8 \mathrm{~Hz}$ ), $7.29\left(\mathrm{~d}, 2 \mathrm{H}, \mathrm{J}=8 \mathrm{~Hz}\right.$ ), $8.28(\mathrm{~s}, 1 \mathrm{H}),{ }^{13} \mathrm{C}$-NMR (benzene- $\left.d_{6}\right) \delta 21.2$ (s, $\left.\mathrm{CH}_{3}\right), 21.9$ (s, $\left.\mathrm{CH}_{3}\right), 109.6(\mathrm{~s}, \mathrm{Cp}), 126.4(\mathrm{~s}, \mathrm{CH}), 127.7$ (s, C), $128.3(\mathrm{~s}, \mathrm{C})$, $129.9(\mathrm{~s}, \mathrm{CH}), 143.1(\mathrm{~s}, \mathrm{CH})$, Anal. Calcd for $\mathrm{C}_{19} \mathrm{H}_{21} \mathrm{NOZr}$ : C, 61.58; $\mathrm{H}, 5.71$; $\mathrm{N}$, 3.78. Found: C, $60.61 ; H, 5.56 ; \mathrm{N}, 3.85$. .

$\mathrm{Cp}_{2} \mathrm{Zr}(\mathrm{Cl})\left(\right.$ thf) $\mathrm{ON}=\mathrm{CH}\left(\mathrm{p}_{-} \mathrm{C}_{6} \mathrm{H}_{4} \mathrm{CH}_{3}\right)$ (2). A Schlenk tube was charged with p-tolualdoxime, $353 \mathrm{mg}$ (2.61 mmoles), and hydridozirconocene chloride, $585 \mathrm{mg}$ ( $2.28 \mathrm{mmoles}$ ). To this was added $7 \mathrm{~mL}$ thf to produce vigorous gas evolution for about 3 minutes and giving a clear solution from which white crystals began to precipitate. After 10 minutes the mixture was cooled to $-30^{\circ} \mathrm{C}$ producing more needle-like crystals. After another 10 minutes at $-30^{\circ} \mathrm{C}$, the supernatant was decanted. The crystals were washed with $15 \mathrm{~mL}$ cool diethyl ether (yield was reduced, should use ether at $-30^{\circ} \mathrm{C}$ ). The product was dried in vacuo for 20 minutes to give 2 ( $490 \mathrm{mg}, 1.08 \mathrm{mmol}, 47.2 \%, \mathrm{MW}=455$ ) as a white solid: $1 \mathrm{H}-\mathrm{NMR}\left(60 \mathrm{MHz}\right.$, acetonitrile- $\left.d_{3}\right): \delta 1.8(\mathrm{t}, 4 \mathrm{H}$, overlapped by solvent multiplet), $2.42(\mathrm{~s}, 3 \mathrm{H}), 3.7(\mathrm{t}, 4 \mathrm{H}, \mathrm{J}=8 \mathrm{~Hz}), 6.20(\mathrm{~s}, 10 \mathrm{H}), 7.40(\mathrm{~d}, 2 \mathrm{H}$, $J=12 \mathrm{~Hz}$ ), $7.70(\mathrm{~d}, 2 \mathrm{H}, \mathrm{J}=12 \mathrm{~Hz}), 8.42(\mathrm{~s}, 1 \mathrm{H})$.

$\mathrm{Cp}_{2} \mathrm{Zr}(\mathrm{Cl}) \mathrm{ON}=\mathrm{C}\left(\mathrm{p}_{-} \mathrm{C}_{6} \mathrm{H}_{4} \mathrm{CH}_{3}\right)$ (3). A Schlenk. tube was charged with methylzirconocene chloride, $514 \mathrm{mg}(1.90 \mathrm{mmoles})$, and $5 \mathrm{~mL}$ diethyl ether to 
give a suspension. A second Schlenk was charged with p-tolualdoxime, $256 \mathrm{mg}(1.90 \mathrm{mmol})$ and dissolved in $5 \mathrm{~mL}$ diethyl ether. The oxime solution was added to the zirconocene suspension producing, simultaneously, vigorous gas evolution and dissolution of nearly all of the suspended matter. The result was an almost clear, colorless liquid which was filtered through a cannula to a third Schlenk, and crystals started to form. After 15 minutes at room temperature, the mixture was cooled to $0^{\circ} \mathrm{C}$ for 45 minutes, cannula-filtered, and washed with hexane $(1 \times 10 \mathrm{~mL})$ at room temperature to give $3(397 \mathrm{mg}$, $1.04 \mathrm{mmol}, 54.6 \%, \mathrm{MW}=382.8)$ as white crystals: ${ }^{1} \mathrm{H}-\mathrm{NMR}(300 \mathrm{MHz}$, benzene- $\left.d_{6}\right): \delta 2.05(\mathrm{~s}, 3 \mathrm{H}), 5.93(\mathrm{~s}, 2 \mathrm{H}$, impurity), $6.03(\mathrm{~s}, 10 \mathrm{H}), 6.98(\mathrm{~d}, 2 \mathrm{H}$, $J=8.1 \mathrm{~Hz}$ ), 7.53 (d, 2H, J=8.1Hz), 8.20 (s, 1H, impurity).

$\mathrm{Cp}_{2} \mathrm{Zr}(\mathrm{Cl}) \mathrm{ON}=\mathrm{C}\left(\mathrm{CH}_{3}\right)_{2}$ (4). Into a Schlenk tube were measured hydridozirconocene chloride, $1.22 \mathrm{~g}(4.75 \mathrm{mmol})$ and 2-propanone oxime, $411 \mathrm{mg}$ (5.63 mmol). To this was added $15 \mathrm{~mL}$ thf producing vigorous gas evolution and a thick white slurry. The solvent was vacuum stripped and the solute dried in vacuo for about 5 minutes. The solid was then suspended in acetonitrile, heated to dissolution, and cannula-filtered into a second warm Schlenk heated in a dewar of warm water. This solution was cooled slowly to $-10^{\circ} \mathrm{C}$ in an acetone bath and held at that temperature overnight to give large white needles. The supernatant was decanted by filter-cannula leaving 4 (927 mg, $2.83 \mathrm{mmol}, 59 \%, M W=328)$ as white needles: ${ }^{1} \mathrm{H}-\mathrm{NMR}(60 \mathrm{MHz}$, acetonitrile-d $\left.d_{3}\right): \delta 1.99(\mathrm{~s}, 3 \mathrm{H}), 2.13(\mathrm{~s}, 3 \mathrm{H}), 6.07(\mathrm{~s}, 10 \mathrm{H})$. Anal. Calcd for $\mathrm{C}_{13} \mathrm{H}_{16} \mathrm{CINOZr}$ C, 47.47; $\mathrm{H}, 4.90 ; \mathrm{N}, 4.26$. Found: $\mathrm{C}, 47.99 ; \mathrm{H}, 4.91$; N, 4.27. 
$\mathrm{Cp}_{2} \mathrm{Zr}\left(\mathrm{CH}_{3}\right) \mathrm{ON}=\mathrm{C}\left(\mathrm{CH}_{3}\right)_{2}$ (5). In one Schlenk was added dimethylzirconocene, $1.610 \mathrm{~g}(6.41 \mathrm{mmol})$ in $7 \mathrm{~mL}$ diethyl ether to give a solution. To a second Schlenk were added 2-propanone oxime, $474 \mathrm{mg}(6.49 \mathrm{mmol})$ and $7 \mathrm{~mL}$ diethyl ether to give a solution. The oxime solution was cannulated into the zirconocene solution, resulting in vigorous gas evolution and a white crystalline precipitate. After 15 minutes at room temperature, this was cooled to $-30^{\circ} \mathrm{C}$ and held for three hours. The supernatant was decanted by filter-cannula and the solid dried in vacuo at room temperature for two hours to give $5(1.66 \mathrm{~g}$, $5.38 \mathrm{mmol}, 84.1 \%, \mathrm{MW}=308$ ) as a white, crystalline powder: ${ }^{1} \mathrm{H}-\mathrm{NMR}$ (60 MHz, benzene- $\left.d_{6}\right): \delta 0.68(\mathrm{~s}, 3 \mathrm{H}), 1.78(\mathrm{~s}, 3 \mathrm{H}), 1.96(\mathrm{~s}, 3 \mathrm{H}), 5.85(\mathrm{~s}, 10 \mathrm{H})$. Anal. Calcd for $\mathrm{C}_{14} \mathrm{H}_{19}$ NOZr: $\mathrm{C}, 54.50 ; \mathrm{H}, 6.21 ; \mathrm{N}, 4.54$. Found: $\mathrm{C}, 54.20$; $H, 6.10 ; N, 4.51$.

\section{Detailed Reactivity Procedure}

The reactivity of the zirconocene-oximato complexes was examined in the presence of several reactive species: metal hydride, base, and acid. The general procedures are covered in the Results and Discussion Section. The following is a specific example of the addition of a reactive species to a zirconocene-oximato solution.

The addition of $\mathrm{Cp}_{2} \mathrm{ZrHCl}$ to a solution of 1 . To an NMR tube fitted with septum were added $1,21 \mathrm{mg}(0.057 \mathrm{mmol})$, and insoluble hydridozirconocene chloride, $14 \mathrm{mg}(0.055 \mathrm{mmol})$. To this was added $0.5 \mathrm{~mL}$ benzene- $d_{6}$, and the tube was shaken. After ten minutes the solution had turned light yellow. ${ }^{1} \mathrm{H}-\mathrm{NMR}(60 \mathrm{MHz}): \delta 0.60(\mathrm{~s}, 3 \mathrm{H}), 2.06(\mathrm{~s}, 3 \mathrm{H}), 5.63(\mathrm{~s}$, 
$10 \mathrm{H}), 7.00(\mathrm{~d}, 2 \mathrm{H}, \mathrm{J}=9 \mathrm{~Hz}), 7.30(\mathrm{~d}, 2 \mathrm{H}, \mathrm{J}=9 \mathrm{~Hz}), 8.27(\mathrm{~s}, 1 \mathrm{H})$. The solution was carefully heated to boiling which dissolved all solids and produced a deep orange solution ${ }^{1} \mathrm{H}-\mathrm{NMR}(60 \mathrm{MHz}): \delta 0.39(\mathrm{~s}, 4 \mathrm{~mm}), 0.60(\mathrm{~s}, 4 \mathrm{~mm}), 2.06(\mathrm{~s}$, $4 \mathrm{~mm}), 2.21(\mathrm{~s}, 4 \mathrm{~mm}), 2.69(\mathrm{~s}, 2 \mathrm{~mm}), 5.69(\mathrm{~m}), 5.81(\mathrm{~s}), 5.98(\mathrm{~m}), 6.94(\mathrm{~d}, 4 \mathrm{~mm}$, $J=9 \mathrm{~Hz}), 7.30(d, J=9 \mathrm{~Hz}), 8.34(\mathrm{~s}, 2 \mathrm{~mm})$. Methylene chloride $(10 \mu \mathrm{L})$ was added to the solution by syringe, producing no apparent reaction as evidenced by an identical ${ }^{1} \mathrm{H}$-NMR spectrum, excepting the $\mathrm{CH}_{2} \mathrm{Cl}_{2}$ peak at $\delta 4.32$.

\section{REFERENCES AND NOTES}

[1] For some reviews of oxime and oxime-îransition metal chemistry see, (a) Keeney, M. E.; Osseo-Asare, K. Coordination Chem. Rev. 1984, 59, pp 141-201, (b) Singh, R. B.; Garg, B. S.; Singh, R. P. Talanta 1979, 26, pp 425-444, (c) Unterhalt, B. Method Chim. 1975, 6, pp 403437, (d) Chakravorty, A. Coordination Chem. Rev. 1974, 13, pp 1-46, (e) Singh, A.; Gupta, V. D.; Srivastava, G.; Mehrotra, R. C. J. Organomet. Chem. 1974, 64, pp 145-169, (f) Egneus, B. Talanta 1972, 19, pp 1387-1419, (g) Freeman, J. P. Chem. Rev. 1973, 73(4), pp 283-292, and [5], below.

[2] (a) Cornish, E. H. Makromol. Chem. 1963, 64, pp 210-12. (b) Howard, E. G., Jr. U. S. Patent 2567 109, 1951, Chem. Abstr. 1951, 46, 783c. (c) van Peski , C. J. (to E. I. du Pont Nemours) U. S. Patent 2478 066, 1949; Chem. Abstr. 1949, 43, P 8666h. (d) E. I. du Pont de Nemours British patent 621 179, 1949; Chem. Abstr. 1949, 43, P 6658a.

(e) Roedel, M. J. (to E. I. du Pont Nemours) U. S. Patent 2462 678, 1949; Chem. Abstr. 1949, 43, P $4514 i$.

[3] Hayden, P.; Wright, D. (Imperial Chemical Industries) South African Patent 6700 710, 1968; Chem. Abstr. 1969, 87049q.

[4] (a) Rose, K. J. Am. Chem. Soc. 1994, 116, 30-33. (b) Nishino, N.; Xu, M.; Mihara, H.; Fujimoto, T.; Ohba, M.; Ueno, Y.; Kumagai, $H$. J. Chem. Soc. , Chem. Commun. 1992, 2, pp 180-181. 
[5] Mehrotra, R. C.; Rai, A. K.; Singh, A.; Bohra, R. Inorg. Chim. Acta 1975, 13, pp 91-103.

[6] Ref. Zh. Khim. 1965, Abstr. No. 13G18.

[7] Wiersma, L. D.; Lott, P. F. Anal. Chim. Acta. 1968, 40(2), pp 291-298.

[8] Gekker, E. N. Ref. Zh. Khim. 1974, Abstr. No. 10 G79.

[9] Szymanowski, J.; Borowiak-Resterna, A. Crit. Rev. in Anal. Chem. 1991, 22(1,2), 519-566.

[10] (a) Arai, M.; Fujioka, K.; Moriyama, Y.; Kawaguchi, A.; Hasuike, H.; Takahashi, K. European Patent EP 510 838, 1992; Chem. Abstr. 1993, 118, 170743s. (b) Massolini, G.; Kitsos, M.; Gandini, C.; Caccialanza, G. Pestic. Sci. 1989, 26(2), pp 209-214. (c) Zsolnai, T. Biochem. Pharmacol. 1961, 7, pp 195-220.

[11] (a) Holan, G.; Johnson, W. M. P.; O'Keefe, D. F.; Quint, G. L.; Rihs, K.; Spurling, T. H.; Walser, R.; Virgona, C. T.; Frelin, C.; et al. Spec. Pub. - R. Soc. Chem. 1985, 53, pp 114-132; Chem. Abstr. 1986, 105, 129392v. (b) Sumitomo Chemical Japanese Patent 59163 302, 1984; Chem. Abstr. 1985, 102, 57842e. (c) Vladimirova, I. L.; Mel'nikova, N. N. Zhur. Obshchei Khim. 1961, 31, pp 852-4.

[12] Eiszner, J. R.; Stanley, W. G. (to Standard Oil(Indiana)) U. S. Patent 2942 961, 1960; Chem. Abstr. 1960, 54, 25830h.

[13] (a) Lundy, P. M.; Hansen, A. S.; Hand, B. T.; Boulet, C. A. From Gov. Rep. Announce. Index (U. S.) 1991, 91(22), Abstr. No. 162,644. (b) Hutzschen-reuter, J.; Hoeg, A.; Busch, E. Ger. (East) Patent DD 300 772, 1992; Chem. Abstr. 1993, 118, 17863m. (c) Kovacevic, V.; Maksimovic, M.; Deljac, V.; Binenfeld, Z. Acta Pharm. Jugosl. 1991, 41(1), pp 75-78. (d) Van Helden, H. P. M.; De Lange, J.; Busker, R. W.; Melchers, B. P. C. Arch. Toxicol. 1991, 65(7), pp 586-593.

(e) Dultz, L.; Epstein, M. A.; Freeman, G.; Gray, E. H.; Weil, W. B. J. Pharmacol. Exptl. Therap. 1957, 119, pp 522-531.

[14] (a) Jedlinski, Z.; Gomulka, A. Polimery 1963, 8(7-8), pp 287-290. (b) Fedtke, M.; Gross, G. East German Patent 33 991, 1964; Chem. Abstr. 1965, 63, P 8610e.

[15] (a) Furukawa, K.; Kobuchi, H.; Kanemitsuya, K. (Mitsubishi Cable Industrial) Japanese Patent 02103806 [90 103 806], 1990; Chem. Abstr. 1990, 113, 213286m. (b) Toshihiro, A.; Sunatsuka, H.; Tanida, M.; Matsura, M.; Ishikawa, T. (Fujikura) Japanese Patent 02155939 [90 155 939], 1990; Chem. Abstr. 1990, 113, 233104d. 
[16] Yasumura, T.; Fujisawa, M.; Yamane, K. (Toyobo) Japanese Patent 74 41 514, 1974; Chem. Abstr. 1975, 83, 29805r.

[17] Petrov, G. N.; Rappoport, L. Ya.; Budkina, V. A. U.S.S.R. Patent 323 415, 1971; Chem. Abstr. 1972, 76, 128479 z.

[18] Morway, A. J.; Bartlett, J. H. (to Esso Research and Engineering) U. S. Patent 2 929 784, 1960; Chem. Abstr. 1960, 54, 13639 c.

[19] Tamblyn, J. W.; Lappin, G. R.; Newland, G. C. Def. Publ. U.S. Pat. Off. 690 071, From Offic. Gaz. 1968, 857(2), p 368; Chem. Abstr. $1969,71,13822 k$.

[20] Shanton, K. J. (Wiggins Teape Group) European Patent 129 380, 1984; Chem. Abstr. 1985, 103, 30361f.

[21] Sargent, D. E. U. S. Patent 2533 181, 1950; Chem. Abstr. 1950, 45, P 2804f.

[22] Tyagi, S. B.; Singh, B.; Kapoor, R. N. Indian J. Chem., Sect. A 1987, 26A(2), pp 162-164, and [22 ]to [27], below.

[23] Naidu, R. S.; Naidu, R. R. Talanta 1978, 25, pp 354-355.

[24] Pande, K. C. U. S. Patent $3387010,1968$.

[25] March, J. Advanced Organic Chemistry, Reactions, Mechanisms, and Structure, Second ed.; John Wiley \& Sons: New York, 1977; p 1185.

[26] Balicki, R.; Kaczmarek, L.; Malinowski, M. Liebigs Ann. Chem. 1989, pp 1139-1140.

[27] March, J. Advanced Organic Chemistry, Reactions, Mechanisms, and Structure, Third ed.; John Wiley \& Sons: New York, 1985; pp 946, 949, 987-989.

[28] Nitta, M.; lino, Y. Bull. Chem. Soc. Jpn. 1986, 59, pp 2365-2367.

[29] Carraher, C. E.; Torre, L. P.; Molloy, H. M. J. Macromol. Sci., Chem. 1981, $A 15(5)$, pp 757-771.

[30] Thewalt, U.; Friedrich, R. Z. Naturforsch. 1991, 46b, pp 475-482.

[31] Sharan, R.; Gupta, G.; Kapoor, R. N. J. Less-Common Metals 1978, $60, \mathrm{pp} 171-178$. 
[32] Carraher, C. E. ,Jr.; Frary, R. A. Makromol. Chem. 1974, 175(8), 23072316.

[33] (a) Carraher, C. E.; Torre, L. P. Organic Coatings and Plastics Chemistry: Preprints of Papers Presented at the Meeting of the American Chemical Society 1980, 42, pp 18-23, (b) Carraher, C. E.; Torre, L. P. Organic Coatings and Plastics Chemistry: Preprints of Papers Presented at the Meeting of the American Chemical Society 1981, 45, pp 252-256.

[34] McQuillan, G. P.; McKean, D. C.; Torto, I. J. Organomet. Chem. 1986, 312, 183-195.

[35] Mindl, J.; Radonsky, F.; Klicnar, J.; Vecera, M. Collection Czechoslov. Chem. Commun. 1979, 44, pp2401-2408.

[36] Jackman, L. M.; Sternhell, S. Applications of Nuclear Magnetic Resonance Spectroscopy in Organic Chemistry, 2nd ed.; Pergamon: New York, 1972; pp 226-227.

[37] Fachinetti, G.; Floriani, C.; Stoeckli-Evans, H. J. Chem. Soc., Dalton Trans. 1977, pp 2297-2302.

[38] Silver, M. E.; Fay, R. C.; Organometallics 1983, 2, pp 44-47.

[39] An attempt to produce crystals of 1 suitable for $X$-ray from diethyl ether provided crystals that were considered too small, Daniel A. Straus, unpublished notes.

[40] Daniel A. Straus, unpublished notes.

[41] Schedler, D. J. A.; Godfrey, A. G.; Ganem, B. Tetrahedron Lett. 1993, 34(32), pp 5035-5038.

[42] (a) Erker, G.; Mena, M.; Bendix, M. J. Organometallic Chem. 1991, 410, pp C5-C8, (b) Erker, G. Angew. Chem. Int. Ed. Engl. 1989, 28, pp 397-412.

[43] We are grateful to Amid Salari's analytical group at Syntex for providing melting point analysis (Olga Ginsburg) and elemental analysis (Rashimi Saxena).

[44] The Systematic Identification of Organic Compounds, a Laboratory Manual, 6th ed.; Shriner, R. L.; Fuson, R. C.; Curtin, D. Y.; Morrill, T. C. Ed.; John Wiley \& Sons: New York, 1980; pp 181-182, 312. 


\title{
Chapter 2
}

\section{An Examination of the Reaction of Some Zirconocenes \\ With Potassium tert-Butoxide in Different Solvents \\ and Some Related Experiments \\ Using Nuclear Magnetic Resonance Spectroscopy}

\begin{abstract}
Products of the addition of different stoichiometric amounts of potassium tert-butoxide to dimethylzirconocene 1, zirconocenemethylchloride 2, and dibenzylzirconocene 3 in various solvents have been examined spectroscopically. With the addition of potassium tert-butoxide, cyclopentadienide anions are displaced from the zirconocene complex. This is evidenced in the proton and carbon NMR spectra by an upfield shift and, in the former, by reduced relative integration, as potassium cyclopentadienide crystallizes out of solution; potassium cyclopentadienide has been isolated in $76 \%$ yield. ${ }^{1}$ In the product from 1 zirconium-bound methyl protons exhibit the remarkably high-field chemical shift of $\delta-1.06$. In each case the methyl or benzyl group is deuterated by acetonitrile- $d_{3}$ solvent to give $\mathrm{C}_{6} \mathrm{H}_{5} \mathrm{CH}_{2} \mathrm{D}$ (from 3 ) or $\mathrm{CH}_{3} \mathrm{D}^{2}$ (from 1 or 2). Some ancillary reactions involving the substitution of sodium bis(trimethylsilyl)amide for potassit!m tert-butoxide in various solvents are examined.
\end{abstract}




\section{INTRODUCTION}

Organozirconium species have been used in organic syntheses in the past, and interest in this field remains high today. 3 The bulk of present research in this area involves $\operatorname{bis}\left(\eta^{5}\right.$-cyclopentadienyl) zirconium derivatives, "zirconocenes." Trialkoxyzirconium-alkyls (produced in situ) serve as nucleophiles in the alkylation of aldehydes and ketones, ${ }^{4}$ but zirconocene alkyls alone do not. Our group recently discovered that simple zirconocene alkyl complexes, $\mathrm{Cp}_{2} \mathrm{ZrRR}^{\prime}\left(\mathrm{R}=\mathrm{CH}_{3}, \mathrm{R}^{\prime}=\mathrm{Cl} ; \mathrm{R}, \mathrm{R}^{\prime}=\mathrm{CH}_{3} ; \mathrm{R}, \mathrm{R}^{\prime}=\mathrm{CH}_{2} \mathrm{Ph}\right.$; $\left.\mathrm{Cp}=\eta^{5}-\mathrm{C}_{5} \mathrm{H}_{5}\right)$, take part in some interesting and potentially useful reactions in the presence of an alkoxide base. 5 The zirconocene alkyl groups become significantly more basic and nucleophilic in the presence of alkoxide (eq 1).

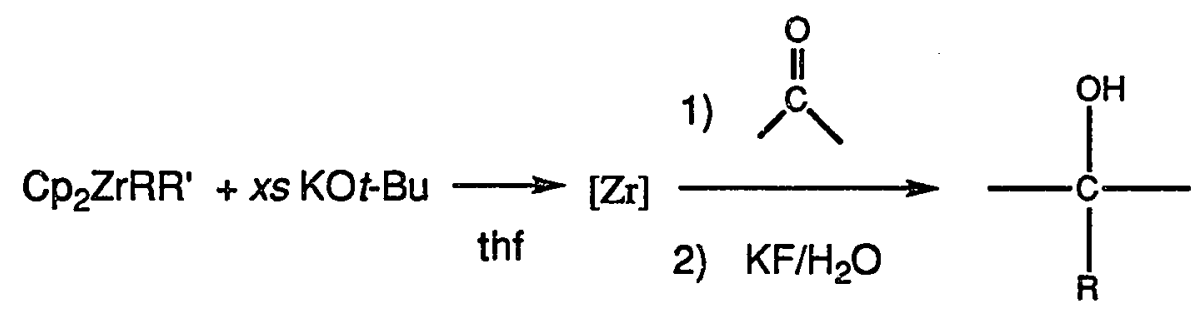

Understanding the mechanism of this reaction could determine the extent of its utility. We discovered that the first part of this reaction sequence could be performed in step-wise fashion, ${ }^{6}$ and that, therefore, the active zirconium alkyl intermediate might be relatively stable or in equilibrium with the starting materials. For example, if the reaction mixture is held at $0^{\circ} \mathrm{C}$, the second step may be performed an hour later without significant effect on yield. Additional characteristics of this first step (the addition of potassium tert-butoxide) are that the cyclopentadienyl $(C p)$ rings are displaced from the metal as anions as 
$\mathrm{K}+\mathrm{Cp}$, in substrates with chloride, the chloride is probably displaced from the metal; and we believe that the active species is either an alkoxyalkylzirconium neutral ${ }^{4}$ or anionic zirconate ("ate") ${ }^{7}$ complex (Figure 1).

Since we have not been able to isolate the intermediate produced by the addition of base, we proposed to characterize this intermediate by proton and ${ }^{13} \mathrm{C}$-NMR (as well as by selectivity studies, Chapter 3 ). Chapter 2 describes early work which led to the discovery of the fundamental chemistry involved as well as more recent studies which reveal some NMR spectral parameters of a possible intermediate.

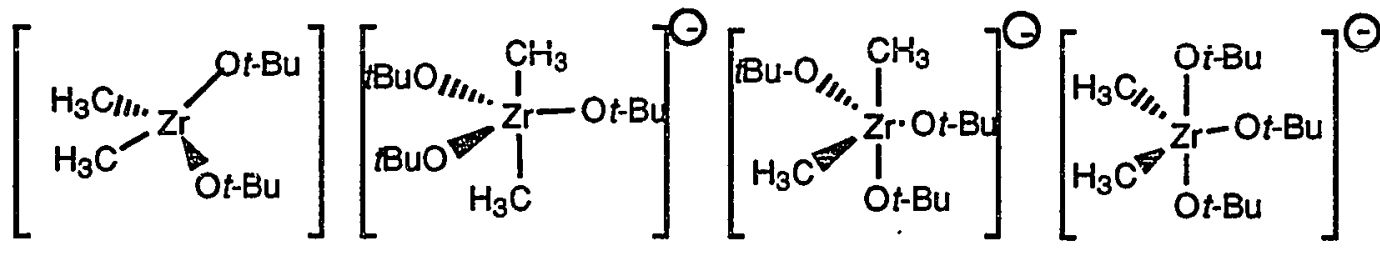

Figure 1. Some Possible Structures for an Alkoxyalkylzirconium Neutral or Anionic "ate" Complex From the Addition of Potassium tert-butoxide to Dimethylzirconocene.

\section{RESULTS AND DISCUSSION}

A search of the literature revealed the following facts concerning alkoxyalkyl-Group IV metal complexes. Triisopropoxymethyltitanium, isolated as a bright yellow oil, distillable without decomposition at $50^{\circ} \mathrm{C} / 0.001$ torr, ${ }^{8}$ exhibits a methyl ${ }^{1} \mathrm{H}$-NMR chemical shift at $\delta 0.5$, the isopropoxy methyls at $\delta 1.3 .9$ Phenyltriisopropoxy-titanium can be recrystallized from cold hexane and 
appears more stable than the methyl derivative. 8 Others have had difficulty in studying alkoxytitanium complexes by NMR. ${ }^{10}$ Alkoxyalkyizirconium complexes of the form (RO) ${ }_{n} Z r R^{\prime}(4-n)$ have not been characterized by NMR except in a few special cases for very bulky alkoxides. ${ }^{11}$ it is also relevant to this discussion to compare the chemical shifts of starting materials with those of the products. Furthermore, this discussion will focus on, but not be limited to, reactions in tetrahydrofuran, the solvent most often employed in the reaction (eq 1).

Examination of the room temperature proton NMR spectra of dimethylzirconocene 1 (Figure 2, and Table 1 , entry $A$ ) and zirconocenemethylchloride 2 (Figure 3 and Table 1, entry I) in tetrahydrofuran- $d_{8}$ revealed the following. A peak for the $\mathrm{Cp}$ protons appears at $\cong \delta 6$ with 1 and 2 and the methyl protons far upfield for 1 and $2(\delta-0.4$ and $\delta 0.2$, respectively). Chemical shifts for 1 in dimethylsulfoxide- $d_{6}$ (Table 1 , entry $B$ ) and acetonitrile- $d_{3}$ (Table 1, entry $C$ ) were nearly the same as above (Table 1). The proton spectrum of 3 in acetonitrile- $d_{3}$ (Table 1, entry $A^{\prime}$ ) exhibits the aryl protons as a multiplet at $\delta 7.0$, the methylene protons as a singlet at $\delta 1.81$, and the $\mathrm{Cp}$ protons as a singlet at $\delta$ 5.98. However, compounds 1 and 2 in benzene- $d_{6}$ (Table 1 , entries $D$ and $J$, respectively) exhibit a $C p$ proton shift at $\delta 5.7$ and methyl protons at $\delta-0.16$ for $y$ and $\delta 0.44$ for 2 . We verified that the impurities noted in Figures 2 and 3 arose from water contamination of the tetrahydrofuran- $d_{8}$ rather than from impure starting materials.

We began the study of the interaction of bases with zirconium alkyls by exploring various reaction conditions. The addition of 1.35 equivalents of potassium tert-butoxide to 1 in acetonitrile- $d_{3}$ at ambient temperature (Table 1, entry Q) gave the characteristic gas evolution and yellow solution. The proton 
NMR shows starting zirconocene (compare with Table 1, entries $C$ and F), a singlet for free (shifted upfield) cyclopentadienyl anion, $\mathrm{Cp}^{-}$, at $\delta 5.51$, and a singlet for the metal bound (shifted downfield) tert-butoxy ligand methyl protons at $\delta 1.18$. Specifically, no monocyclopentadienyl intermediates'were observed. The spectrum is not significaritly changed by heating at $100^{\circ} \mathrm{C}$ for as long as twelve minutes. This experiment was repeated at ambient temperature with the same result.

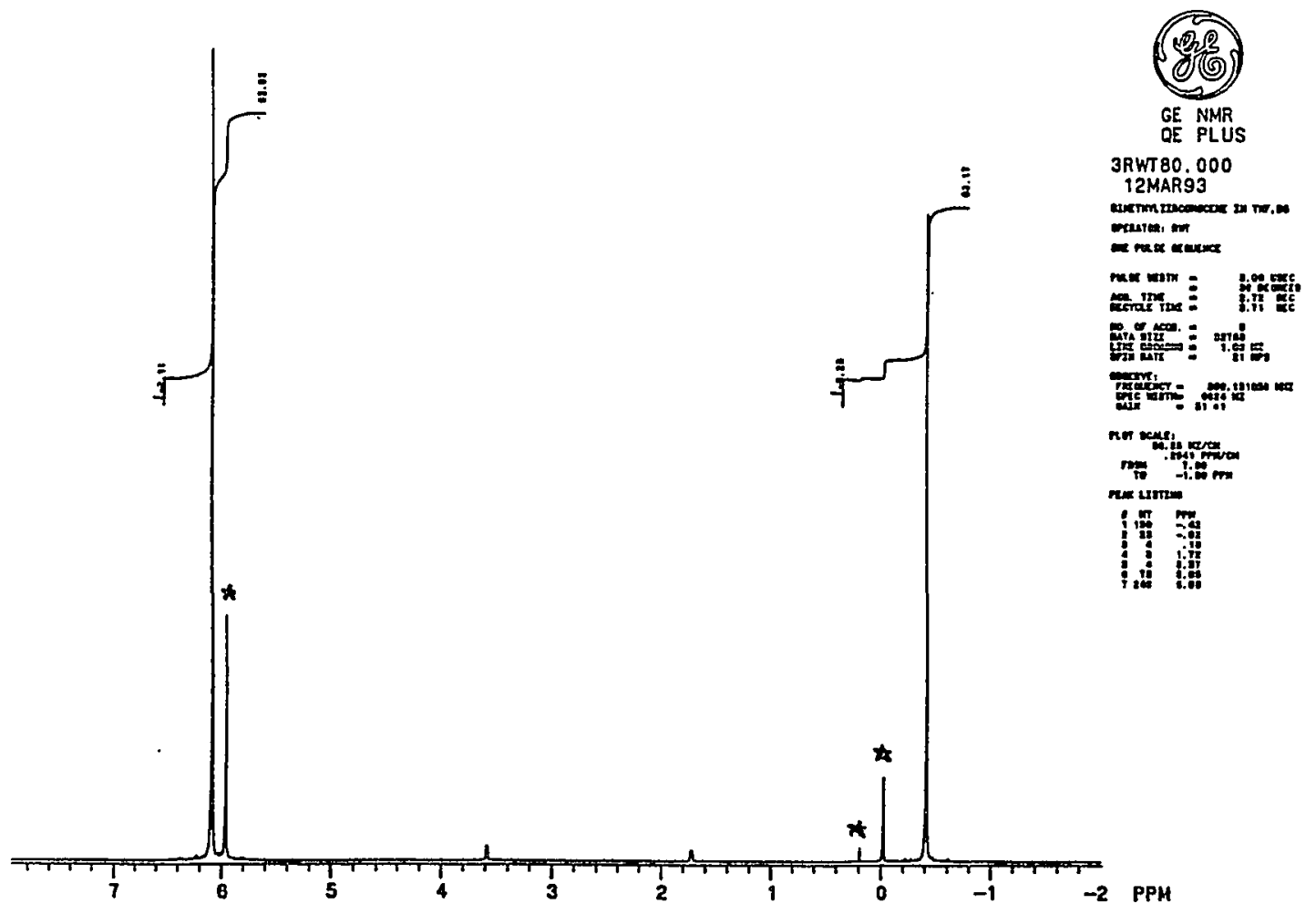

Figure 2. ${ }^{1} \mathrm{H}-\mathrm{NMR}$ Spectrum of 1 in tetrahydrofuran- $d_{8}$ (Table 1 , entry A).

* Impurity in NMR sample 


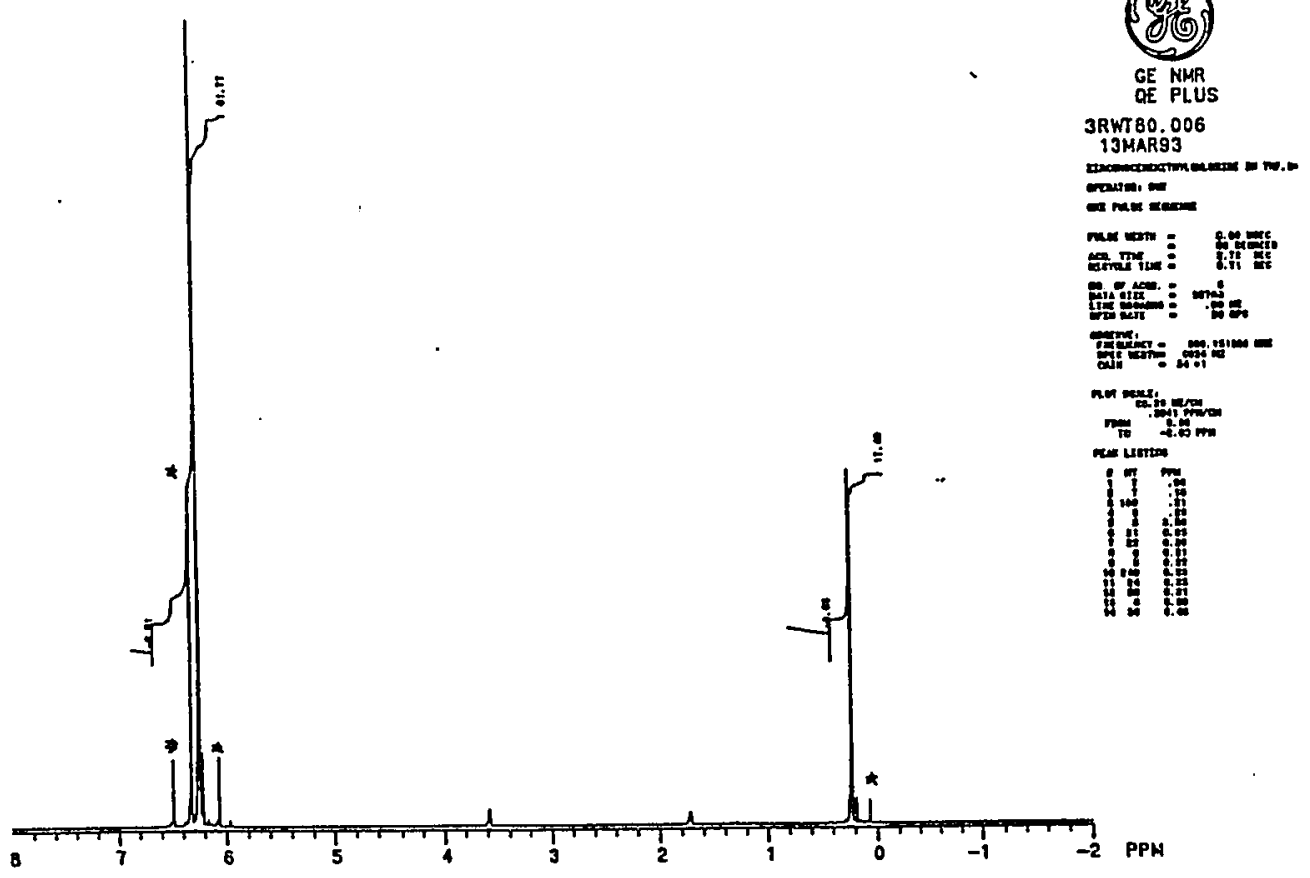

Figure 3. 'it-NîR Spectrum of 2 in tetrahydrofuran- $d_{8}$ (Table 1 , entry I).

* Impurity in NMR sample.

Table 1. NMR Spectral Shifts $(\delta)$ of Authentic Starting Materials and Reaction Products

Compound or Reaction Mixture ${ }^{1} \mathrm{H}$-NMRChemical Shift ${ }^{13} \mathrm{C}$-NMRChemical

Shifit

(Solvent)

$\mathrm{Cp} \quad \mathrm{CH}_{3}$ Ot-Bu $\quad \underline{\mathrm{CH}_{3}} \quad \underline{\mathrm{O} t-\mathrm{Bu}}$

$\begin{array}{llllll}\text { A. Dimethylzirconocene (1) } & 6.08 & -0.42 & \mathrm{~N} / \mathrm{A} & 111.129 .6 \quad \mathrm{~N} / \mathrm{A}\end{array}$

$\left(\right.$ thf- $\left.d_{8}\right)[$ Figure 2]

B. (Dimethylsulfoxide- $d_{6}$ ) $6.09 \quad-0.45 \quad$ N/A

C. (Acetonitrile- $d_{3}$ ) $\quad 6.06 \quad-0.42 \quad \mathrm{~N} / \mathrm{A}$

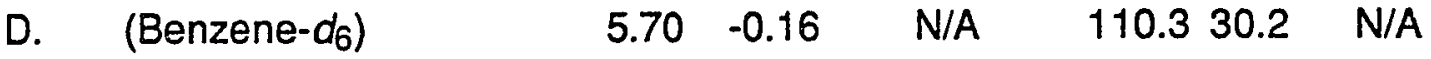


Compound or Reaction Mixture ${ }^{1} \mathrm{H}$-NMRChemical Shift ${ }^{13}$ C-NMRChemical

Shift

(Solvent) $\quad \mathrm{Ep} \quad \mathrm{CH}_{3} \quad \underline{\mathrm{O} t-\mathrm{Bu}} \quad \mathrm{Cp} \quad \mathrm{CH}_{3} \mathrm{Ot-Bu}$

$\begin{array}{llllll}\text { E. Potassium tert-butoxide (KOt-Bul) N/A N/A } & 0.98 & \text { N/A } & \text { N/A } & 37.4\end{array}$ (thf-d8)

67.2

F. (Acetonitrile- $\left.d_{3}\right) \quad$ N/A $\quad N / A \quad 1.06$

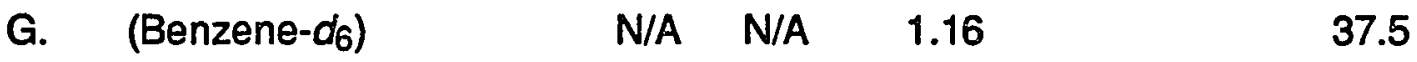

66.5

$\begin{array}{llllll}H . & \text { (Dimethylsulfoxide- } d_{6} \text { ) } & \text { N/A } & \text { N/A } & 0.93 & 37.0\end{array}$

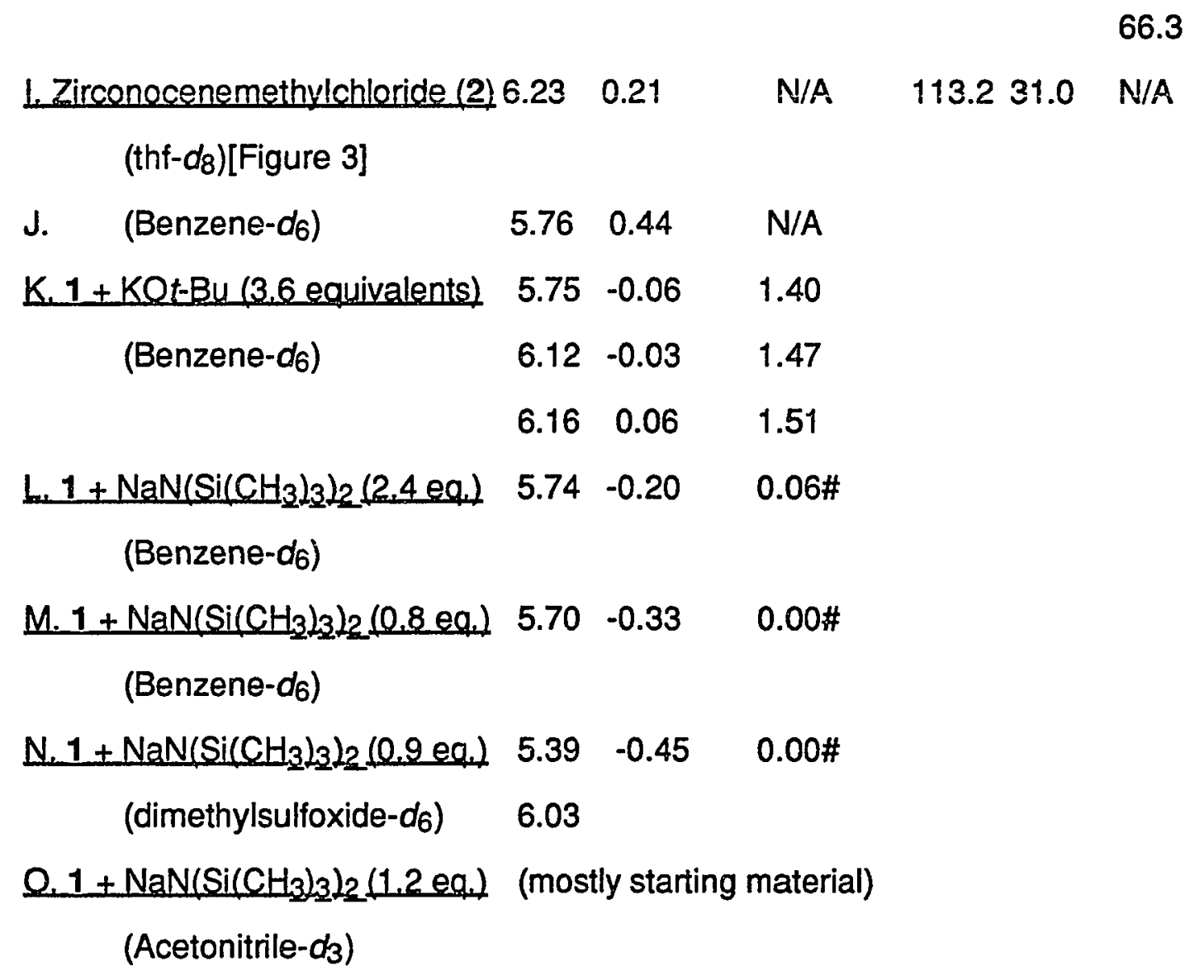


Compound or Reaction Mixture ${ }^{1} \mathrm{H}$-NMBChemical Shift ${ }^{13}$ C-NMRChemical Shift

(Solvent) $\quad \mathrm{Cp} \quad \mathrm{CH}_{3} \mathrm{Ot-Bu} \quad \mathrm{Co} \quad \mathrm{CH}_{3} \quad \mathrm{Ot}-\mathrm{Bu}$

$\begin{array}{llll}\text { P.1+KOt-Bu (1 equivalent) } & 5.45 \quad \mathrm{~N} / \mathrm{A} & 1.18 @\end{array}$

(Dimethylsulfoxide- $d_{6}$ )

Q.1+KOt-Bu (1.35 equivalents) $5.51 \quad \mathrm{~N} / \mathrm{A}$ 1.18@

(Acetonitrile-d $d_{3}$ )

R. $1+\mathrm{KOf}-\mathrm{Bu}$ (5.5 equivalents) 5.53 none 1.12

(Acetonitrile-d $d_{3}$ )

$\begin{array}{llll}\text { S. } 1+K O t-B u(1 \text { equivalent) } & 5.49 & -0.46 & 1.12 @\end{array}$

(Acetonitrile-d $d_{3}$ ) $\quad 6.02$

$\begin{array}{lllllll}\mathrm{T} .1+\mathrm{KO} t \mathrm{Bu} \text { (4.3 equivalents) } & 5.57 & \text { none } & 1.15 & 105.4 \mathrm{~N} / \mathrm{A} & 33.8\end{array}$

(Acetonitrile- $d_{3}$ )

1.18

34.2

1.02

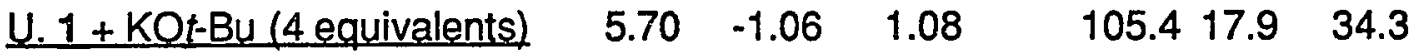

(Tetrahydrofuran-dg)

1.19

34.7

[Figures 5, 6]

69.9

71.9

$\begin{array}{llllll}\mathrm{V} .1+\mathrm{KO} t-\mathrm{Bu} \text { (2 equivalents) } & 5.69 & -0.55 & 1.25 & 105.324 .4 & 33.5\end{array}$

$\begin{array}{lllllll}\left.\text { (Tetrahydrofuran- } \alpha_{8}\right) & 5.84 & -0.60 & 1.30 & 111.1 & 24.8 & 72.3\end{array}$

[Figures 8, 9]

W. 2+KOt-Bu (4.9 equivalents) $5.68 \quad-0.99 \quad 1.16 \quad 105.3 \quad 16.4 \quad 71.2$

$\begin{array}{lllllll}\text { (Tetrahydrofuran- } d_{8} \text { ) } & 5.96 & -0.07 & 1.25 & 110.8 & 17.1 & 71.9\end{array}$

$\begin{array}{lll}\text { [Figures 10, 11] } & 0.18 & 33.8\end{array}$

34.7

34.1 
Comoound or Reaction Mixture ${ }^{1} \mathrm{H}$-NMRChemical Shift ${ }^{13} \mathrm{C}$-NMRChemical

(Solvent)

Cp $\mathrm{CH}_{3}$ Qt-Bu $\mathrm{Cp} \quad \mathrm{CH}_{3}$ Ot-Bu

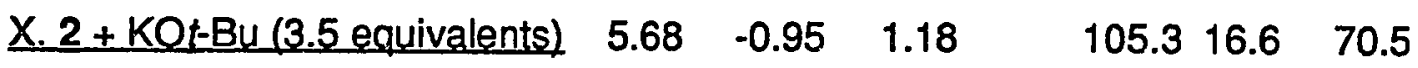

(Tetrahydrofuran- $d z$ )

1.22

71.9

[Figures 12, 13]

1.29

34.2

34.8

(Solvent)

$\mathrm{Cp}-H_{1}^{\mathrm{C}_{2}} \quad \mathrm{C}_{6} H_{5} \quad \underline{K O H-B U-H}$

$\begin{array}{lllll}A^{\prime} \text {. Dibenzylzirconocene (3) } & 5.98 & 1.81 & 7.00 & \text { N/A }\end{array}$

(Acetonitrile-d $d_{3}$ )

$\begin{array}{lllll}\text { B'. 3 + KOt-Bu (5 equivalents) } & 5.55 & 2.23 & 7.10 & 1.10\end{array}$

(Acetonitrile- $d_{3}$ )

$\begin{array}{lllll}\text { C'. } 3+K O t-B u^{\prime} \text { (6.5 equivalents) } & 5.55 & 2.31 & 7.18 & 0.97\end{array}$

(dimethylsulfoxide- $d_{6}$ ) $\quad 1.24$

1.34

$\begin{array}{lllll}D^{\prime} .3+K O t-B u(5.8 \text { equivalents) } & 5.55 & 1.85 & 7.25(d) & 1.24\end{array}$

(Benzene- $\left.d_{6}\right) \quad 6.85(d) \quad 1.36$

Notes: $\quad \cdot(d)=$ doublet, $(m)=$ multiplet

@ Here there is starting material present, also, $\mathrm{Cp}-\mathrm{H}$ at $\delta 6.1$ and $\mathrm{Zr}-\mathrm{CH}_{3}$ at $\delta \quad-0.45$.

\# This shitt is for $\mathrm{Si}\left(\mathrm{CH}_{3}\right)_{2}$.

The addition of excess (5.5 equivalents) of potassium tert-butoxide to 1 in acetonitrile- $d_{3}$ (Figure 1, entry R) produces gas evolution and a very slightly 
yellow solution, but still a good deal of undissolved base. The proton spectrum shows only zirconium bound tert-butoxide and free cyclopentadienyl anions. 12

Since the addition of potassium tert-butoxide to 1 in acetonitrile produces gas evolution, and a 1:1:1 triplet in the proton NMR spectrum at $\delta 0.17$ we attribute to $\mathrm{CH}_{3} \mathrm{D}, 2$ we examined the addition of five equivalents of the base to 3 in acetonitrile- $d_{3}$ (Figure 4 and Table 1 , entry $B^{\prime}$ ), and one of the products proved to be deuterated toluene $\left(\mathrm{C}_{6} \mathrm{H}_{5} \mathrm{CH}_{2} \mathrm{D}\right)$ with the 1:1:1 methyl triplet ${ }^{1} \mathrm{H}$ NMR chemical shift at $\delta 2.23$ and $J \cong 2 \mathrm{~Hz}$. The singlet in the spectrum at $\delta$ 5.55 corresponds with $\mathrm{Cp}^{-}$protons. The addition of only one equivalent of base, with all other parameters unchanged, gave toluene- $d, \mathrm{Cp}^{-}$, and starting material. Heating produced a more complex spectrum that could not be completely interpreted.

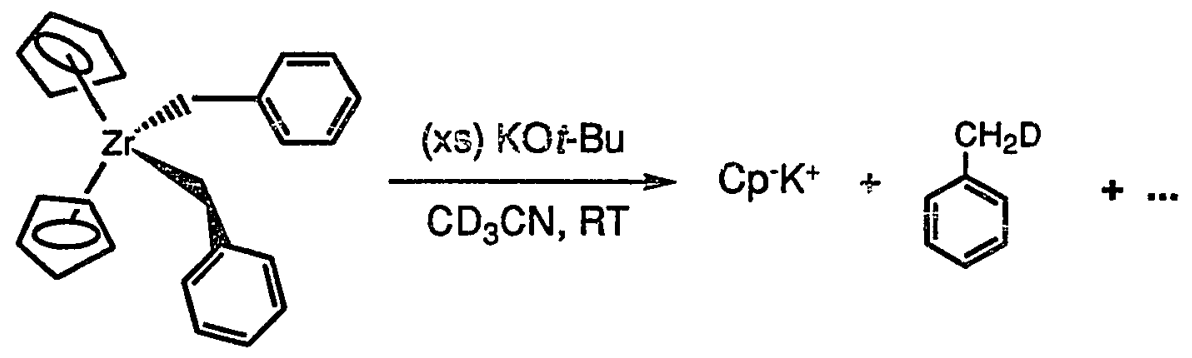

Figure 4. The Addition of Potassium tert-Butoxide to Dibenzylzirconocene

The addition of 6.5 equivalents of potassium tert-butoxide to 3 in dimethylsulfoxide- $d_{6}$ (Table 1 , entry $C^{\prime}$ ) gave unreacted base, what appear to be toluene peaks at $\delta 7.18$ and a 1:1:1 triplet at $\delta 2.31$, a $\mathrm{Cp}^{-}$peak at $\delta 5.55$, and additional tert-butoxy methyl peaks at $\delta 1.24$ and 1.31. The toluene was confirmed by addition of authentic toluene to the NMR sample. 
The addition of one equivalent of potassium tert-butoxide to 1 in dimethylsulfoxide- $d_{6}$ at room temperature (Table 1 , entry P) produces the characteristic evolution of gas (methane) and yellow color. The proton spectrum shows a Cp- peak and two metal-bound tert-butoxy peaks as well as those for siarting zirconocene. Heating over steam for a minute caused a further reaction and produced a proton spectrum with peaks very similar to that obtained by the addition of two equivalents of base to 1 in thf-dg. ${ }^{12}$

The addition of 5.8 equivalents of potassium tert-butoxide to 3 in benzene- $d_{6}$ (Table 1 , entry $D^{\prime}$ ) produced a possible $C p$ - peak at $\delta 5.55$ and what may be a dibenzylalkoxyzirconocene complex exhibiting aryl proton shifts at $\delta 6.85$ and 7.25 and alkoxy methyl proton shifts at $\delta 1.24$ and 1.36 .

The same reaction of base with 2 was attempted in benzene- $\alpha_{6}$ with no success, even with the addition of 18-crown-6 to help facilitate the dissolution of potassium tert-butoxide. The solubility issue is addressed in Chapter 3.

The addition of 3.6 equivalents of potassium tert-butoxide to 1 in benzene- $d_{6}$ (Table 1 , entry $K$ ) produces a reaction, but the proton NMR spectrum is too complex to be interpreted. The addition of acetonitrile (2.5 equivalents) releases gas, probably methane, and the proton NMR spectrum becomes even more complex.

The complex 1 has been shown to alkylate benzaldehyde in benzene in the presence of excess potassium tert-butoxide base. In this case 17.3 equivalents of potassium tert-butoxide were added to 1, and to this was added benzene- $d_{6}$. The addition of 2.36 equivalents of benzaldehyde produced a bright orange solution with some undissolved solids. Heating gave a dark redbrown solution, which on work-up gave a major component by gas 
chromatography with the same retention time as $\alpha$-methyl benzyl alcohol. As there was no quantitation, this might be worth repeating; however, for safety reasons, we chose to use tetrahydrofuran, a viable and less hazardous alternative, as solvent in further studies.

The addition of 2.4 equivalents of sodium bis(trimethylsilyl)amide to 1 in benzene- $d_{6}$ (Table 1 , entry $L$ ) produces a reaction (the solution changes from clear to yellow), Cp- (proton NMR shift at $\delta$ 5.74), and a possible silylamidozirconium complex with metal bound methyl protons little shifted at $\delta \mathbf{- 0 . 2 0}$ and silylmethyl protons at $\delta 0.06 .{ }^{13}$ The addition of acetonitrile gives a reaction, but the products were not determined; the resulting gelatinous matrix was not suitable for NMR spectroscopy. This experiment was repeated without acetonitrile using 0.8 equivalents of bis(trimethylsilyl)amide (Table 1 , entry $M$ ) to give metal-bound methyl protons at $\delta-0.33$. The solution turned opaque due to an emulsified clear oil that slowly floated to the surface to form a layer. It was discovered that bis(trimethylsilyl)amine floats atop dimethylsulfoxide- $d_{6}$, but that a reaction does take place in this solvent to give a yellow solution that darkens to orange with heat, a $\mathrm{Cp}^{-}$peak at $\delta 5.39$ and a metal-bound methyl peak at $\delta-0.45$ plus unreacted starting material. The reaction in acetonitrile- $d_{3}$ (Table 1 , entry 0) gives a clear yellow solution and gas evolution, but much undissolved solid, and the ${ }^{1} \mathrm{H}-\mathrm{NMR}$ spectrum shows mostly starting material. ${ }^{13}$

The proton spectrum for the product of the addition of four equivalents of potassium tert-butoxide at room temperature to 1 in tetrahydrofuran- $d_{8}$ (Figure 5 and Table 1, entry $U$ ) shows two peaks representing the tert-butoxy methyls at $\delta 1.08$ and 1.19 (both downfield of free alkoxy protons at $\delta 0.98$ and integrated about equally), no free alkoxy protons, reduced representation for the metal- 
bonded methyls (relative to the 36 alkoxy protons) that have also shifted remarkably far upfield to $\delta-1.06$, and the $C p$ protons are underrepresented in relation to the alkoxy protons by a singlet that has shifted upfield to $\delta 5.70$ from the metal-bound shift at $\delta 6.08$. Crystals of $\mathrm{K}^{+} \mathrm{Cp}^{-}$were noted in the reaction mixture. The yellow color imparted to the solution is, perhaps, also evidence of zirconium-bound alkoxy groups. ${ }^{7}$

The carbon NMR spectrum of this mixture (Figure 6) shows six types of carbons, one metal-bound methyl at $\delta 17.9$ (remarkably upfield of those in 1 at $\delta$ 29.6), two alkoxy methyl carbons at $\delta 34.3$ and 34.7, two alkoxy carbinol carbons at $\delta 69.9$ and 71.9 (shifts of unbound tert-butoxides are at $\delta 37.4$ and 67.2, respectively), and the Cp- carbons at 105.4 (upfield of 1 at $\delta 111.1$ ).

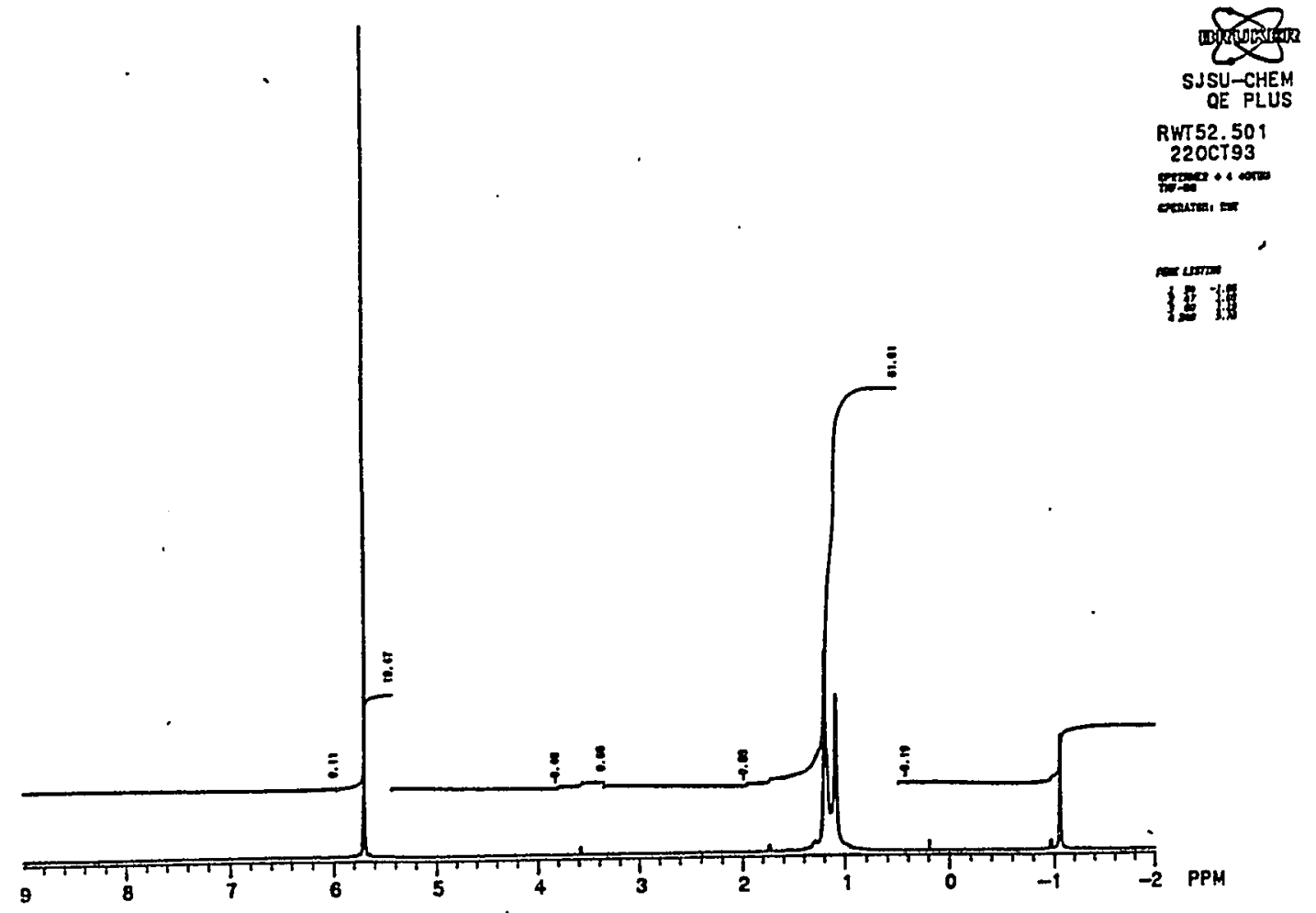

Figure 5. ${ }^{1} \mathrm{H}-\mathrm{NMR}$ Spectrum for the Product of the Addition of Four Equivalents of Potassium tert-Butoxide to 1 in Tetrahydrofuran-do (Table 1, entry U). 


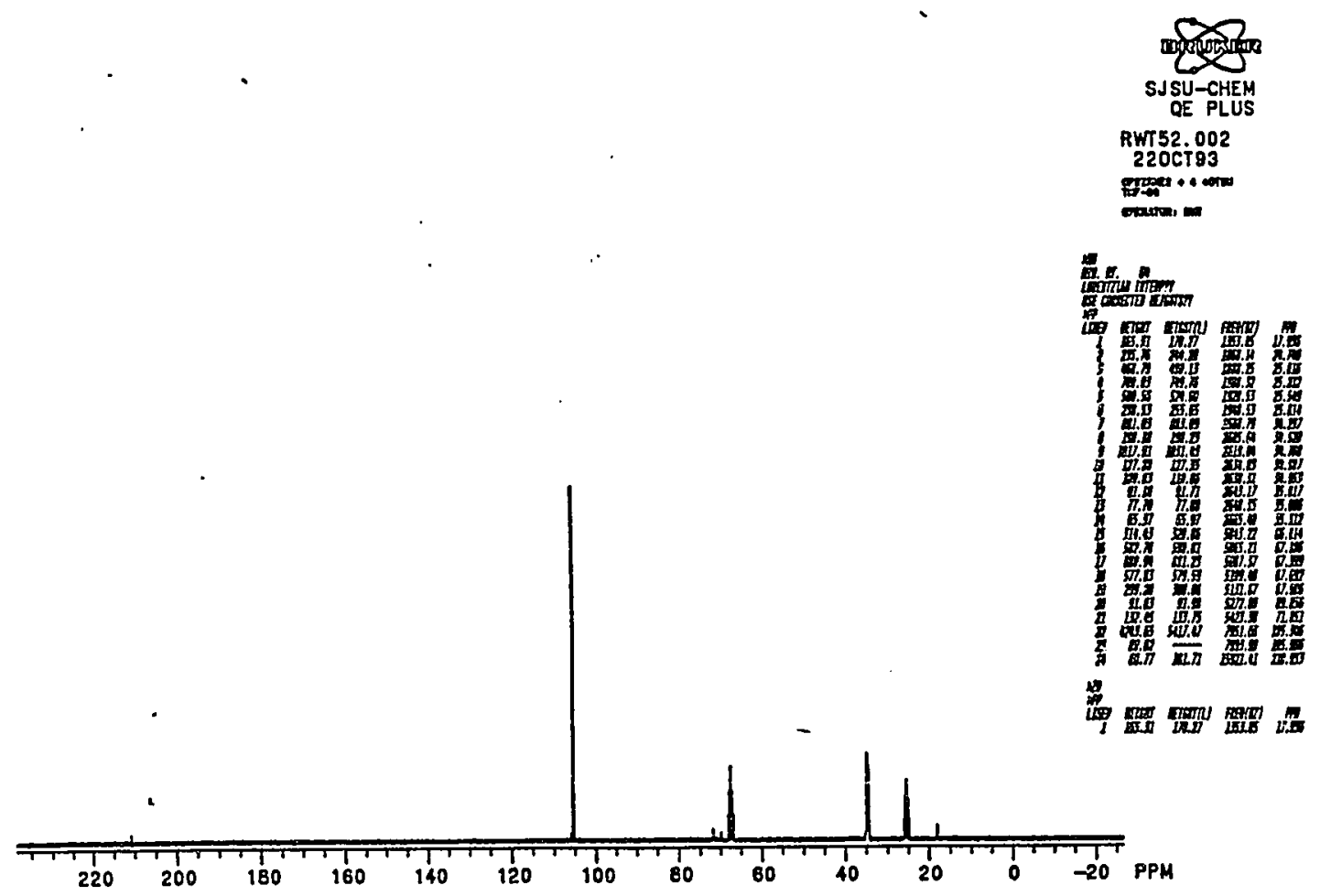

Figure 6. ${ }^{13} \mathrm{C}-\mathrm{NMR}$ Spectrum of the Product of the Addition of Four Equivalents of Potassium tert-butoxide to 1 in Tetrahydrofuran-ds (Table 1, entry U).

These data suggest a product that includes in its structure all four tertbutoxides zirconium-bound, and/or perhaps in two different environments, and the zirconium-bound methyl groups, but of only one type. Rapid exchange from free to bound alkoxides can give shifts that are averages of the exchanging types. Since variable temperature NMR studies have not yet been conducted, any conclusions are tenuous at best. After four days at $-50^{\circ} \mathrm{C}$, the material shows an extra upfield $\mathrm{Cp}$ peak and a growing multiplet (at least ten peaks) just downfield of and overlapping the downfield tert-butoxy peak which has grown in relation to the upfield tert-butoxy peak. The carbon spectrum, however, shows 
only one $\mathrm{Cp}$ - peak, but it shows a new peak on the downfield shoulder of the downfield tert-butoxy methyl peak. Subjecting the sample to three days in the dark at room temperature changes the proton spectrum (Figure 7). The upfield tert-butoxy singlet has shrunk to about $10 \%$ of the downfield peak and is now smaller than the downfield multiplet, by $50 \%$. The methyls are now represented by two peaks that integrate about equally: a singlet at $\delta-0.95$, and a combination singlet/multiplet at about $\delta-1.04$. The carbon spectrum is too complex to be interpreted.

The proton spectrum of the product(s) formed from the addition of just two equivalents of potassium tert-butoxide to 1 in tetrahydrofuran-d8 (Figure 8 and Table 1 , entry $V$ ) is much more complicated, and the peaks are broader. The solution, however, was a characteristic yellow color. There appear to be starting $\mathrm{Cp}$ ligand protons at $\delta 6.09$ and methyl starting material protons at $\delta-0.44$. The tert-butoxy protons are entirely shifted downfield, and it appears that there are two such peaks at $\delta 1.25$ and 1.30 , probably integrated equally although the peaks are not well resolved. The metal bound methyl peaks appear at $\delta \quad-0.55$ and -0.60 , upfield of the starting material and are also unresolved.

The carbon spectrum is also more complex (Figure 9) than with the addition of four equivalents of base, but there appears to be the starting complex 1, and perhaps more than two types of tert-butoxy methy! groups. Broad peaks in the proton spectrum are suggestive of intermediate exchange rates (NMR timescale), and low temperature NMR analysis might slow this exchange to give resolved peaks. 


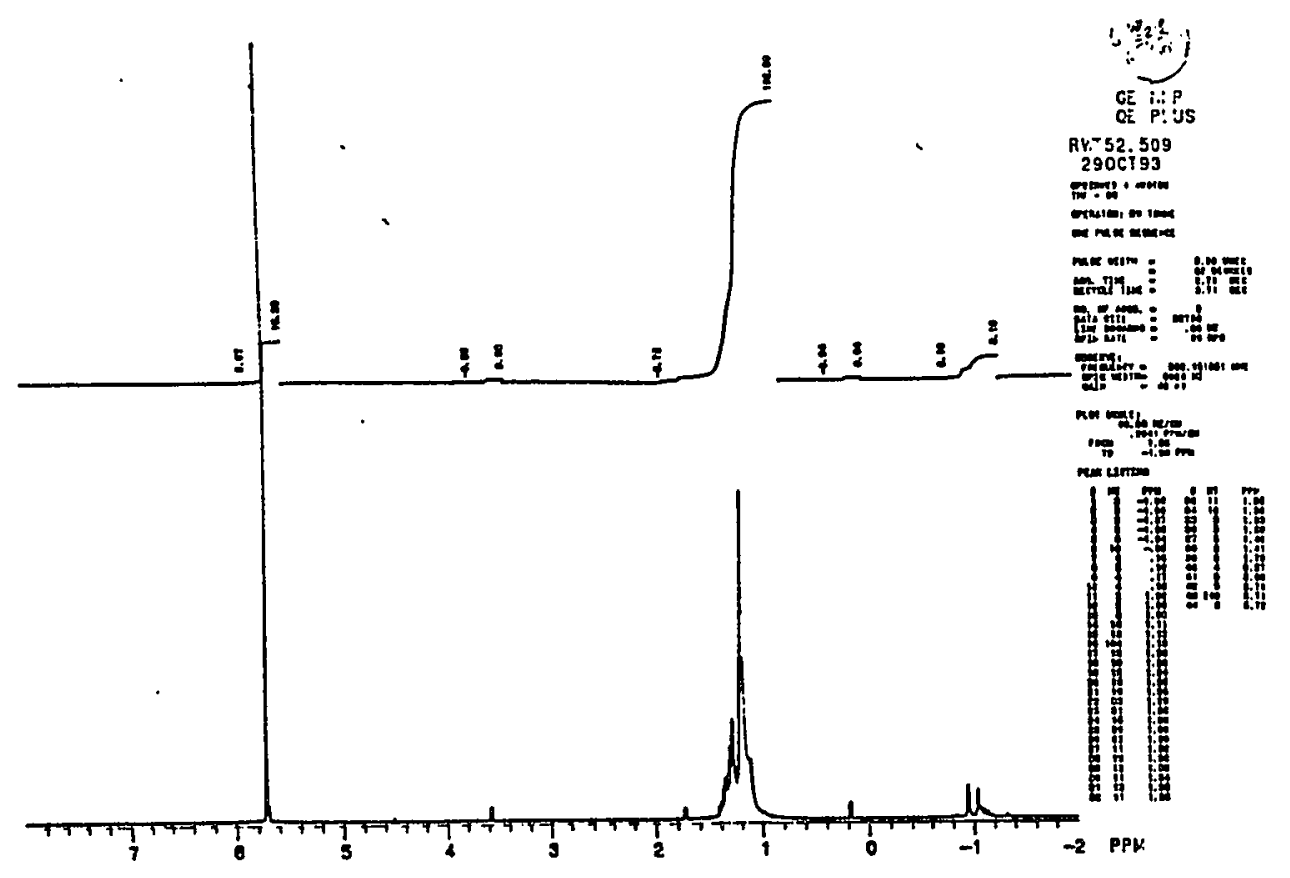

Figure 7. The ${ }^{1} \mathrm{H}-\mathrm{NMR}$ Spectrum of the Product of the Addition of Four Equivalents of Potassium tert-Butoxide to 1 in Tetrahydrofuran- $d_{8}$ After Four Days at $-50^{\circ} \mathrm{C}$ and Three Days at Room Temperature in the Dark.

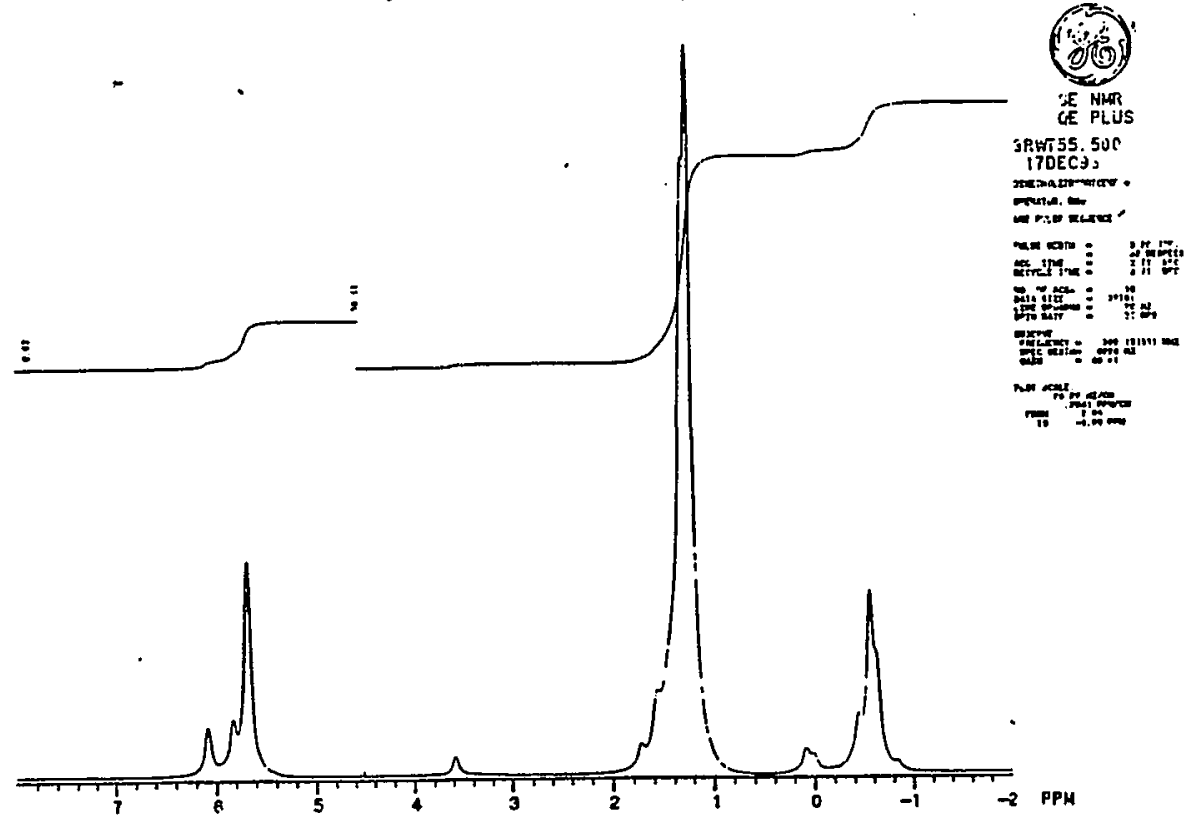

Figure 8. The ${ }^{1 H}$-NMR Spectrum of the Product(s) of the Addition of Two Equivalents of Potassium tert-Butoxide to 1 in Tetrahydrofuran-d $d_{8}$ (Table 1, entry V). 


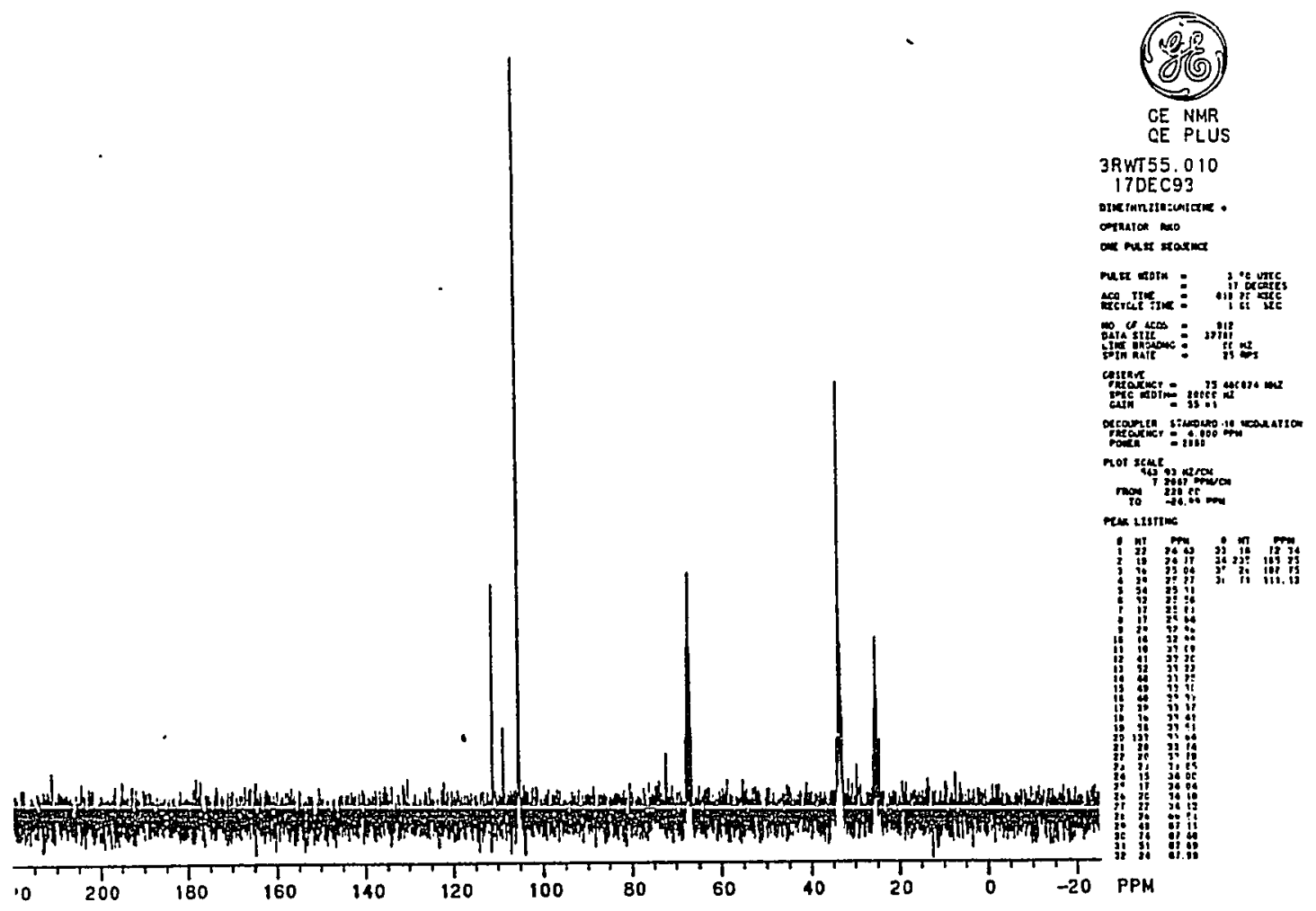

Figure 9. ${ }^{13} \mathrm{C}$-NMR Spectrum of the Product of the Addition of Two Equivalents of Potassium tert-Butoxide to 1 in Tetrahydrofuran-ds (Table 1, entry V).

After 36 days in the dark at room temperature the solution had turned so dark that light from a high intensity bulb was not visible through it. However, the peaks in the proton spectrum of this sample were much sharper, but the mixture was still complex. There still appears to be starting complex 1 present and a large singlet, suggestive of a metal-bound tert-butoxy peak. Further interpretation is difficult.

The addition of 4.9 equivalents of potassium tert-butoxide to zirconocenemethyl chloride (2) in tetrahydrofuran- $d_{8}$ (Figure 10 and Table 1, entry W) gives a proton NMR spectrum with broad peaks that are suggestive of exchange. 
However, Cp peaks at $\delta 5.68$ and 5.96 are both upfield of that for 2 at $\delta 6.23$, the metal-bound methyl peak at $\delta-0.99$ is considerably upfield of starting material and there appear to be two other equally sized metal-bound methyls at $\delta-0.07$ and +0.18 , both still upfield of the starting material and each integrated at about $60 \%$ of the downfield $\mathrm{Cp}$ proton peak which integrates to about $12 \%$ of the total $\mathrm{Cp}$ present.

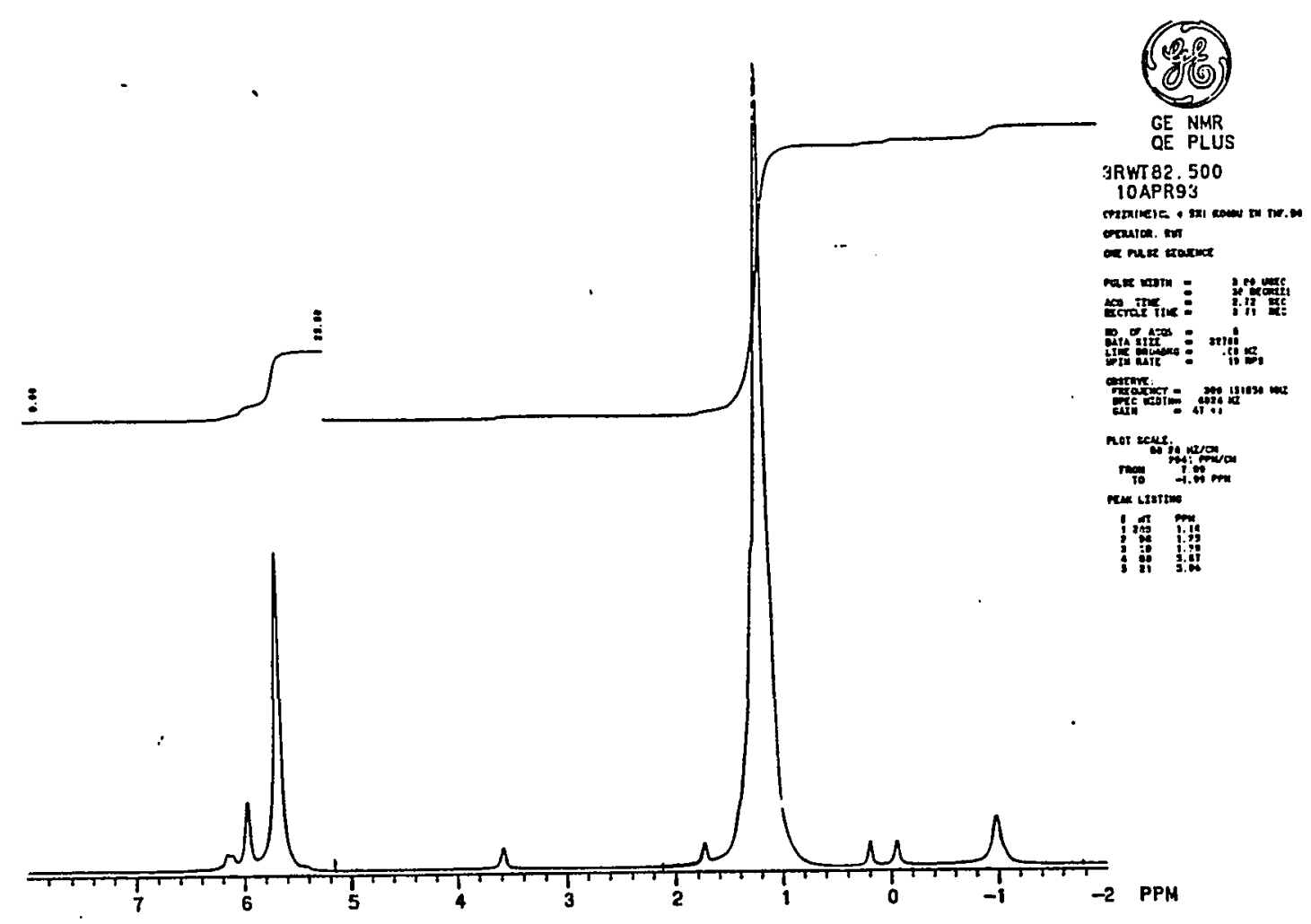

Figure 10. 1H-NMR Spectrum of the Product(s) of the Addition of 4.9 Equivalents of Potassium tert-Butoxide to 2 in Tetrahydrofuran-d $d_{8}$ (Table 1, entry W). 


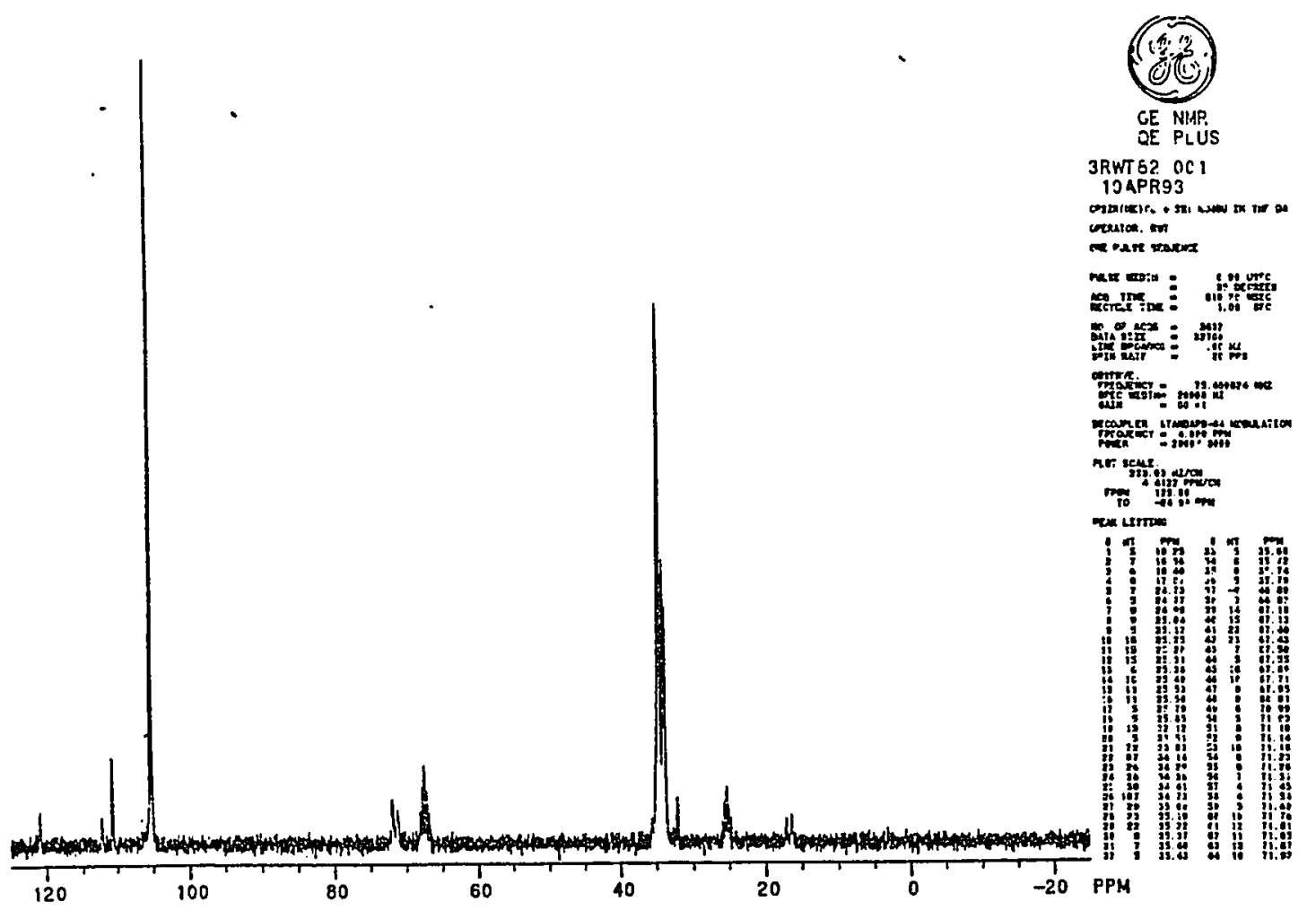

Figure 11. ${ }^{13} \mathrm{C}$-NMR Spectrum of the Addition of 4.9 Equivalents of Potassium tert-Butoxide to 2 in Tetrahydrofuran-d8 (Table 1, entry W).

Metal-bound tert-butoxy proton peaks at $\delta 1.16$ and 1.25 (severely overlapped) appear downfield of the starting material. The carbon NMR spectrum (Figure 11 and Table 1, entry W) shows two Cp peaks at $\delta 105.3$ and 110.8 (upfield of 2 at $\delta$ 113.2), two metal-bound methyl peaks at $\delta 16.4$ and 17.1 (upfield of 2 at $\delta$ 31.0), two resolved tert-butoxy carbinol carbons at $\delta 71.2$ and 71.9 , and three poorly resolved tert-butoxy methyl carbons at $\delta 33.8,34.1$, and 34.7. Qualitatively, there is much similarity between these two spectra and those in Figures 8 and 9, although the peaks in the latter are not well enough resolved to make similar inferences. 
The addition of just 3.5 equivalents of potassium tert-butoxide to 2 in tetrahydrofuran-d8 (Figure 12 and Table 1 , entry $X$ ) produces a sample that exhibits the following proton NMR spectral parameters: a metal-bound methyl singlet at $\delta-0.95$; two large, broad overlapping singlets at $\delta 1.18$ and 1.22 in turn overlapping what appears to be a multiplet at $\delta 1.29$ (the integration of these three when compared to the methyl is $78 \%$ greater than the predicted ratio of tert-butoxy to methyl protons); and a $\mathrm{Cp}$ - singlet at $\delta 5.68$ that integrates, compared to the metal-bound methyl, in about the same proportion as 2 (ie. 10:3). Qualitatively, this spectrum shows similarity to that in Figure 7.

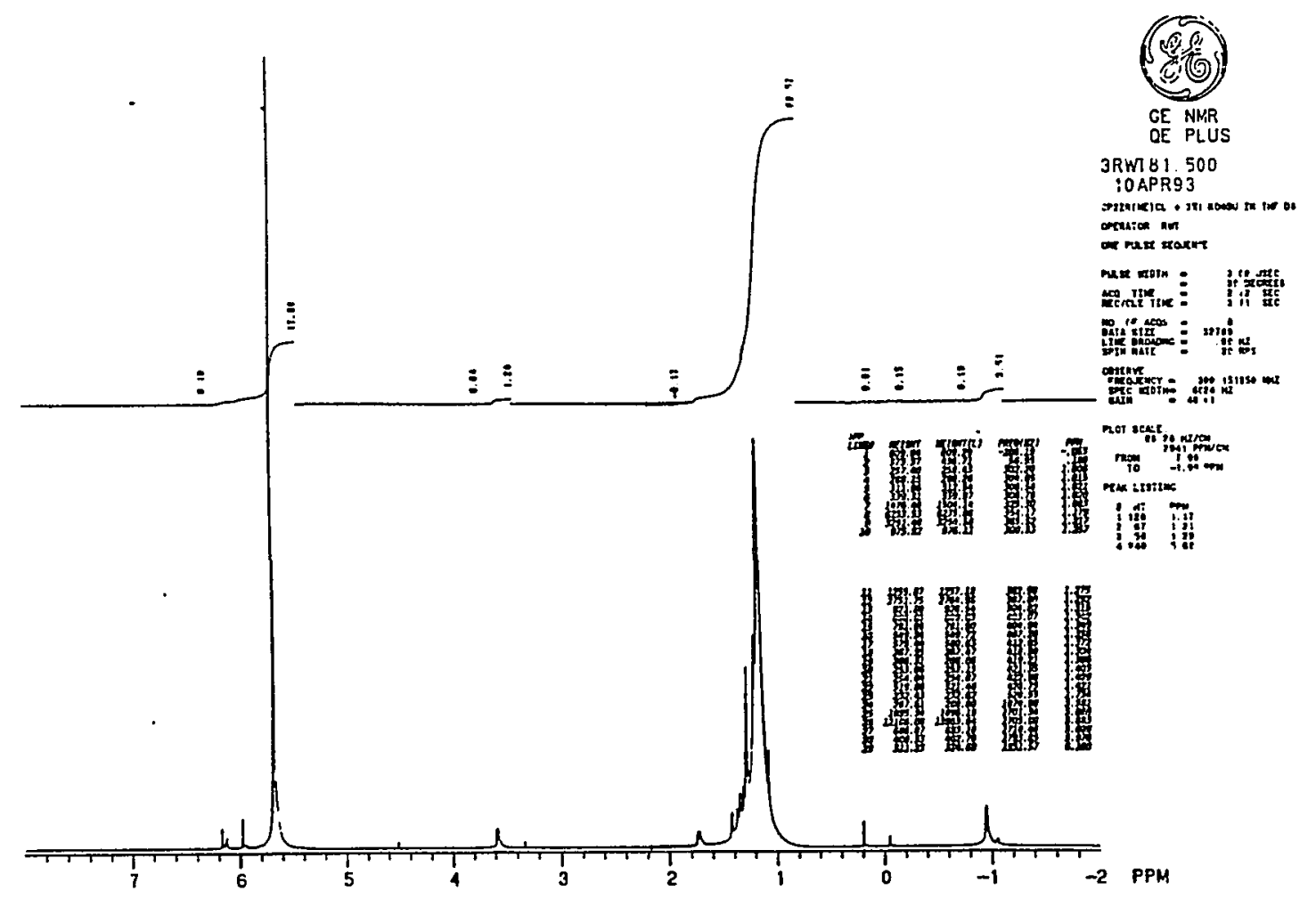

Figure 12. ${ }^{1} \mathrm{H}-\mathrm{NMR}$ Spectrum of the Addition of 3.5 Equivalents of Potassium tert-Butoxide to 2 in Tetrahydrofuran-d8 (Table 1, entry X). 


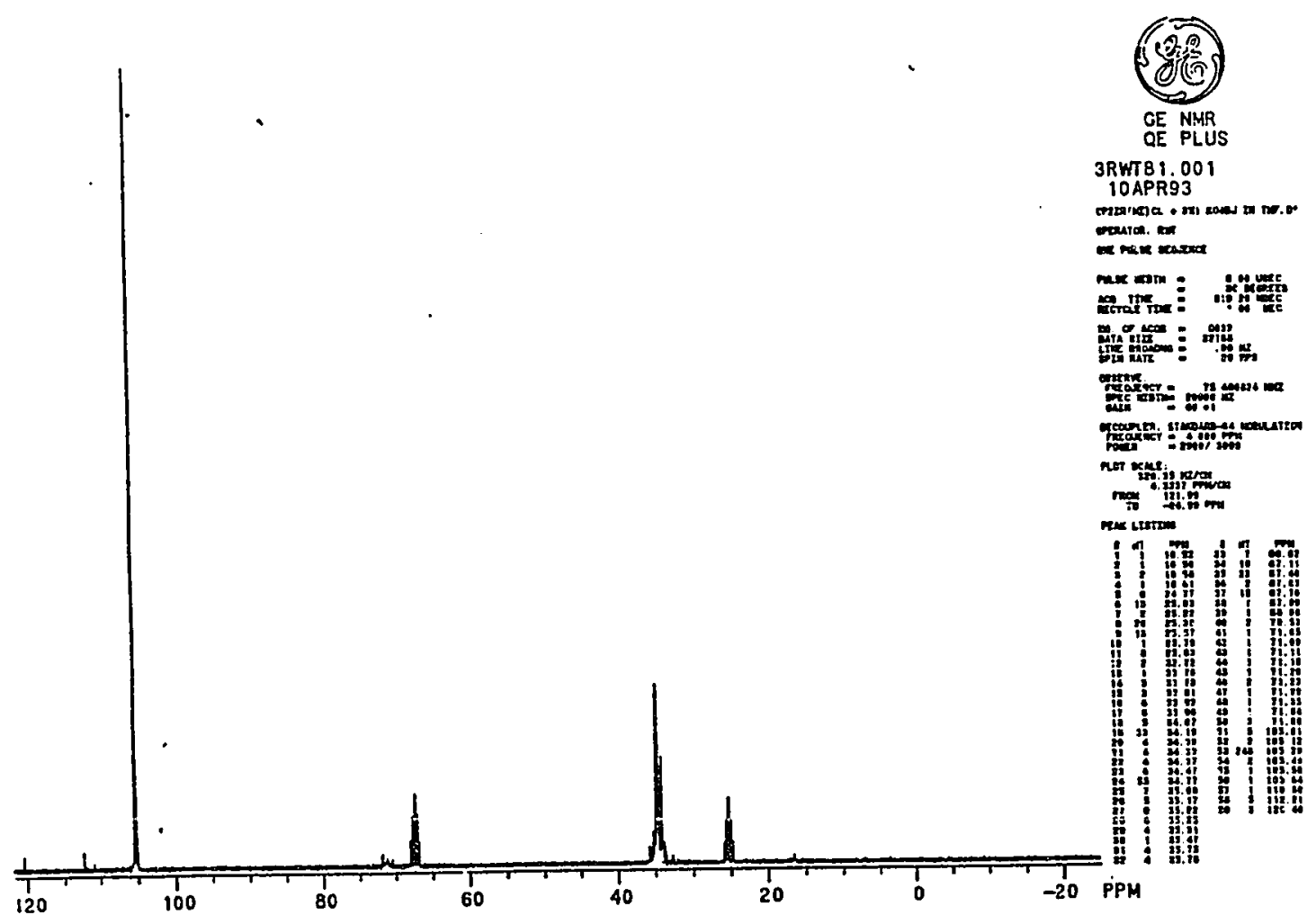

Figure 13. ${ }^{13} \mathrm{C}-$ NMR Spectrum of the Addition of 3.5 Equivalents of Potassium tert-Butoxide to 2 in Tetrahydrofuran- $d_{8}$ (Table 1, entry X).

The carbon NMR spectrum of the sample (Figure 13 and Table 1, entry X) shows a metal-bound methyl carbon peak at $\delta 16.6$, Cp- peak at $\delta 105.3$, and the tert-butoxy carbon peaks as follows: two methyl peaks at $\delta 34.2$ and 34.8 superimposed on a broad disturbance and two carbinol carbon peaks at $\delta 70.5$ and 71.9 bracketing a broad peak at about $\delta$ 71.2. 


\section{SUMMARY}

The goal of these exercises was to determine the spectral parameters of an intermediate, formed upon the addition of base to alkylzirconocenes, that will alkylate carbonyl substrates as in eq. 1. The following is a discussion of what can be concluded from these experiments and suggestions for the future to help clarify issues that are not conclusive. The reaction in acetonitrile-d $d_{3}$ with 1 or 3 as substrate produces methane or toluene, respectively, formed by protonation by the solvent; and we believe acetonitrile protonates the methyl groups (gas is released) of the intermediate produced by the addition of potassium tert-butoxide to 1 in benzene. The addition of 5.5 equivalents (perhaps less, but more than 1.35) of potassium tert-butoxide to 1 in acetonitrile protonates both equivalents of methyl from 1 and displaces both equivalents of $\mathrm{Cp}$ from 1 as $\mathrm{Cp}^{-}$(upfield shift). The chemical shift for the zirconium-bound tertbutoxy protons is downfield of that for free tert-butoxide; however, since the room temperature proton NMR spectrum may show a single peak averaged of free and bound quickly exchanged, low temperature NMR may determine how many equivalents of tert-butoxide are actually metal-bound.

The reaction with 3 as substrate in dimethylsulfoxide- $d_{6}$ also gives toluene- $d_{1}$, deuterated by the solvent. The same approach might be taken in studying the reaction in this solvent as with acetonitrile- $\alpha_{3}$, above.

The reaction with 1 or 3 as substrates in benzene- $d_{6}$ produces observable intermediates. In the case of 1 , that intermediate does methylate benzaldehyde, and the metal-bound methyl protons of that intermediate exhibit room temperature chemical shift(s) slightly downfield of those in 1 . The $\mathrm{Cp}^{-}$ 
protons also appear downfield of zirconium-bound in benzene-d $d_{6}$. The tertbutoxy methyl protons are shifted downfield with both substrates. With this information it appears that benzene is the solvent of choice after tetrahydrofuran and might be investigated in the same manner.

The reaction with $\mathbf{1}$ or $\mathbf{2}$ as substrates in tetrahydrofuran gives products that do methylate aldehydes and ketones. The molar ratio of potassium tertbutoxide to substrate $1(4: 1)$ that gives the greatest yield produces an intermediate in tetrahydrofuran- $d_{8}$, the proton NMR spectrum of which exhibits tert-butoxy protons shifted downfield of the starting butoxide, and zirconiumbound methyl protons shifted remarkably upfield of those in 1. $\mathrm{Cp}^{-}$protons appear upfield of $\mathrm{Cp}$ protons in 1 in tetrahydrofuran- $d_{8}$. Low temperature NMR analysis might determine if there is fast exchange occurring here with the methyls and tert-butoxides and perhaps an internal standard could be used to quantitate the product mixture. The addition of two equivalents of base to substrate 1 produces a more complex product mix that might be gainfully investigated by low temperature NMR analysis. Under similar conditions, compound 2 produces complex mixtures of product with either 3.5 or five equivalents of base. These, too, might be interpreted using low temperature NMR spectroscopy.

Finally, the mixtures of sodium bis(trimethylsilyl)amide to 1 in benzene- $\alpha_{6}$, dimethylsulfoxide- $d_{6}$, and acetonitrile- $d_{3}$ were examined. ${ }^{1} \mathrm{H}-\mathrm{NMR}$ analysis in benzene- $d_{6}$ showed that no reaction had occurred, and the subsequent addition of acetonitrile produced a reaction, but no apparent gas evolution as with potassium tert-butoxide as base. Gas (possibly methane-d) was produced in dimethylsulfoxide- $d_{6}$, and this is similar to the same reaction using potassium 
tert-butoxide as base. The same reactants in acetonitrile- $d_{3}$ produced some gas evolution with heating, but almost no reaction by ${ }^{1} \mathrm{H}-\mathrm{NMR}$ analysis, contrary to the results using potassium tert-butoxide as base. The use of sodium bis(trimethylsilyl)amide in this reaction might be examined further in benzene and in tetrahydrofuran.

\section{EXPERIMENTAL}

\section{General Considerations}

All operations were performed under dry conditions and inert atmosphere using glove-box and vacuum line techniques. Dimethylzirconocene,15 zirconocenemethylchloride, ${ }^{16}$ and dibenzylzirconocene, ${ }^{15}$ were prepared by known methods. Potassium tert-butoxide was sublimed and titrated for purity. Sodium bis(trimethylsilyl)amide was recrysytallized from toluene/pentane. The tetrahydrofuran- $d_{8}$ was distilled by vacuum distillation from sodium/ benzophenone ketal directly into the reaction vessel (NMR tube), except in the cases of Figures 2 and 3 in which adventitious water resulted in some decomposition of the substrate. Benzene- $d_{6}$ was distilled from sodium/ benzophenone ketal and transferred under nitrogen to a screw top bottle to be stored under an inert atmosphere. Acetonitrile- $d_{3}$, dimethylsulfoxide- $d_{6}$, and chloroform- $d$ were distilled under nitrogen, freeze-degassed, and transferred to bottles with screw-tops and stored under nitrogen. 18-Crown-6 was purified by recrystallization from acetonitrile that had been dried over freshly activated $3 \AA$ sieves and dried in vacuo 24 hours. Air, argon, hydrogen, nitrogen, oxygen, and 
liquid nitrogen were used as received from Air Products. ${ }^{1} \mathrm{H}-\mathrm{NMR}$ spectra were acquired as noted on a $60 \mathrm{MHz}$ Varian T $60 \mathrm{NMR}$ spectrometer, a $90 \mathrm{MHz}$ Varian EM 390 NMR spectrometer, or a GE QE Plus $300 \mathrm{MHz}$ Spectrometer, and ${ }^{13} \mathrm{C}$-NMR spectra were acquired on the GE QE Plus spectrometer. Proton and carbon shifts were adjusted to the deuterated solvent standard. Gas chromatography was performed using a Hewlett-Packard HP 5880A Gas Chromatograph with terminal.

\section{Specific Procedures}

The addition of 3.6 equivalents of potassium tert-butoxide to 1 in benzene- $d_{6}$. To an NMR tube were added dimethylzirconocene, $39 \mathrm{mg}(0.16$ $\mathrm{mmol})$, potassium tert-butoxide, $63 \mathrm{mg}(0.56 \mathrm{mmol})$, and $1 \mathrm{~mL}$ benzene- $d_{6}$ to give a cloudy gelatinous suspension: ${ }^{1} \mathrm{H}-\mathrm{NMR}(90 \mathrm{MHz}) \delta-0.06(\mathrm{~s}),-0.03$ (s), $0.06(\mathrm{~s}), 1.40$ (s), 1.47 (s), 1.51 (s), 5.75 (s), 6.12 (s), 6.16 (s). To this mixture was added acetonitrile, $20 \mu \mathrm{L}(0.38 \mathrm{mmol})$. Simultaneously the solution turned yellow with the evolution of bubbles. After a couple of minutes a yellow substance appeared to settle out and deposit on the sides of the tube, leaving a slightly yellow solution: ${ }^{1} \mathrm{H}-\mathrm{NMR}(90 \mathrm{MHz}) \delta-0.05(\mathrm{~s}, 6 \mathrm{~mm}), 0.25(\mathrm{~s}, 5 \mathrm{~mm})$, $0.81(\mathrm{~s}, 5 \mathrm{~mm}), 1.07$ (s, $5 \mathrm{~mm}), 1.35$ (s, $7 \mathrm{~mm}), 1.48(\mathrm{~s},>50 \mathrm{~mm}), 1.64(\mathrm{~s}$, $7 \mathrm{~mm}$ ), $1.72(\mathrm{~s}, 7 \mathrm{~mm}), 1.90$ (d, acetonitrile- $d), 5.70(\mathrm{~s}, 12 \mathrm{~mm}), 6.25(\mathrm{~s}, 12 \mathrm{~mm})$.

The addition of 17.3 equivalents of potassium tert-butoxide to 1 in benzene- $d_{6}$ followed by the addition of 2.36 equivalents of benzaldehyde. To an NMR tube were added potassium tert-butoxide, $161 \mathrm{mg}(1.44 \mathrm{mmol})$, dimethylzirconocene, $21 \mathrm{mg}(0.083 \mathrm{mmol})$, and $1 \mathrm{~mL}$ benzene- $d_{6}$ to give a clear colorless liquid in which none of the solids appeared to have dissolved. To this 
was added by syringe benzaldehyde, $20 \mu \mathrm{L}$ ( $d=1.044,0.19 \mathrm{mmol}$ ), to give almost immediately a bright orange solution with some undissolved solids. The mixture was carefully heated on a steam bath for about 30 seconds to give a dark red-brown solution: ${ }^{1} \mathrm{H}-\mathrm{NMR}(60 \mathrm{MHz}) \delta 0.12(\mathrm{~s}), 0.19(\mathrm{~s}), 1.00(\mathrm{~s}), 1.16$ (s), 1.50 (s), 5.74 (s), 6.00 (s). The NMR tube was then washed with $1 \mathrm{~mL}$ water followed by $1 \mathrm{~mL}$ diethyl ether and the mixture was stirred vigorously to give an orange aqueous layer below a deep orange organic layer. The organic layer was removed by pipette, dried over magnesium suliate, and assayed by gas chromatography (isothermal, $80^{\circ} \mathrm{C}, \mathrm{DB}-5,30 \mathrm{~m}$ column, FID). The major component had the same retention time as an authentic sample of $\alpha$-methylbenzyl alcohol. This experiment was not quantitated.

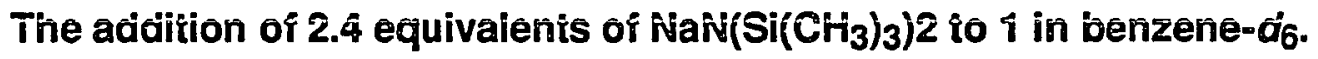
To an NMR tube were added dimethylzirconocene, $26 \mathrm{mg}(0.10 \mathrm{mmol})$, sodium hexamethyldisilazide, $46 \mathrm{mg}(0.25 \mathrm{mmol})$, and $1 \mathrm{~mL}$ benzene- $d_{6}$ to give, after shaking, a clear, very slightly yellow solution: ${ }^{1} \mathrm{H}-\mathrm{NMR}(90 \mathrm{MHz}) \delta-0.20(\mathrm{~s}$, $7 \mathrm{~mm}$ ), 0.06 (s, $43 \mathrm{~mm}$ ), 5.74 (s, $9 \mathrm{~mm}$ ). To this solution was added acetonitrile to give a creamy, very gelatinous sample that was not amenable to NMR spectroscopy.

The addition of 0.8 equivalents of $\mathrm{NaN}\left(\mathrm{Si}\left(\mathrm{CH}_{3}\right)_{3}\right)_{2}$ to 1 in benzene-d $d_{6}$. To an NMR tube were added dimethylzirconocene, $135 \mathrm{mg}$ ( $0.54 \mathrm{mmol})$, sodium bis(trimethylsilyl)amide, $80 \mathrm{mg}(0.44 \mathrm{mmol})$, and $0.5 \mathrm{~mL}$ benzene- $d_{6}$ to give a clear, colorless solution: ${ }^{1} \mathrm{H}-\mathrm{NMR}(90 \mathrm{MHz}) \delta$ - $0.33\left(\mathrm{~s}, \mathrm{ZrCH}_{3}\right), 0.00$ (s, $\left.\mathrm{Si}\left(\mathrm{CH}_{3}\right)_{3}\right), 5.70(\mathrm{~s}, \mathrm{Cp})$.

The addition of 0.9 equivalents of $\mathrm{NaN}\left(\mathrm{Si}\left(\mathrm{CH}_{3}\right)_{3}\right)_{2}$ to 1 in dimethylsulfoxide- $d_{6}$. To an NMR tube were added dimethylzirconocene, 
$112 \mathrm{mg}$ (0.45 mmol), sodium bis(trimethylsilyl)amide, $74 \mathrm{mg}(0.40 \mathrm{mmol})$, and $0.7 \mathrm{~mL}$ dimethylsulfoxide- $\sigma_{6}$ to give some gas evolution and a yellow solution: ${ }^{1} \mathrm{H}-\mathrm{NMR}(90 \mathrm{MHz}) \delta-0.45\left(\mathrm{~s}, \mathrm{ZrCH}_{3}\right), 0.00\left(\mathrm{~s}, \mathrm{SiCH}_{3}\right), 5.39\left(\mathrm{~s}, \mathrm{Cp}^{-}\right), 6.03$ (s, $\mathrm{ZrCp}$ ). Heating to $100^{\circ} \mathrm{C}$ for about two minutes with venting gave gas evolution, an orange color, and some opacity that cleared as a clear oil emulsified and floated to the surface of the clear orange solution: ${ }^{1} \mathrm{H}-\mathrm{NMR}(90 \mathrm{MHz}) \delta-0.41$ (s), $0.06(s), 5.49(s), 6.18(s)$.

The addition of 1.2 equivalents of $\mathrm{NaN}\left(\mathrm{Si}\left(\mathrm{CH}_{3}\right)_{3}\right)_{2}$ to 1 in acetonitrile-d3. To an NMR tube were added dimethylzirconocene, $90 \mathrm{mg}$ ( $0.36 \mathrm{mmol}$ ), sodium bis(trimethylsilyl)amide, $81 \mathrm{mg}(0.44 \mathrm{mmol})$, and $0.7 \mathrm{~mL}$ acetonitrile- $d_{3}$ to give, after shaking, undissolved solids suspended in a clear, colorless liquid. Warming carefully with a heat gun for about two minutes gave some gas evolution, but still considerable suspended solids in a slightly yellow liquid: ${ }^{1} \mathrm{H}-\mathrm{NMR}(60 \mathrm{MHz})$ exhibits only starting material.

The addition of one equivalent of potassium tert-butoxide to 1 and 18-crown-6 in benzene- $d_{6}$. Into an NMR tube were added dimethylzirconocene, $117 \mathrm{mg}$ (0.47 mmol), 18-crown-6, $123 \mathrm{mg}(0.47 \mathrm{mmol})$, and $0.5 \mathrm{~mL}$ benzene- $d_{6}$ to give a solution: ${ }^{1} \mathrm{H}-\mathrm{NMR}(60 \mathrm{MHz}) \delta-0.21(\mathrm{~s}, 6 \mathrm{H})$, $3.48(s, 18 H), 5.80(s, 10 H), 7.15\left(s\right.$, benzene- $\left.d_{5} H\right)$. To this was added potassium tert-butoxide, $46 \mathrm{mg}(0.41 \mathrm{mmol})$, and the tube was shaken. Not all of the base dissolved, and the resulting solution was cloudy with solid, undissolved base in the bottom of the tube. ${ }^{1} \mathrm{H}-\mathrm{NMR}(60 \mathrm{MHz}) \delta 1.76(\mathrm{~s}), 6.04$ (s), both small peaks, the former larger, but mostly starting materials (SM).

The addition of one equivalent of potassium tert-butoxide to 1 in dimethylsulfoxide- $d_{6}$. An NMR tube was charged with dimethyzirconocene, 
$113 \mathrm{mg}(0.450 \mathrm{mmol})$, and potassium tert-butoxide, $52 \mathrm{mg}(0.46 \mathrm{mmol})$. The addition of $0.5 \mathrm{~mL}$ dimethylsulfoxide- $d_{\sigma}$ produced vigorous gas evolution and a yellow solution: $1 \mathrm{H}-\mathrm{NMR}(90 \mathrm{MHz}) \delta-0.45(\mathrm{~s}, 28) \mathrm{SM}, 1.07(\mathrm{~s}, 7), 1.18(\mathrm{~s}, 30)$, $1.24(s, 30), 5.45(s, 40), 6.09$ (s, 40)SM. The sample was steam-heated for about a minute which produced more gas evolution and a yellow-orange solution: ${ }^{1} \mathrm{H}-\mathrm{NMR}(90 \mathrm{MHz}) \delta-0.42(\mathrm{~s}),-0.05(\mathrm{~s}), 0.25$ (s), 1.10 (s), 1.21 (s), $5.50(s), 5.98(s), 6.05(s)$.

The addition of 1.35 equivalents of potassium tert-butoxide to 1 in acetonitrile-d3. An NMR tube was charged with dimethyl-zirconocene, $125 \mathrm{mg}$ $(0.498 \mathrm{mmol})$, and potassium tert-butoxide, $75 \mathrm{mg}(0.67 \mathrm{mmol})$. Acetonitrile- $d_{3}$, $0.5 \mathrm{~mL}$, was added to give vigorous gas evolution and a clear, intense yellow solution: $1 \mathrm{H}-\mathrm{NMR}(90 \mathrm{MHz}) \delta-0.42(\mathrm{~s}, 28), 0.03(\mathrm{~s}, 4), 1.18(\mathrm{~s}, 93), 5.51(\mathrm{~s}, 33)$, $6.06(s, 40)$. The solution was then heated on a steam bath for 2 minutes to give some more gas evolution, initially, and an even more intense yellow solution: ${ }^{1} \mathrm{H}-\mathrm{NMR}(90 \mathrm{MHz}) \delta-0.45(\mathrm{~s}, 23), 1.17(\mathrm{~s}, 114), 5.47(\mathrm{~s}, 40), 6.04(\mathrm{~s}$, 40). The solution was heated an additional 10 minutes on steam to give a still yellow solution: ${ }^{1} \mathrm{H}-\mathrm{NMR}(90 \mathrm{MHz}) \delta-0.45(\mathrm{~s}, 22), 1.18(\mathrm{~s}, 127), 5.47(\mathrm{~s}, 27)$, $6.06(s, 21)$.

The addition of 5.5 equivalents of potassium tert-butoxide to 1 in acetonitrile-d3. An NMR tube was charged with potassium tert-butoxide, 81 $\mathrm{mg}(0.72 \mathrm{mmol})$, and dimethylzirconocene, $32 \mathrm{mg}(0.13 \mathrm{mmol})$. The addition of acetonitrile- $d_{3}, 0.5 \mathrm{~mL}$, gave gas evolution, some large, still undissolved solid under a clear, very slightly yellow solution: ${ }^{1} \mathrm{H}-\mathrm{NMR}(90 \mathrm{MHz}) \delta 1.12(\mathrm{~s}), 5.53$ (s). 
The addition of 1 equivalent of potassium tert-butoxide to 1 in acetonitrile-d3. An NMR tube was charged with potassium tert-butoxide, $32 \mathrm{mg}$ (0.29 mmol), and dimethylzirconocene, $77 \mathrm{mg}(0.31 \mathrm{mmol})$. Acetonitrile- $d_{3}, 0.5$ $\mathrm{mL}$, was added and the tube shaken. At eight minutes at room temperature: ${ }^{1} \mathrm{H}-\mathrm{NMR}(60 \mathrm{MHz}) \delta-0.46(\mathrm{~s}, \mathrm{SM}), 1.12(\mathrm{~s}, 35), 5.49(\mathrm{~s}, 15), 6.02(\mathrm{~s}, 39, \mathrm{SM})$.

The addition of 4.3 equivalents of potassium tert-butoxide to 1 in acetonitrile-d3. An NMR tube was charged with potassium tert-butoxide, $60 \mathrm{mg}$ ( $0.536 \mathrm{mmol})$, and dimethylzirconocene, $31 \mathrm{mg}(0.124 \mathrm{mmol})$. The addition of acetonitrile- $d_{3}, 0.5 \mathrm{~mL}$, produced immediate gas evolution, dissolution of all solids (the solution was cooled to $-78{ }^{\circ} \mathrm{C}$ in liquid nitrogen to be assayed at Stanford, then thawed), and a very pale yellow solution: ${ }^{1} \mathrm{H}-\mathrm{NMR}(200 \mathrm{MHz})$ $\delta 1.02(\mathrm{~s}, 15 \mathrm{~mm}), 1.15(\mathrm{~s}, 41 \mathrm{~mm}), 1.18(\mathrm{~s}, 20 \mathrm{~mm}), 5.57(\mathrm{~s}, 15 \mathrm{~mm}) ;{ }^{13} \mathrm{C}-\mathrm{NMR}$ $(200 \mathrm{MHz}) \delta 33.8,34.2,105.4$.

The addition of 4 equivalents of Potassium tert-Butoxide to 1 in tetrahydrofuran- $d_{8}$. To an NMR tube were added dimethylzirconocene, $35 \mathrm{mg}$ $(0.14 \mathrm{mmol})$, and potassium tert-butoxide, $63 \mathrm{mg}(0.56 \mathrm{mmol})$. The tube was fitted to a vacuum line and thf,d8 was vacuum distilled into it giving a clear, slightly-yellow solution. The tube was sealed with a torch, and the sample was submitted to NMR analysis: ${ }^{1} \mathrm{H}-\mathrm{NMR}(300 \mathrm{MHz}) \delta-1.06(\mathrm{~s}, 6 \mathrm{~mm}),-0.98(\mathrm{~s}$, $1 \mathrm{~mm}), 1.08(\mathrm{~s}, \approx 28 \mathrm{~mm}), 1.19(\mathrm{~s}, \approx 28 \mathrm{~mm}), 1.24(\mathrm{~d}, 3 \mathrm{~mm}), 5.70(\mathrm{~s}, 13 \mathrm{~mm})$. The sample was stored at $-50^{\circ} \mathrm{C}$ for about 30 minutes to give a clear, full-blown yellow solution with clear to white crystals beginning, visibly, to precipitate: ${ }^{1} \mathrm{H}$-NMR $\delta-1.06$ (s), 1.08 (s), 1.19 (s), 1.28 (s), 1.30 (s), 5.70 (s). ${ }^{13} \mathrm{C}$-NMR $(300 \mathrm{MHz}) \delta 17.9,34.3,34.7,69.9,71.9,105.4$; The sample was wrapped in foil and stored in a freezer at $-50^{\circ} \mathrm{C}$ for four days. The sample was then removed 
from the freezer and thawed to give a bright yellow solution with white precipitate that was spun to the bottom of the tube in a centrifuge, and assayed by ${ }^{1} \mathrm{H}-\mathrm{NMR}(300 \mathrm{MHz}) \delta-1.06(\mathrm{~s}, 0.5 \mathrm{~mm}),-1.00(\mathrm{~s}, 5 \mathrm{~mm}),-0.90(\mathrm{~s}, 1 \mathrm{~mm})$, 0.18 (q, $0.5 \mathrm{~mm}, \mathrm{~J}=2.5 \mathrm{~Hz}$ ), 1.14 (s, $15 \mathrm{~mm}$ ), 1.21 (s, $27 \mathrm{~mm}$ ), 1.29 (m, $6 \mathrm{~mm}$, $\mathrm{J}=2.7 \mathrm{~Hz}$ ), 5.82 (d, $4 \mathrm{~mm}, \mathrm{~J}=2.5 \mathrm{~Hz}$ ); ${ }^{13} \mathrm{C}-\mathrm{NMR} \delta 17.9,34.3,34.7,69.9,71.9$, 105.3; APT $\delta 34.3\left(\mathrm{CH}_{3}\right), 34.7\left(\mathrm{CH}_{3}\right), 105.3(\mathrm{CH})$.

The addition of 2 equivalents of Potassium tert-Butoxide to 1 in tetrahydrofuran- $d_{8}$. An NMR tube was charged with dimethylzirconocene, $44 \mathrm{mg}(0.18 \mathrm{mmol})$, and potassium tert-butoxide, $45 \mathrm{mg}(0.40 \mathrm{mmol})$. Tetrahydrofuran- $d_{8}, 1 \mathrm{~mL}$, was vacuum distilled into the tube from sodium/benzophenone ketal. The tube was sealed with a torch under vacuum/argon, the reaction mixture in a liquid nitrogen bath. Thawing gave some white precipitate at the bottom of the tube below a clear, yellow solution: $1 \mathrm{H}-\mathrm{NMR}(300 \mathrm{MHz}) \delta-0.60(\mathrm{~s}, 5 \mathrm{~mm}),-0.55(\mathrm{~s}, 6 \mathrm{~mm}),-0.43(\mathrm{~s}, 4 \mathrm{~mm}), 1.25(\mathrm{~s}$, $40 \mathrm{~mm}$ ), 1.30 (s, $40 \mathrm{~mm}$ ), $5.69(\mathrm{~s}, 12 \mathrm{~mm}), 5.84$ (s, $4 \mathrm{~mm}), 6.09$ (s, $1.5 \mathrm{~mm})$; ${ }^{13} \mathrm{C}-\mathrm{NMR} \delta$ 24.4, 24.8, 32.9-34.1 (17-19peaks), 72.3, 105.3, 108.8, 111.1; APT $\delta 33.2\left(\mathrm{~m}, \mathrm{CH} / \mathrm{CH}_{3}\right), 105.2\left(\mathrm{CH} / \mathrm{CH}_{3}\right), 108.8\left(\mathrm{CH} / \mathrm{CH}_{3}\right), 111.1\left(\mathrm{CH} / \mathrm{CH}_{3}\right)$. After two hours, the sample was again submitted to a proton assay ${ }^{1} \mathrm{H}-\mathrm{NMR}$ (300 MHz) $\delta-0.84(\mathrm{~s}, 1 \mathrm{~mm}),-0.62(\mathrm{~s}, 5 \mathrm{~mm}),-0.59(\mathrm{~s}, 4 \mathrm{~mm}),-0.56(\mathrm{~s}, 3 \mathrm{~mm})$, $1.25(\mathrm{~s}, 37 \mathrm{~mm}), 1.30(\mathrm{~s}, \approx 38 \mathrm{~mm}), 1.40(\mathrm{~m}, 10 \mathrm{~mm}), 5.68(\mathrm{~s}, 10 \mathrm{~mm}), 5.84(\mathrm{~s}$, $2 \mathrm{~mm}), 6.09$ (s, $3 \mathrm{~mm})$. The sample was stored in the dark at room temperature for 36 days to give a black liquid: ${ }^{1} \mathrm{H}-\mathrm{NMR}(300 \mathrm{MHz}) \delta-0.83(\mathrm{~s}, 1 \mathrm{~mm}),-0.62$ (s, $5 \mathrm{~mm}$ ), $-0.59(\mathrm{~s}, 2 \mathrm{~mm}),-0.56(\mathrm{~s}, 3 \mathrm{~mm}),-0.43(\mathrm{~s}, 2 \mathrm{~mm}), 1.25(\mathrm{~s}, 70 \mathrm{~mm})$, 1.28-1.59 (16 peaks, not all related), $5.68(\mathrm{~s}, 15 \mathrm{~mm}), 5.84(\mathrm{~s}, 1 \mathrm{~mm}), 6.09(\mathrm{~s}$, $3 \mathrm{~mm}$ ); ${ }^{13} \mathrm{C}-\mathrm{NMR} \delta$ 20.7, 29.5, 32.9-34.3 (18 peaks), 33.6, 105.2, 108.7, 111.1; 
APT $\delta$ 33.2-34.1 $\left(\mathrm{CH} / \mathrm{CH}_{3}\right), 72.3\left(\mathrm{C} / \mathrm{CH}_{2}\right), 105.2\left(\mathrm{CH} / \mathrm{CH}_{3}\right), 108.8\left(\mathrm{CH} / \mathrm{CH}_{3}\right)$, $111.1\left(\mathrm{C} / \mathrm{CH}_{2}\right), 111.1\left(\mathrm{CH} / \mathrm{CH}_{3}\right)$.

The addition of 4.9 equivalents of potassium tert-butoxide to 2 in tetrahydrofuran- $d_{8}$. To an NMR tube were added methylzirconocene chloride, $83 \mathrm{mg}$ ( $0.31 \mathrm{mmol})$, potassium tert-butoxide, $170 \mathrm{mg}$ (1.52 $\mathrm{mmol})$, and $1 \mathrm{~mL}$ tetrahydrofuran- $\alpha_{g}$, the tube was fitted with a vacuum line adapter, and the tube was sealed with a torch. The sample was shaken to give fine, clear crystals forming in a clear, light yellow solution: ${ }^{1} \mathrm{H}-\mathrm{NMR}(300 \mathrm{MHz}) \boldsymbol{\delta}-0.99$ (s, $2 \mathrm{~mm}$ ), $-0.07(\mathrm{~s}, 0.5 \mathrm{~mm}), 0.18(\mathrm{~s}, 0.5 \mathrm{~mm}),\{1.16(\mathrm{~s}), 1.25(\mathrm{~s})(52 \mathrm{~mm}$, total of two peaks)\}, 5.68 (s, $10 \mathrm{~mm}), 5.96(\mathrm{~s}, 1.5 \mathrm{~mm}) ;{ }^{13} \mathrm{C}-\mathrm{NMR} \delta$ 16.4, 17.1, 33.8, $34.1,34.7,71.2,71.9,105.3,110.8$.

The adidition of 3.5 equivalents of potassium tert-butoxide to 2 in tetrahydrofuran- $d_{8}$. To an NMR tube were added methylzirconocene chloride, $35 \mathrm{mg}(0.13 \mathrm{mmol})$, potassium tert-butoxide, $50 \mathrm{mg}(0.45 \mathrm{mmol})$, and $0.5 \mathrm{~mL}$ tetrahydrofuran- $d_{8}$, the iube was attached to a vacuum adapter and sealed with a torch, and the sample was shaken to give crystals beginning to precipitate in a clear, light-yellow solution: $1 \mathrm{H}-\mathrm{NMR}(300 \mathrm{MHz}) \delta$-0.95 (s, $3 \mathrm{~mm}),\{1.18(\mathrm{~s})$, $1.22(\mathrm{~s}), 1.29$ (s)(56 mm, total, three peaks)\}, $5.68(\mathrm{~s}, 10 \mathrm{~mm}) ;{ }^{13} \mathrm{C}-\mathrm{NMR}$ $\delta 16.6,34.2,34.8,70.5,71.2,71.9,105.3$.

The addition of 5 equivalents of Potassium tert-Butoxide to $\mathrm{Cp}_{2} \mathrm{Zr}\left(\mathrm{CH}_{2} \mathrm{C}_{6} \mathrm{H}_{5}\right)_{2}$ (3) in acetonitrile-d $d_{3}$. To an NMR tube were added dibenzylzirconocene, $42 \mathrm{mg}(0.10 \mathrm{mmol})$, potassium tert-butoxide, $63 \mathrm{mg}$ $(0.56 \mathrm{mmol})$, and a minimum volume of acetonitrile- $d_{3}$ to give a dark orange solution above solids, the solution turning to clear yellow with shaking (about $20 \%$ of the base failed to dissolve): $1 \mathrm{H}-\mathrm{NMR}(60 \mathrm{MHz}) \delta 1.10(\mathrm{~s}, 65 \mathrm{~mm})$, 
$2.23(\mathrm{t}, 1: 1: 1,6 \mathrm{~mm}, \mathrm{~J}=2.4 \mathrm{~Hz}), 5.55(\mathrm{~s}, 15 \mathrm{~mm}), 7.10(\mathrm{~s}, 15 \mathrm{~mm})$. A small but unmeasured amount of cyclopentadienyllithium was added to the reaction mixture to give a cloudy suspension (perhaps from impure $\mathrm{CpLi}$ ): $1 \mathrm{H}-\mathrm{NMR}$ $(60 \mathrm{MHz}) \delta 1.10(\mathrm{~s}, 51 \mathrm{~mm}), 2.23(\mathrm{t}, 6 \mathrm{~mm}, \mathrm{~J}=2.4 \mathrm{~Hz}), 5.55$ (s, $74 \mathrm{~mm}), 7.10$ (s, $52 \mathrm{~mm})$.

The addition of 6.5 equivalents of potassium tert-butoxide to 3 in dimethylsulfoxide- $d_{6}$. Into an NMR tube were added dibenzylzirconocene, $38 \mathrm{mg}$ (0.094 mmol), potassium tert-butoxide, $68 \mathrm{mg}$ (0.61 mmol), and $0.5 \mathrm{~mL}$ dimethylsulfoxide- $d_{6}$ to give a clear, dark-brown liquid: ${ }^{1} \mathrm{H}-\mathrm{NMR}(90 \mathrm{MHz})$ $\delta 0.97(\mathrm{~s}, 60 \mathrm{~mm}), 1.24(\mathrm{~s}), 1.34(\mathrm{~s}), 2.31$ (t, 1:1:1, $7 \mathrm{~mm}), 5.55$ (s, $16 \mathrm{~mm}), 7.18$ $(\mathrm{s}, 18 \mathrm{~mm})$. Authentic toluene was added to give a still clear, dark-brown liquid: $1 \mathrm{H}-\mathrm{NMR}(60 \mathrm{MHz}) \delta 1.00(\mathrm{~s}), 1.24(\mathrm{~s}), 1.31$ (s), 2.27 (s, $17 \mathrm{~mm}), 5.50$ (s, $23 \mathrm{~mm}$ ), 7.15 (s, $40 \mathrm{~mm}$ ).

The addition of 5.8 equivalents of potassium tert-butoxide to 3 in benzene-d6. To an NMR tube were added dibenzylzirconocene, $22 \mathrm{mg}$ (0.055 mmol), potassium tert-butoxide, $36 \mathrm{mg}(0.32 \mathrm{mmol})$, and $0.5 \mathrm{~mL}$ benzene- $d_{6}$ to give a clear, orange solution (with some suspension that looks like undissolved base): ${ }^{1} \mathrm{H}-\mathrm{NMR}(90 \mathrm{MHz}) \delta 1.24$ (s), 1.36 (s), 1.85 (s, $\left.17 \mathrm{~mm}\right)$, $5.55(\mathrm{~s}, 38 \mathrm{~mm}), 6.85(\mathrm{~d}, \mathrm{~J}=8 \mathrm{~Hz}), 7.25(\mathrm{~d}, \mathrm{~J}=8 \mathrm{~Hz})$. Upon removal the solution was seen to be a deep red-brown color. The NMR tube was heated over steam for about two minutes to give a deep red-brown solution (with no solids): ${ }^{1} \mathrm{H}-\mathrm{NMR}(90 \mathrm{MHz}) \delta 1.37(\mathrm{~s}), 1.55(\mathrm{~s}), 2.15(\mathrm{~s}, 6 \mathrm{~mm}), 5.70(\mathrm{~s}, 3 \mathrm{~mm}), 5.94(\mathrm{~s}$, $5 \mathrm{~mm}), 6.25(\mathrm{~s}, 17 \mathrm{~mm}), 7.04(\mathrm{~s}, 8 \mathrm{~mm})$. Upon removal it was discovered that some solids had formed in the solution. 
The addition of benzophenone to $\mathrm{Cp}_{2} \mathrm{Z} \mathrm{rHCl}$ in benzene- $d_{6}$. To an NMR tube were added insoluble zirconocenehydridochloride, $30 \mathrm{mg}$ ( $0.12 \mathrm{mmol})$, benzophenone, $24 \mathrm{mg}(0.13 \mathrm{mmol})$, and $1 \mathrm{~mL}$ benzene- $d_{6}$, and this was shaken and heated on a steam bath to give a clear, slightly yellow solution: ${ }^{1} \mathrm{H}-\mathrm{NMR}(90 \mathrm{MHz}) \delta 6.67(\mathrm{~m}, 52 \mathrm{~mm}), 5.40(\mathrm{~s}, 50 \mathrm{~mm})$.

The addition of 4-tert-butylcyclohexanone to zirconocene hydridochloride in benzene-d6. To an NMR tube were added insoluble zirconocene hydridochloride, $33 \mathrm{mg}(0.13 \mathrm{mmol})$, tert-butylcyclohexanone, $19 \mathrm{mg}(0.12 \mathrm{mmol})$, and $1 \mathrm{~mL}$ benzene- $d_{6}$ to give no visible sign of reaction even with vigorous shaking. The sample was heated over a steam bath to give a clear, slightly yellow solution: ${ }^{1} \mathrm{H}-\mathrm{NMR}(90 \mathrm{MHz}) \delta 0.70(\mathrm{~s}, 7 \mathrm{~mm}), 0.85(\mathrm{~s}$, $35 \mathrm{~mm}), 0.95$ (s, $28 \mathrm{~mm}), 1.08(\mathrm{~s}, 7 \mathrm{~mm}), 1.55(\mathrm{~m}, 38 \mathrm{~mm}), 6.00$ (s, $60 \mathrm{~mm})$. To this sample was added glacial acetic acid, $15 \mu \mathrm{L}(0.24 \mathrm{mmol})$, to give a clear, slightly yellow solution: ${ }^{1} \mathrm{H}-\mathrm{NMR}(90 \mathrm{MHz}) \delta 0.81(\mathrm{~s}, 33 \mathrm{~mm}), 0.92(\mathrm{~s}, 17 \mathrm{~mm})$, $1.55(\mathrm{~m}), 1.79(\mathrm{~s}, 20 \mathrm{~mm}), 6.05(\mathrm{~s}, 35 \mathrm{~mm}), 6.30$ (s, $8 \mathrm{~mm})$.

The addition of 1.71 equivalents of $\mathrm{CH}_{2} \mathrm{Cl}_{2}$ to $\mathrm{Cp}_{2} \mathrm{ZrHCl}$ (a check for metal hydrides) in benzene- $d_{6}$. To an NMR tube were added insoluble zirconocenehydridochloride, $51 \mathrm{mg}(0.20 \mathrm{mmol})$, methylene chloride, $25 \mu \mathrm{L}$ ( $0.34 \mathrm{mmol}$ ), and $0.5 \mathrm{~mL}$ benzene- $d_{6}$ to give, after centrifuging the undisolved solid to the top, a clear, yellow liquid: ${ }^{1} \mathrm{H}-\mathrm{NMR}(90 \mathrm{MHz}) \delta 1.09(\mathrm{~s}, 130 \mathrm{~mm})$, $3.31(\mathrm{~s}, 20 \mathrm{~mm}), 4.90(\mathrm{~s}, 10 \mathrm{~mm}), 5.01$ (t, $12 \mathrm{~mm}, \mathrm{~J}=3 \mathrm{~Hz}$ ), 6.02(d), 6.13 (s). 


\section{REFERENCES AND NOTES}

[1] Towne, R. W.; Mohtashemi, B.; Hammond, S. M.; Kachel, K. J. L.; Straus, D. A. Mechanism of Base-Promoted Zirconocene Alkyl Transfers to Carbonyl Compounds Poster session presented at the 207th Annual American Chemical Society National Meeting, 1994.

[2] This result was confirmed by ${ }^{1} \mathrm{H}-\mathrm{NMR}(200 \mathrm{MHz}) \delta 0.17\left(\mathrm{t}, 1: 1: 1, \mathrm{CDH}_{3}\right)$ Daniel A. Straus, unpublished results.

[3] (a) Guram, A. S.; Jordan, R. F. J. Org. Chem. 1992, 57, pp 59945999. (b) Takahashi, T. et al. Chem. Lett. 1993, 6, pp 1001-1004. (c) Askham, K. M.; Carroil, K. M. J. Org. Chem. 1993, 58(26), pp 7328-7329. (d) Wipf, P.; Xu, W. J. Org. Chem. 1993, 58(22), pp 5880-5882. (e) Harris, M. C. J.; Whitby, R. J.; Blagg, J. Synlett 1993, 9, pp 705-707. (f) Ito, H.; Taguchi, T.; Hanzawa, Y. Tetrahedron Lett. 1993, 34(47), pp 7639-7640. (g) Godfrey, A. G.; Ganem, B. Tetrahedron Lett. 1992, 33(49), pp 7461-7464.

[4] (a) Reetz, M. T.; Kylung, S. H.; Hüllmann, M. Tetrahedron 1986 , 42(11), pp 2931-2935. (b) Reetz, M. T.; Steinbach, R.; Westermann, J.; Peter, R.; Wenderoth, B. Chem. Ber. 1985, 118, pp 1441-1454. Reetz, M. T.; Jung, A. J. Am. Chem. Soc. 1983, 105, pp 4833-4835.

(c) Reetz, M. T.; Steinbach, R.; Westermainn, J.; Urz, R.; Wenderoth, B.; Peter, R. Angew. Chem. Int. Ed. Engl. 1982, 21(2), p 135. (d) Olivero, A. G.; Weidmann, B.; Seebach, D. Helv. Chim. Acta 1981, 64(7), pp 2485-2488. (e) Weidmann, B.; Maycock, C. D.; Seebach, D. Helv. Chim. Acta 1981, 64(5), pp 1552-1557. (f) Weidmann, B.; Wilder, L.; Olivero, A. G.; Maycock, C. D.; Seebach, D. Helv. Chim. Acta 1981, 64(1), pp 357-361. (g) Weidmann, B.; Seebach, D. Helv. Chim. Acta 1980, 63(8), pp 2451-2454. (h) Reetz, M. T.; Steinbach, R.; Westermann, J.; Peter, R. Angew. Chem. Int. Ed. Engl. 1980, 19(12), pp 1011-1012.

[5] Larson, A. L.; Baker, D. L.; Towne, R. W.; Straus, D. A. Tetrahedron Lett. 1991, 32, pp 5893-5894.

[6] Behzad Mohtashemi, unpublished results.

[7] Takahashi, T.; Nitto, Y.; Seki, T.; Saburi, M.; Negishi, E. Chem. Lett. 1990, pp 2259-2262.

[8] Weidmann, B.; Seebach, D. Angew. Chem. Int. Ed. Eng. 1983, 22, pp 31-45. 
[9] Reetz, M. T.; Westermann, R.; Steinbach, R.; Wenderoth, B.; Peter, R.; Ostarek, R.; Maus, S. Chem. Ber. 1985, 118, pp 1421-1440.

[10] Reetz, M. T.; Wünsch, T. J. Chem. Soc., Chem. Commun. 1990, pp 1562-1564.

[11] Lubben, T. V.; Wolczanski, P. T.; Van Duyne, G. D. Organometallics 1984, 3, pp 977-983.

[12] Daniel A. Straus, unpublished results.

[13] More work could be done in the DMSO system, perhaps starting with the addition of four equivalents of base to see if a cleaner reaction mixture is possible.

[14] It would be interesting to see if the reaction (eq 1) proceeds in acetonitrile, slowly or in poor yield because the reactive intermediate is not formed readily.

[15] Pearson, A. J. Metallo-organic Chemistry John Wiley \& Sons: New York, 1985; p 107.

[16] Wailes, P. C.; Coutts, R. S. P.; Weigold, H. Organometallic Chemistry of Titanium, Zirconium, and Hafnium Academic Press: New York, 1974; p 125. 


\section{Chapter 3}

An Indirect Examination of the Methylation of Aldehydes and Ketones

Using Zirconocenes in the Presence of Excess Base

\section{ABSTRACT}

Our group reported earlier that complexes of the form $\mathrm{Cp}_{2} \mathrm{ZrR}_{2}$ $\left(\mathrm{Cp}=\eta^{5}-\mathrm{C}_{5} \mathrm{H}_{5}, \mathrm{R}=\mathrm{CH}_{3}, \mathrm{CH}_{2} \mathrm{Ph}\right)$, which do not alkylate aldehydes or ketones under ambient conditions, do alkylate non-enolizable carbonyl compounds in the presence of potassium tert-butoxide. These alkylations of aldehyde and ketone substrates, and related reactions using dialkylzirconocenes and zirconocene methyl chloride with excess potassium tert-butoxide, are discussed. The scope and experimental conditions of these alkylation reactions are covered, including substrates, yieids, observed side reactions, and comparisons with other alkylation reactions (using a Grignard reagent, methyllithium, and " $(\mathrm{RO})_{3} \mathrm{ZrCH}_{3}$ ", $\mathrm{R}=n-\mathrm{Bu})$. The selectivity in competition experiments is measured, where mixed substrates are competing for these reagents in alkylation reactions (some key data is presented in Table 1).

Table 1 Competition Experiments (with Benzaldehyde and Benzophenone as Substrates)

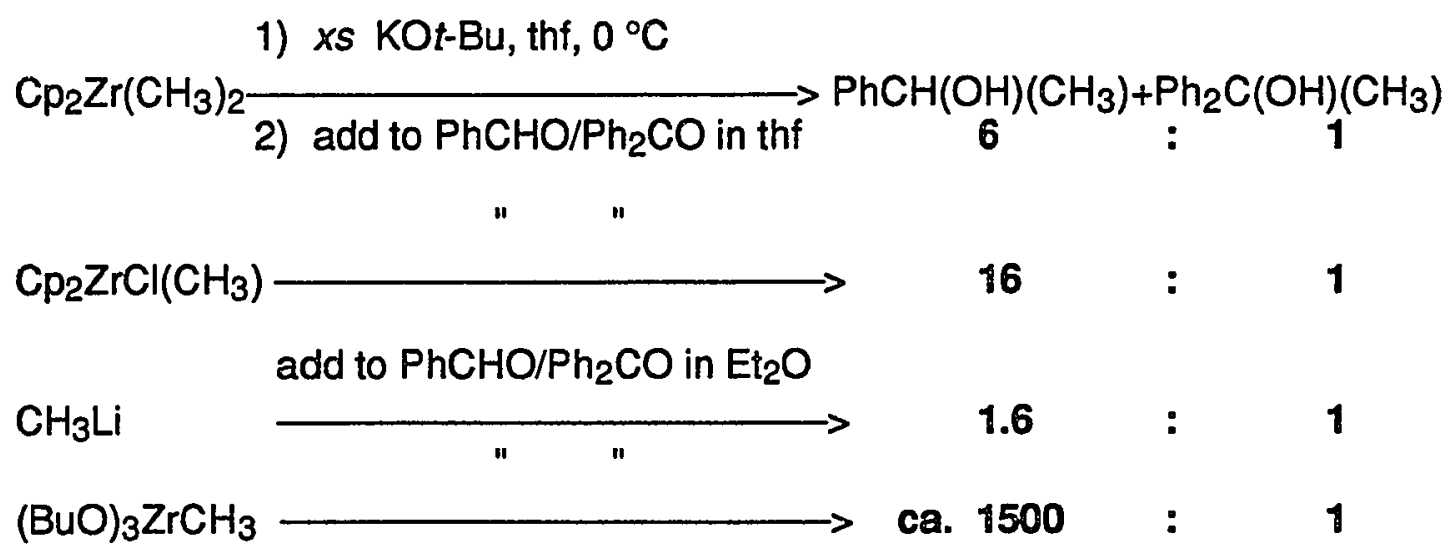




\section{INTRODUCTION}

While investigating zirconium-oxo leaving groups our group recently discovered that although bis $\left(\eta^{5}\right.$-cyclopentadienyl) zirconium alkyl complexes cannot alone alkylate aldehydes or ketones, they can be used to alkylate aldehydes and non-enolizable ketones when treated with alkoxide base (eq 1). ${ }^{1}$ The addition of base causes the displacement of halide and/or both cyclopentadienyl (Cp) groups from the metal to form, we believe, either a neutral or anionic "ate" complex, [Zr] (Figure 1).

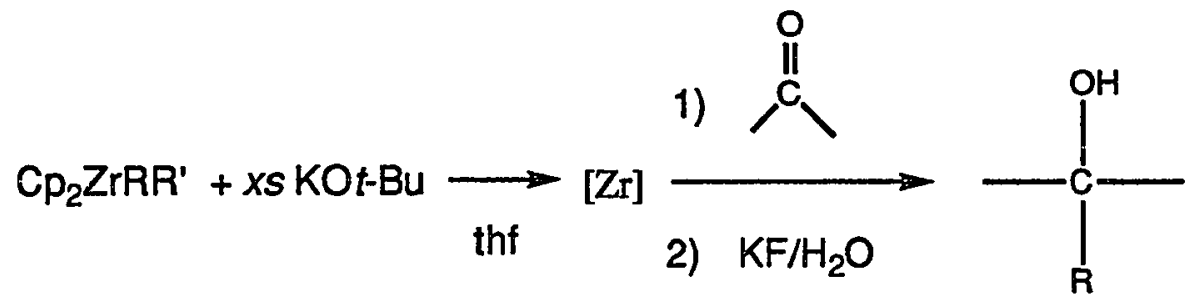

$R, \mathrm{R}^{\prime}=\mathrm{CH}_{3}, \mathrm{CH}_{2} \mathrm{Ph}, \mathrm{Ph}^{2}$ or $\mathrm{R}=\mathrm{Cl}, \mathrm{R}^{\prime}=\mathrm{CH}_{3}, n$-penty $\left.\right|^{3}$

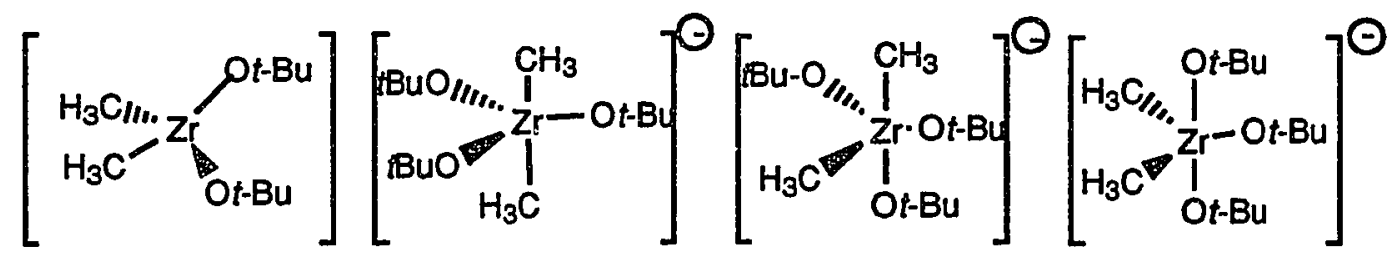

Figure 1. Some Possible Structures for an Alkoxyalkylzirconium Neutral or Anionic "Ate" Complex From the Addition of Potassium tert-Butoxide to Dimethylzirconocene (1). 
In the first step (eq 1), the addition of potassium tert-butoxide, cyclopentadienide anions are displaced from the zirconocene complex (in the case of 1 , potassium cyclopentadienide has been isolated in $76 \%$ yield). ${ }^{4}$ In acetonitrile both the $\mathrm{Cp}$ rings and the alkyl groups are displaced. 5 Toluene-d $\left(\mathrm{C}_{6} \mathrm{H}_{5} \mathrm{CH}_{2} \mathrm{D}\right)$ is detected as a product from substrate 3 in acetonitrile- $d_{3}$ by ${ }^{1} \mathrm{H}$-NMR (Figure 2), and $\mathrm{CH}_{3} \mathrm{D}$ as product from 1 in acetonitrile- $d_{3}$ (Chapter 2, ref. 2).

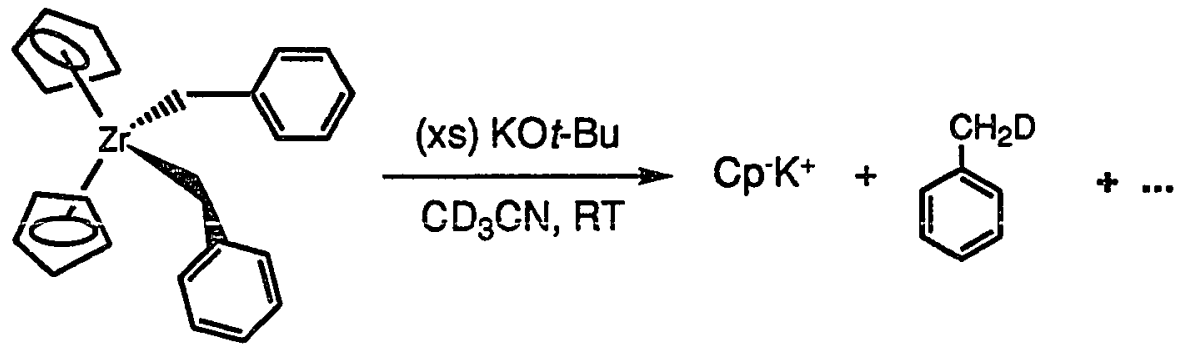

Figure 2. The Addition of Potassium tert-Butoxide to Dibenzylzirconocene (3).

Titanium alkoxyalkyls of the type (i-PrO) ${ }_{3} \mathrm{TiCH}_{3}$, which are considered more basic than their zirconium analogs, can be used in acetonitrile solution. If we attribute protonolysis to the basicity of our intermediate, it is sufficiently basic to deprotonate an enolizable ketone or acetonitrile. Another possibility is that the alkoxide deprotonates the substrate/solvent (eq. 2) and the equilibrium amount of alcohol formed then protonates the alkylzirconium. These two processes might be distinguished by measurement of the rate of gas evolution from the zirconium methyl species, $(n-B u O)_{3} \mathrm{ZrCH}_{3}$ 


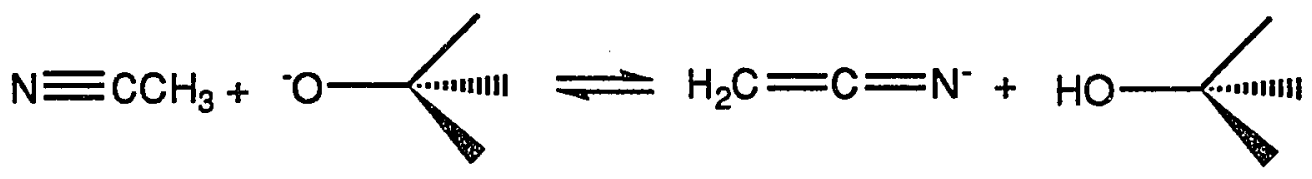

Preliminary studies have been performed. A reaction was run (eq. 3) with potassium tert-butoxide $(7.26 \mathrm{mmol})$ and dimethylzirconocene $(1.59 \mathrm{mmol}$, 4.87:1) in acetonitrile, and the volume of gas (methane) evolved was measured. With the reaction mixture at $-40^{\circ} \mathrm{C}$ gas evolution ceased at 49 minutes and

$$
\mathrm{Cp}_{2} \mathrm{Zr}\left(\mathrm{CH}_{3}\right)_{2}+\mathrm{K}+-\mathrm{Ot}-\mathrm{Bu} \underset{\mathrm{H}_{3} \mathrm{CCN}}{\longrightarrow}[\mathrm{Zr}]+\mathrm{K}^{+}-\mathrm{Cp}+\mathrm{CH}_{4}
$$

$40.0 \mathrm{~mL}(\sim 1.65 \mathrm{mmol})$ volume. Raising the temperature to $0^{\circ} \mathrm{C}$ produced additional rapid gas evolution to completion at 55 minutes and $95.0 \mathrm{~mL}$ ( $3.93 \mathrm{mmol}$ ) gas evolved. 6

The question of the importance of eq. 2 was addressed with the reaction (eq. 4) of tert-butyl alcohol $(6.78 \mathrm{mmol}, 4.49: 1)$ and dimethylzirconocene $(1.51 \mathrm{mmol})$ in acetonitrile at $-40^{\circ} \mathrm{C}$. After 5 minutes, $5.0 \mathrm{~mL}(\sim 0.21 \mathrm{mmol})$ of gas had evolved and no more was observed through 48 minutes. Raising the reaction temperature to $0^{\circ} \mathrm{C}$ produced slow gas evolution until 65 minutes when $53.0 \mathrm{~mL}(\sim 2.19 \mathrm{mmol})$ had evolved.

$$
\mathrm{Cp}_{2} \mathrm{Zr}\left(\mathrm{CH}_{3}\right)_{2}+\mathrm{HOt}-\mathrm{Bu} \underset{\mathrm{H}_{3} \mathrm{CCN}}{\longrightarrow}[\mathrm{Zr}]+\mathrm{CH}_{4}
$$

At 67 minutes the reaction temperature was raised to room temperature $\left(22^{\circ} \mathrm{C}\right)$ to give faster gas evolution until $90 \mathrm{~mL}(\sim 3.72 \mathrm{mmol})$ had evolved at 
75 minutes. ${ }^{7}$ An appropriate experiment to follow these would be to determine whether the methyl group of the complex, $(n-\mathrm{BuO})_{3} \mathrm{ZrCH}_{3}$ is protonated faster than dimethylzirconocene in acetonitrile using identical experimental conditions.

We have noted that in addition to basicity, the nucleophilicity of zirconocene alkyls is enhanced by the addition of alkoxide (Figure 3).

$$
\begin{aligned}
& \mathrm{Cp}_{2} \mathrm{Zr}\left(\mathrm{CH}_{3}\right)_{2}+2 \longrightarrow \stackrel{\mathrm{H}_{2} \mathrm{O}}{\longrightarrow} \text { N. R. }
\end{aligned}
$$

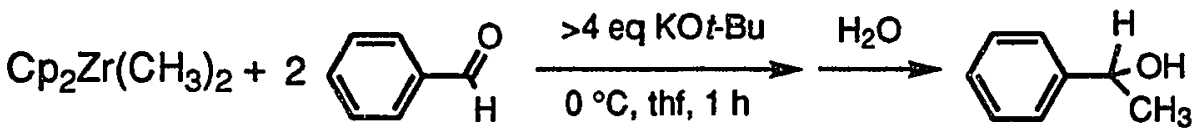

Figure 3. Enhanced Nucleophilicity of Zr-Alkyls in the Presence of Potassium tert-Butoxide.

Zirconocenemethylchloride, dibenzylzirconocene, diphenylzirconocene, and $n$-pentylzirconocenechloride (the last generated in situ from zirconocenehydridochloride and 1-pentene) behave similarly. However, carbonyl substrates with $\alpha$-hydrogens are not compatible with this reaction, as enolization and the evolution of the zirconium-bound alkyl groups as alkanes is preferred over nucleophilic addition. It should be noted here that $(n-\mathrm{BuO})_{3} \mathrm{ZrCH}_{3}$ does alkylate enolizable carbonyls.

A series of carbonyl compounds (Figure 4) has been alkylated using the zirconocene reaction. 8 This reaction is compatible with heterocycles and the alkylation takes place at the carbonyl carbon in compounds with conjugated double bonds. 
<smiles>O=Cc1ccccc1</smiles>

$(78 \%)[52 \%]^{\#}$<smiles>O=C/C=C/c1ccccc1</smiles>

$(99 \%)$<smiles>O=Cc1ccc2ccccc2c1</smiles>

$(83 \%)[69 \%]$<smiles>O=C(c1ccccc1)c1ccccc1</smiles>

$(100 \%)[89 \%]$<smiles>O=Cc1ccco1</smiles>

$(70 \%)$<smiles>CC(=O)c1ccccc1</smiles>

$(0 \%)$ *

\# Figures in brackets represent isolated yields.

* In the last case methane evolved rapidly during the reaction and only unreacted ketone was recovered upon work up.

Figure 4. Examples of Carbonyl Compounds Methylated by the Zirconocene Reaction.

The alkylation reactions were performed under inert atmosphere in thf at $0^{\circ} \mathrm{C}$ for one hour. Four to five equivalents of base were used in all cases, and the reaction was followed by hydrolysis with aqueous $\mathrm{KF}$ and standard benchtop work up. The yields were quantitated by using $G C$ analysis with internal standards, as described above. n-Pentyl, an alkyl group posessing $\beta$-hydrogens, has been transferred to naphthaldehyde. Benzyl groups are transferred to benzaldehyde, but the major product is stilbene, which may be the result of base-promoted elimination from an intermediate zirconium alkoxide. Phenyl groups have been transferred to benzaldehyde in $60 \%$ yield from 
diphenylzirconocene under similar conditions. ${ }^{2}$ We have not, however, been able to transfer vinyl groups successfully.

We have found in related work that bis(tritox)dimethylzirconium prepared by the Wolzanski method ${ }^{9}$ will methylate aldehydes and ketones, the latter even with $\alpha$-hydrogens (eq 5). In the case of 4-tert-butylcyclohexanone, stereoselectivity is surprisingly similar to that reported with the use of the far less bulky $(n-\mathrm{BuO})_{3} \mathrm{ZrCH}_{3}$ prepared in situ. ${ }^{10}$

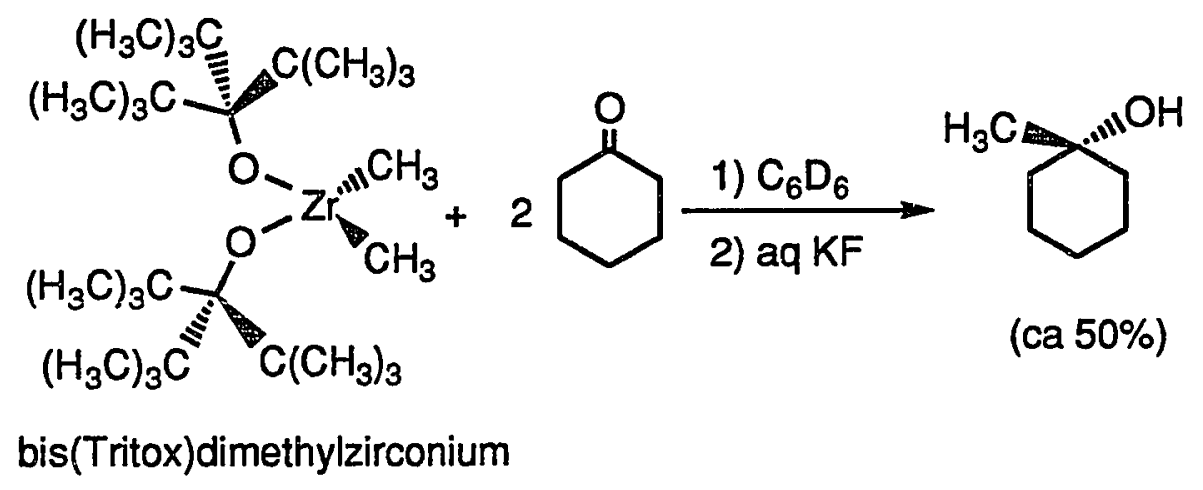

Trialkoxyzirconiumalkyls (presumably neutral species produced in situ from $\mathrm{RLi}$ and $\left.\left(\mathrm{R}^{\prime} \mathrm{O}\right)_{3} \mathrm{ZrCl}\right)$ have been shown to be nucleophiles in the alkylation of carbonyl functional groups in aldehydes and ketones. ${ }^{11}$ As a mechanistic probe, aldehyde/ketone and aldehyde/aldehyde competition reactions were undertaken (Figure 5) to compare the selectivity of these trialkoxyzirconiumalkyl systems with our zirconium-base procedure. Similar selectivities would support a neutral intermediate species with the zirconium-base, but significantly different selectivities might argue for an anionic "ate" species. The zirconocene method first used in this procedure is shown as equation (a) (Figure 5). The zirconocene method that gives slightly better yields and moderately better 
selectivity, and has also been compared in some cases, is shown as equation (b). In the latter reaction an intermediate, [ $\mathrm{Zr}]_{\mathrm{a}}$, is presumably formed with the addition of butoxide base to the zirconocene, and that mixture is then added to the substrate.

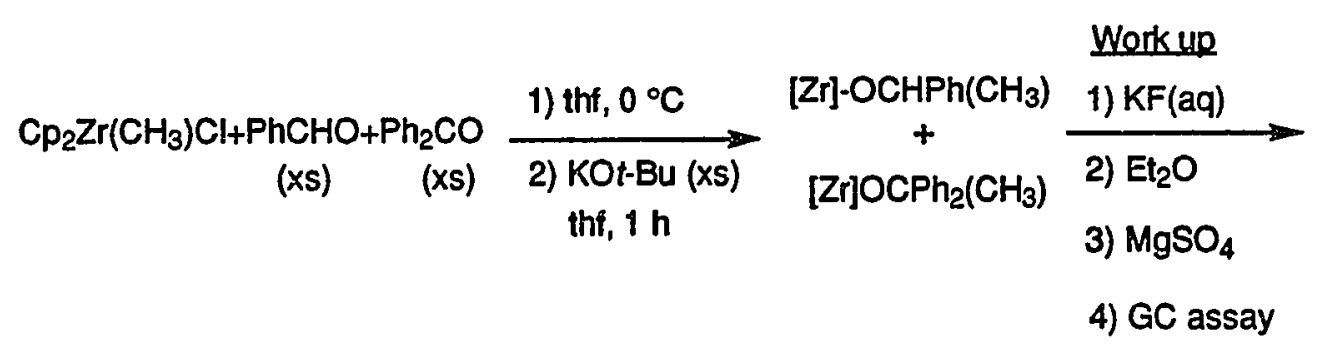

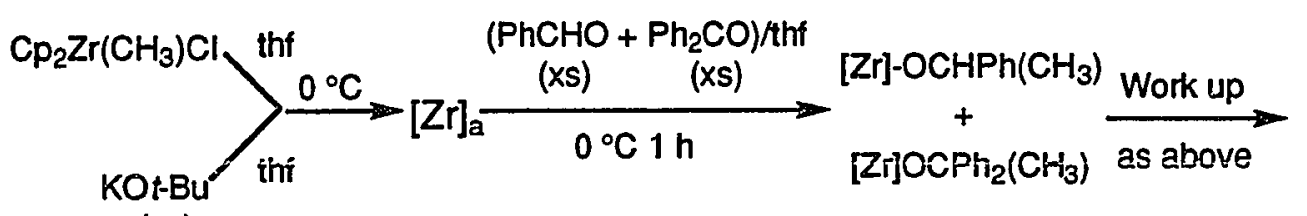

(xs)

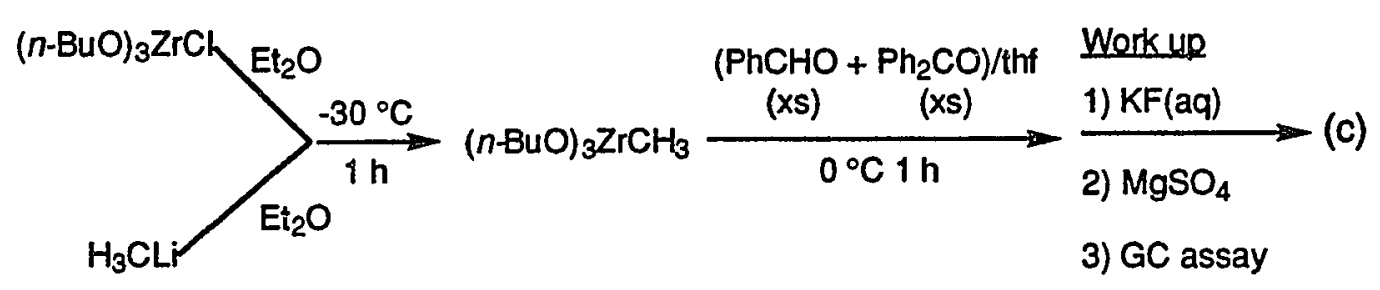

Figure 5. Competition Experiments to Compare Selectivities of Two Reactions.

Equation (c) shows the procedure for the well-characterized reaction involving trialkoxyzirconiummethyl prepared in situ. A typical procedure for the alkoxyalkylzirconium system, equation (c) (Figure 5) gives the products in the organic phase, which is dried over magnesium sulfate, filtered, and assayed by gas chromatography. As thf is miscible in water, the products of the zirconium- 
base system are extracted into diethyl ether after quenching with aqueous potassium fluoride. The organic phase, which contains the product mixture, is then dried over magnesium sulfate, gravity filtered, and assayed by gas chromatography.

\section{RESULTS AND DISCUSSION}

Our first consideration in comparing the reactions (eq a) and (eq c) of Figure 5 was to attempt to eliminate the obvious differences for a more direct comparison of the two systems. ${ }^{12}$ We to used zirconocenemethylchloride, rather than dimethylzirconocene, in order to compare monoalkyl zirconium intermediates; the chloride as counterion also matches. These changes presented no problem in our studies described below. We proposed lithium $n$-butoxide as our base to match cations and alkoxides in our study, but were unable to dissolve lithium $n$-butoxide in the necessary aprotic solvents even with the use of 18 -crown- 6 or 12 -crown- 4 ethers. This problem may not have a solution for this reaction (eqs (a), (b)). ${ }^{13}$ Furthermore, the recent development of lithium specific ionophores ${ }^{14}$ may be of little use because of their amine functionality, which could interfere with the reaction. The solvent used (in eqs (a), (b)) remained thf in this study because potassium tert-butoxide is sparingly soluble in thf, but is absolutely insoluble in diethyl ether. Methyllithium (eq (c)), however, is typically purchased as a solution in diethyl ether. ${ }^{15}$

Table 2 shows the results of the competition experiments. In entries 1 through 4 the active species is competing for benzaldehyde and benzophenone, the latter of which is much more sterically hindered. Here the selectivity in 
eq (c), the "Seebach reaction," is almost two orders of magnitude greater than for eq (a). ${ }^{16}$ Entry 2 shows the effect of added alkoxide base to the reaction mixture. The selectivity is reduced, but not significantly, and is still far in excess of an order of magnitude greater than entries 3 and 4, reaction (eq (a)), and the yield is also lower. These results differ significantly, and argue for an anionic "ate" complex as intermediate in eq (a). Additional characteristics of the eq (a) are that selectivity is best when base is added to the zirconocene solution first ${ }^{17}$ and when there is an excess of substrate. When $\mathrm{Cp}_{2} \mathrm{Zr}\left(\mathrm{CH}_{3}\right)_{2}$ was used as the zirconium moiety in eq (a), lower selectivity was obtained than with $\mathrm{Cp}_{2} \mathrm{Zr}\left(\mathrm{CH}_{3}\right) \mathrm{Cl}$, but selectivity was maximized with the same parameters. We could not find a correlation between the number of equivalents of base used and selectivity. Yield ${ }^{16}$ in the methylation of benzaldehyde or benzophenone (eq (b)), however, is maximized in the following manner: solvent volume is kept to a minimum; the ratio of zirconocene to substrate is $1.5: 1(1.25: 1$ for dimethylzirconocene); the base is added to zirconocene solution first; and five equivalents of base are used (four for dimethylzirconocene). The yield is also better if the reaction is run at $0^{\circ} \mathrm{C}$ than at room temperature. ${ }^{18}$

The scarcity of possible non-enolizable ketone substrates led to the choice of various aldehydes as competing substrates. Entries 5 through 10 show the attempt to further clarify the role of steric hindrance in the selectivity of these two reaction paths. Substrates in 5 through 8 are benzaldehyde and the slightly more sterically hindered 0 -tolualdehyde. Entries 7 and 8 represent an attempt to increase selectivity of one or both of the systems by lowering the temperature. The selectivity was not significantly changed in either case. The 
Grignard reagent, methylmagnesiumbromide, gave a selectivity of $1.06: 1$ with the same substrate in diethyl ether at $0^{\circ} \mathrm{C} .19$

Entries 9 and 10 represent an investigation into the effect of further steric hindrance in the form of mesitaldehyde versus benzaldehyde. Here, again, the addition of alkoxide base in reaction (eq c) reduces both the selectivity and the yield. As benzyl alcohol is found in the product mixture, a Cannizaro reaction

Table 2. Competition Experiments (The Methylation of Benzaldehyde vs Other Substrates)

\begin{tabular}{|c|c|c|c|c|}
\hline $\begin{array}{l}\text { Competing } \\
\text { Substrate }\end{array}$ & $\frac{\text { Reaction }}{\text { (Figure 5) }}$ & $\frac{\text { Temperature }}{\left({ }^{\circ} \mathrm{C}\right)}$ & $\frac{\text { Reagent\$ }}{\text { Excess }}$ & $\frac{\frac{\text { Product\# }}{\text { Ratio }}}{\text { Yielód }}$ \\
\hline 1 Benzophenone & (c) & 0 & $2.5: 1$ & $\begin{array}{r}>1500: 1 \\
(94 \%)\end{array}$ \\
\hline 2 & (c) & -30 & $\begin{array}{c}2.34: 1 \\
(1.22 e q \mathrm{KO} t-\mathrm{Bu})\end{array}$ & $\begin{array}{c}675: 1 \\
(63.2 \%)\end{array}$ \\
\hline 3 & (a) & 0 & $\begin{array}{c}10: 1 \\
\text { (4eq KOi-Bu) }\end{array}$ & $\begin{array}{c}19: 1 \\
(72.3 \%)\end{array}$ \\
\hline 4 & (a) & 0 & $\begin{array}{c}1: 1 \\
\text { (4.5eq KOt-Bu) }\end{array}$ & $\begin{array}{c}15.5: 1 \\
(73.1 \%)\end{array}$ \\
\hline 50 -Tolualdehyde & (c) & 0 & $1: 1$ & $1.53: 1$ \\
\hline 6 & $\begin{array}{l}\text { (a) } \\
\text { ((b)) }\end{array}$ & $\begin{array}{l}0 \\
(0)\end{array}$ & $\begin{array}{c}1: 1 \\
(4 \mathrm{eq} \mathrm{KOt-Bu}) \\
(5.9 \mathrm{eq} \mathrm{KO}-\mathrm{Bu})\end{array}$ & $\begin{array}{l}1.03: 1 \\
(35 \%) \\
\left(1: 1.18^{*}\right)\end{array}$ \\
\hline 7 & (c) & -50 & 10:1 & $\begin{array}{l}1.27: 1 \\
(58.2 \%)\end{array}$ \\
\hline 8 & (a) & -50 & $\begin{array}{c}10: 1 \\
\text { (5eq KOt-Bu) }\end{array}$ & $\begin{array}{l}1: 1.27 \\
(70.85 \%)\end{array}$ \\
\hline
\end{tabular}




\begin{tabular}{|c|c|c|c|c|}
\hline$\frac{\text { Competing }}{\text { Substrate }}$ & $\begin{array}{l}\text { Reaction } \\
\text { (Figure 5) }\end{array}$ & $\frac{\text { Iemperature }}{\left({ }^{\circ} \mathrm{C}\right)}$ & $\begin{array}{l}\text { Reagent\$ } \\
\text { Excess }\end{array}$ & $\begin{array}{l}\text { Product\# } \\
\frac{\text { Ratio }}{\text { (Yield) }}\end{array}$ \\
\hline 9 Mesitaldehyde & (c) & 0 & 2.3:1 & $\begin{array}{c}3.51: 1 \\
(>100 \%)\end{array}$ \\
\hline 10 & (c) & 0 & $\begin{array}{c}2.3: 1 \\
\text { (1.4eq KOt-Bu) }\end{array}$ & $\begin{array}{l}1.99: 1 \\
(69.9 \%)\end{array}$ \\
\hline \multicolumn{2}{|c|}{$11 p$-Nitrobenzaldehyde (c) } & -50 & 5:1 & $\begin{array}{l}1: 1.01 \\
(56 \%)\end{array}$ \\
\hline 12 & (a) & -50 & $\begin{array}{c}10: 1 \\
\text { (4.5eq KOt-Bu) }\end{array}$ & $\begin{array}{l}1: 1.2 \\
(25.6 \%)\end{array}$ \\
\hline $13 p$-Tolualdehyde & (c) & -30 & $1: 1$ & $1: 1.01$ \\
\hline 14 p-Anisaldehyde & (c) & -30 & $1: 1$ & $1.06: 1$ \\
\hline
\end{tabular}

Notes: \# Product ratio is defined as [alcohol product from benzaldehyde]: [alcohol product from competing substrate]

$¥$ Yields are calculated by an internal standard method using p-xylene, biphenyl, or 4,4'-dimethylbiphenyl as necessary to avoid coelution with reaction products.

$\S$ Reagent excess is the ratio of each carbonyl substrate to equivalents of zirconium complex.

* The base (5.9 eq) was added to zirconocene solution and, then, that mixture to the substrate solution ( $5.1 \mathrm{eq}$, each aldehyde) to give this product ratio in $33 \%$ yield. 20

is postulated as the mechanism leading to this byproduct. Indeed, benzyl alcohol is a product of the reaction of potassium tert-butoxide with benzaldehyde in thf. ${ }^{18}$ The reaction (eq (a)) with only mesitaldehyde as substrate produced none of the expected alcohol product when quenched at one hour; however, it was discovered that reaction mixture aliquots taken and quenched at $1,5,15$, 40 , and 60 minutes showed the maximum $11.3 \%$ yield at one minute 
disappearing with time. ${ }^{18}$ A Meerwein-Ponndorf-Verley reduction, (eq. 4) for example, was postulated as a possible mechanism for this disappearance.

$$
\mathrm{PhCHO}+\mathrm{R}^{\prime} \mathrm{CHOHR}=\mathrm{PhCH}_{2} \mathrm{OH}+\mathrm{R}^{\prime} \mathrm{COR} "
$$

Entries $11,12,13$, and 14 were attempts to compare the reactions (eqs (a) and (c)) under the influence of different substituents at the para position effecting different electronic character to the competing aldehydes. Entries 13 and 14 (eq (c)) produced no selectivity; and, as zirconium-base conditions (eqs (a) or (b)) in general appear to be less or, at best, equally selective, these experiments were not repeated under conditions of the latter reaction. Entries 11 and 12 investigate the electronic effect of the p-nitro group on the reactivity of benzaluehyde..$^{21}$ Reactions were carried out at $-50{ }^{\circ} \mathrm{C}$ in order to increase selectivity. The reaction (eq (a)) shows a slight selectivity favoring p-nitrobenzaldehyde over benzaldehyde, but the electronic effect is not large for this reaction. At $-50^{\circ} \mathrm{C}$ the reaction is quite slow and there must to be other reactants competing for the substrate, especially judging from the disappearance of $p$-nitrobenzaldehyde and many product peaks in the GC chromatograph. The highly colored reaction mixture may be caused by p-nitrophenylfulvene, as we know that fulvenes are formed in these reactions. 22 Reaction (eq (c)) shows no selectivity due to electronic effects (1:1.01), however, the reaction is faster, leading to greater yield, and the disappearance of $p$-nitrobenzaldehyde is about $33 \%$ of that in the other reaction. 


\section{SUMMARY}

The results for the experiments, above, although far from conclusive, suggest (on the basis of the benzaldehyde/benzophenone competition experiments) the possibility of a zirconium anionic "ate" complex as an active intermediate in the zirconium-base reactions (eqs (a), (b)). Although there was no significant change in selectivity in entry 2 (Table 1 ), when the diethyl ether suspension of potassium tert-butoxide was first added to the Seebach reagent, this may be due to solubility problems associated with the base. However, another argument suggestive of the anionic zirconate intermediate in the zirconium-base system is that it does not alkylate enolizable substrates while the trialkoxyzirconiumalkyl system does. Further experiments are needed.

Although we have not discovered conditions for the zirconocene reaction (eqs (a), (b)) that are compatible with enolizable substrates, in some cases the enolization might be useful. For example, we attempted the zirconocene reaction (eq (a)) with methyl benzoate as substrate (in the presence of potassium tert-butoxide. Methyl benzoate was converted to acetophenone in $56 \%$ yield using dimethylzirconocene. 23 It should be noted that Grignard reagents, in the presence of trialkylamines, prefer enolization over their normal alkylation pathway thus converting esters to alkyl ketones. ${ }^{24}$ This application is worthy of further study. 


\section{EXPERIMENTAL SECTION}

\section{General Considerations}

All operations were performed under dry conditions and inert atmosphere using glove-box and vacuum line techniques. Zirconocene dichloride was purchased from Boulder Scientific. Dimethylzirconocene, ${ }^{17}$ zirconocenemethylchloride, 18 and dibenzylzirconocene, 17 were prepared by known methods. Potassium tert-butoxide was sublimed and titrated for purity with $\mathrm{HCl}$ to a phenolphthalein end-point after quenching with water. Methyllithium was received as a solution in diethyl ether, transferred to a round bottom flask with Teflon screw valve, and titrated for purity as $\mathrm{KO} t-\mathrm{Bu}$, above. Tri-n-butoxyzirconiumchloride was prepared by a known methodi1 and diluted to volume to give a 0.4 molar solution in diethyl ether which was stored under nitrogen. Benzaldehyde, $p$-tolualdehyde, $p$-anisaldehyde, and $p$-xylene were vacuum distilled and stored over $3 \AA$ sieves under nitrogen. Methyl benzoate and mesitaldehyde were assayed pure by gas chromatography (conditions below) as received and stored in screw-top bottles under nitrogen. 0 -Tolualdehyde was washed with sodium bicarbonate and stored over $3 \AA$ sieves in a screw-top bottle under nitrogen. Potassium fluoride, anhydrous magnesium sulfate, and

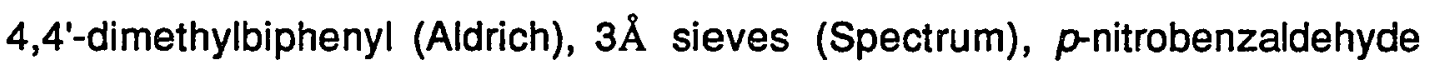
(Eastman Kodak), and $\alpha$-methylbenzyl alcohol (Eastman Organic Chemicals) were used as received. Biphenyl was recrystallized from toluene. Diethyl ether and thf were distilled under nitrogen from sodium benzophenone ketyl and transferred to storage flasks sealed with Teflon screw valves. Benzaldehyde was vacuum distilled and stored over $3 \AA$ sieves under nitrogen. 18-Crown-6 
was purified by recrystallization from acetonitrile that had been dried over freshly activated $3 \AA$ sieves and dried in vacuo 24 hours. Authentic 1-methyl alcohols of the following aldehydes were prepared from those aldehydes using methyllithium in diethyl ether followed by vacuum distillation and transfer to screw-top bottles to be stored under nitrogen: $p$-anisaldehyde, o-tolualdehyde, and $p$-tolualdehyde.25 Authentic methylated alcohol products of p-nitrobenzaldehyde 25 and mesitaldehyde ${ }^{18}$ were prepared by sodium borohydride reduction of p-nitroacetophenone and $\left(2^{\prime}, 4^{\prime}, 6^{\prime}\right.$-trimethyl)acetophenone, respectively, in diethyl ether followed by purification by vacuum distillation for the former and recrystallization from hexane for the latter. Acetonitrile used in gas evolution experiments was stored over $3 \AA$ sieves for one week and degassed by "freeze-pump-thaw" repeated three times. Air, argon, hydrogen, nitrogen, oxygen, and liquid nitrogen were used as received from Air Products. Gas chromatography was performed using a HewlettPackard HP 5880A Gas Chromatograph with "terminal" (FID detection), HP 5890A Gas Chromatograph with HP 3396A "Integrator" (TCD detection), or HP 5880A Gas Chromatograph with Spectra-Physics integrator and Labnet 8 "software" (FID detection). This last system was used to quantitate the Seebach reagent selectivity for benzaldehyde over benzophenone. Unless otherwise noted, the chromatographic conditions were as follows: DB5 column, $0.25 \mu \mathrm{m}$ film thickness, $30 \mathrm{~m} \times 54 \mu \mathrm{m}$; injector, $250^{\circ} \mathrm{C}$; detector, $300^{\circ} \mathrm{C}$; initial temperature/time, $40^{\circ} \mathrm{C} / 1$ minute; programmed rate, $30^{\circ} \mathrm{C} /$ minute; final temperature/time, $220^{\circ} \mathrm{C} / 3$ minutes. 


\section{Specific Procedures}

In an effort to simplify this section, I shall describe in detail the gas evolution experiments, one yield maximization experiment, preparation and characterization of an authentic alcohol product, preparation and assay of a GC standard solution, and one competition experiment of each type, Figure 5 (eq (a), eq (b), and eq (c)). Stoichiometric ratios for all of the experiments discussed appear in Table 1, and notebook references appear in the appendix.

\section{Gas Evolution Experiment to Test the Kinetics of the of the} Reaction of Zirconocenemethylchloride and Potassium tert-Butoxide in Acetonitrile. Into a $250 \mathrm{~mL}$ round bottom flask were added dimethylzirconocene, $400 \mathrm{mg}(1.59 \mathrm{mmol})$, and acetonitrile, $50 \mathrm{~mL}$. The flask was attached via syringe needle to a hose that was inserted under an inverted graduated cylinder filled with water at room temperature. The round bottom flask was cooled to $-40^{\circ} \mathrm{C}$ in an acetone/dry ice bath, and the flask was injected with potassium tert-butoxide in thf solution, $3.0 \mathrm{~mL}(2.42 \mathrm{M}, 7.26 \mathrm{mmol})$. The solution turned a cloudy-tan color, and gas (methane) evolved into the inverted graduated cylinder. The elapsed time and total volume were noted periodically. At about 4 minutes the bath was over-cooled to $-45^{\circ} \mathrm{C}$ for 30 seconds. By 49 minutes gas evolution had ceased, and the total evolved volume was $40 \mathrm{~mL}$ ( $1.79 \mathrm{mmol} @$ room temperature). The acetone/ dry ice bath was then replaced with a water/ ice bath at $0^{\circ} \mathrm{C}$ to give immediate and rapid gas evolution. At 65 minutes the gas evolution had stopped, and the total evolved gas measured $95 \mathrm{~mL}$ ( $4.24 \mathrm{mmol})$. Calculations were made to correct for the difference in vapor pressure of acetonitrile at $0^{\circ} \mathrm{C}(25 \mathrm{~mm}, \mathrm{Hg})$, and at $-40^{\circ} \mathrm{C}$ 
(1 $\mathrm{mm}, \mathrm{Hg}$ ). An attempt was made, using the Ideal Gas Law, to correct for the head space gases in the flask ( $246 \mathrm{~mL}$ ) and the change in temperature from $-40^{\circ} \mathrm{C}$ to $0^{\circ} \mathrm{C}$, calculated at $\sim 29 \mathrm{~mL}$. These corrections gave best and worst case yields of $110 \%$ and $74.1 \%$, respectively.

Gas Evolution Experiment to Test the Kinetics of the Reaction of tert-Butyl Alcohol and Dimethylzirconocene in Acetonitrile. Into a $250 \mathrm{~mL}$ round bottom flask were added dimethylzirconocene, $378 \mathrm{mg}(151 \mathrm{mmol}$ ) and a measured, but unnoted volume of acetonitrile. The flask was attached via syringe needle to a rubber hose inserted under an inverted graduated cylinder filled with water at room temperature. The flask and solution were cooled to $-40{ }^{\circ} \mathrm{C}$ with stirring in an acetone/dry ice bath. The flask was then injected with tert-butyl alcohol, $640 \mu \mathrm{L}(6.78 \mathrm{mmol})$ and enough thi to make a total of $4 \mathrm{~mL}$. Immediately after injection, the gas in the graduated cylinder measured $13 \mathrm{~mL}$. The solution remained clear. Elapsed time and total gas volume evolved were noted periodically. Gas evolution ceased at 12 minutes and $5 \mathrm{~mL}$ gas ( $0.223 \mathrm{mmol}$ ) evolved. At 48 minutes the acetone/dry ice bath was exchanged for a water/ice bath at $0{ }^{\circ} \mathrm{C}$. Gas evolved at a moderate rate, and at 67 minutes (53 $\mathrm{mL}, \sim 2.37 \mathrm{mmol}$ ) the bath was removed and the reaction allowed to warm to room temperature until 75 minutes and a volume of $90 \mathrm{~mL}(\sim 4.02 \mathrm{mmol})$ evolved. Similar calculations were made to correct for the temperature difference between $-40^{\circ} \mathrm{C}$ and room temperature, $22^{\circ} \mathrm{C}$. The best and worst case yields were $109 \%$ and $50.7 \%$, respectively.

Preparation and Characterization of Authentic 1-(a-Tolyl)ethanol (4). Into a Schlenk flask were added o-tolualdehyde, $4.4 \mathrm{~mL}(\mathrm{~d}=1.039,38.0 \mathrm{mmol}$ ), and $5 \mathrm{~mL}$ of diethyl ether and this was brought to $0^{\circ} \mathrm{C}$ with stirring. To this 
solution was slowly added a diethyl ether solution of methyllithium, $30 \mathrm{~mL}$ (1.4 M, $42 \mathrm{mmol})$, to give a yellow solution that darkened with time to a deep yellow. The solution was allowed to come to room temperature after about 15 minutes at which time water was added dropwise until gas evolution had ceased. A white precipitate formed which dissolved with the addition of the remainder of $25 \mathrm{~mL}$ of water to give a yellow organic phase solution over a clear, colorless aqueous phase. The organic phase was separated, dried over magnesium sulfate, filtered, and the diethyl ether removed on a rotary evaporator. The resulting solution was distilled at 10 torr $\left(115^{\circ} \mathrm{C}\right)$ to give 4 $(2.71 \mathrm{~g}, 19.9 \mathrm{mmol}, 52 \%, \mathrm{MW}=136)$ as a clear, colorless liquid: ${ }^{1} \mathrm{H}-\mathrm{NMR}$ (300 MHz, acetone- $\left.d_{6}\right) \delta 1.34\left(\mathrm{~d}, 3 \mathrm{H},-\mathrm{CH}_{3}, \mathrm{~J}=6 \mathrm{~Hz}\right.$ ), 2.28 (s, 3H, $\left.\mathrm{CH}_{3}\right), 4.12$ $(\mathrm{d}, 1 \mathrm{H}, \mathrm{C}(\mathrm{OH}) \mathrm{H}, \mathrm{J}=4 \mathrm{~Hz}), 5.04\left(\mathrm{~d} / \mathrm{d}, 1 \mathrm{H},-\mathrm{OH}, \mathrm{J}=6 \mathrm{~Hz}, \mathrm{~J}^{\prime}=4 \mathrm{~Hz}\right), 7.11(\mathrm{~m}, 3 \mathrm{H}$, $\operatorname{Ar}-H), 7.50(\mathrm{~d}, 1 \mathrm{H}, \mathrm{Ar}-\mathrm{H}, \mathrm{J}=7 \mathrm{~Hz}$ ).

Preparation and Quantitation of a Standard Solution for Gas Chromatography. To $10 \mathrm{~mL}$ diethyl ether were added $p$-xylene, $70 \mu \mathrm{L}$ (d = $0.866,0.57 \mathrm{mmol})$, benzaldehyde, $50 \mu \mathrm{L}(\mathrm{d}=1.044,0.49 \mathrm{mmol})$, o-tolualdehyde, $60 \mu \mathrm{L}$ ( $\mathrm{d}=1.039,0.52 \mathrm{mmol}), \alpha$-methylbenzyl alcohol, $50 \mu \mathrm{L}$ $(d=1.018,0.42 \mathrm{mmol})$, and 1-o-tolylethanol, $50.0 \mathrm{mg}(0.365 \mathrm{mmol})$ and this was subjected to analysis by gas chromatography (DB-WAX column, $1 \mathrm{~min}$ at $40^{\circ} \mathrm{C}$, $30^{\circ} \mathrm{C} / \mathrm{min}, \quad 3 \mathrm{~min}$ at $220^{\circ} \mathrm{C}$, detection by ECD). The results as multiplicative correction factors are calculated as follows: the analysis produces a peak area percent (AP) for each component; these are prorated, divided, by the p-xylene standard area percent $\left(A P_{x}\right)$; the known number of millimoles ( $\left.m m o l\right)$ is divided by that ratio (eq 5 ). 


$$
\text { Factor }=\frac{(m m o l)}{(A P) /\left(A P_{x}\right)}
$$

Competition Experiment Representing Equation (a), Figure 5, with Substrates of Benzaldehyde and o-Tolualdehyde. To a Schlenk tube were added potassium tert-butoxide, $267 \mathrm{mg}(2.38 \mathrm{mmol})$, and $10 \mathrm{~mL}$ thf and this was brought to $0{ }^{\circ} \mathrm{C}$ with stirring. To a second Schlenk tube were added 4,4'-dimethylbiphenyl, $100 \mathrm{mg}$ (0.549 mmol), zirconocene methyl chloride, $150 \mathrm{mg}$ (0.552 mmol), benzaldehyde, $281 \mu \mathrm{L}(\mathrm{d}=1.044,2.76 \mathrm{mmol})$, o-tolualdehyde, $319 \mu \mathrm{L}$ ( $d=1.039,2.76 \mathrm{mmol}$ ), and $10 \mathrm{~mL}$ thf, and this clear, nearly coloriess solution was stirred at $0^{\circ} \mathrm{C}$. The contents of the first were cannulated into the second, with stirring, at $0{ }^{\circ} \mathrm{C}$ to give a cloudy yellow suspension that was stirred at $0^{\circ} \mathrm{C}$ for one hour slowly turning orange. The reaction was quenched with saturated aqueous potassium fluoride that produced some slow gas evolution and after stirring ten minutes at $0{ }^{\circ} \mathrm{C}$, a deep orange organic phase with some white precipitate over a clear colorless aqueous phase. Two mililiters of diethyl ether were added, and the organic phase was separated, dried over magnesium sulfate, filtered, and assayed by gas chromatography in duplicate to show $\alpha$-methylbenzyl alcohol $(0.098 \mathrm{mmol})$ and 1-(o-tolyl)ethanol $(0.095 \mathrm{mmol})$ in the ratio of $1.03: 1$ and $35.0 \%$ total yield when compared to the limiting zirconocene reagent.

Competition Experiment Representing Equation (b), Figure 5, with Substrates of Benzaldehyde and o-Tolualdehyde. To a Schlenk tube were added potassium tert-butoxide, $254 \mathrm{mg}(2.27 \mathrm{mmol})$ and $5 \mathrm{~mL}$ thf, and these were stirred at $0^{\circ} \mathrm{C}$ to give a clear colorless solution. To a second Schlenk tube were added $5 \mathrm{~mL}$ thf, 4,4'-dimethylbiphenyl, $114 \mathrm{mg}(0.625 \mathrm{mmol})$, and 
zirconocenemethylchloride, $126 \mathrm{mg}(0.465 \mathrm{mmol})$, and these were stirred at $0^{\circ} \mathrm{C}$ to give a clear colorless solution. To a third Schlenk tube were added $5 \mathrm{~mL}$ thf, benzaldehyde, $240 \mu \mathrm{L}$ ( $\mathrm{d}=1.044,2.36 \mathrm{mmol}$ ), and o-tolualdehyde, $275 \mu \mathrm{L}$ $(d=1.039,2.38 \mathrm{mmol})$, and these were stirred to give a clear colorless solution. The base solution in the first tube was cannulated into the second with stirring at $0{ }^{\circ} \mathrm{C}$ to give, momentarily, a clear bright yellow solution that faded quickly to a clear almost colorless solution. After about five minutes, this solution was cannulated with stirring at $0^{\circ} \mathrm{C}$ into the third tube to give a bright yellow solution that turned opaque and then darkened to brown over about two minutes. This suspension was stirred at $0^{\circ} \mathrm{C}$ for one hour with no further visible changes. The reaction was then quenched with saturated aqueous potassium fluoride, and $5 \mathrm{~mL}$ diethyl ether was added to give a dark orange-brown organic solution with a creamy suspended precipitate over a clear yellowish aqueous phase. The organic phase was separated, dried over magnesium sulfate, filtered, and assayed in duplicate by GC to provide $\alpha$-methylbenzyl alcohol and 1 -(a-tolyl)ethanol in the ratio of $1: 1.18$ in $33.3 \%$ yield.

Competition Experiment Representing Equation (c), Figure 5, with Substrates of Benzaldehyde and o-Tolualdehyde. To a Schlenk tube were added with stirring at $0^{\circ} \mathrm{C}$ a diethyl ether solution of tri-n-butoxyzirconium chloride, $10 \mathrm{~mL}(0.4 \mathrm{M}, 4.0 \mathrm{mmol})$, and a diethyl ether solution of methyllithium, $2.9 \mathrm{~mL}(1.4 \mathrm{M}, 4.1 \mathrm{mmol})$, and these were stirred for one hour at $0^{\circ} \mathrm{C}$. Into a second Schlenk tube were added benzaldehyde, $0.41 \mathrm{~mL}(d=1.044,4.0 \mathrm{mmol})$, o-tolualdehyde, $0.46 \mathrm{~mL}(\mathrm{~d}=1.039,4.0 \mathrm{mmol})$, and $10 \mathrm{~mL}$ diethyl ether, and these were stirred at $0^{\circ} \mathrm{C}$. The contents of the first were cannulated into the second with stirring, and these were allowed to stir at $0^{\circ} \mathrm{C}$ for two hours. The 
reaction was quenched with saturated aqueous potassium fluoride, the organic layer separated, dried over magnesium sulfate, filtered, and assayed by gas chromatography to provide $\alpha$-methylbenzyl alcohol and 1-(0-tolyl)ethanol in the ratio of 1.53:1.

\section{References AND Notes}

[1] Larson, A. L.; Baker, D. L.; Towne, R. W.; Straus, D. A. Tetrahedron Leit. 1991, 32, pp 5893-5894.

[2] Kelli J. A. Kachel, unpublished results.

[3] Darrell Bishop, unpublished results.

[4] Hydrolysis and acid titration yields $M W=117$; actual = 104, Daniel A. Straus, unpublished notes. Crystalline KCp precipitates from thf solution, this has been noted in Chapter 2, and, in addition, $\mathrm{Cp}$ - has been detected by ${ }^{1} \mathrm{H}-\mathrm{NMR}$ and ${ }^{13} \mathrm{C}-\mathrm{NMR}$ in this reaction.

[5] In the case of dimethylzirconocene, 2 moles of methane are evolved and quantitated by gas buret. Addition of less base produces partial conversion. No intermediates have been observed at room temperature by ${ }^{1} \mathrm{H}-\mathrm{NMR}$, but the product, $\mathrm{CH}_{3} \mathrm{D}$, has been detected in the proton NMR spectrum as a 1:1:1 triplet at $\delta 0.17$, Daniel A. Straus, unpublished results. 
[6] The results must be corrected for the vapor pressure of acetonitrile at $-40^{\circ} \mathrm{C}$ and $0^{\circ} \mathrm{C}$ (ca. $6 \mathrm{~mL}$ ). The use of a large volume reaction vessel, $250 \mathrm{~mL}$ requires correction using the ldeal Gas Law, for the difference in bath temperatures and the temperature of the collection vessel (less than $29 \mathrm{~mL}$ ). In this last case, using $0 \mathrm{~mL}$ and $29 \mathrm{~mL}$ as end points, the calculated yield is between $74.1 \%$ and $110 \%$. This procedure should be repeated with a smaller reaction vessel to reduce the imprecision introduced by the need for the correction.

[7] Using the same argument as above, the correction for the temperature difference of the gas in the flask is $<45 \mathrm{~mL}$, and the yield is between $50.7 \%$ and $109 \%$. This experimental technique needs refining.

[8] Towne, R. W.; Mohtashemi, B.; Hammond, S. M.; Kachel, K. J. L.;

Straus, D. A. "Mechanism of Base-Promoted Zirconocene Alkyl Transfers to Carbonyl Compounds" Presented at the 207th Annual American Chemical Society National Meeting, San Diego, CA, March 9-16, 1994.

[9] Lubben, T. V.; Wolczanski, P. T.; Duyne, V. D. Organometallics 1984, 3, pp 977-983.

[10] Scott Hammond, unpublished results.

[11] Weidmann, B.; Maycock, C. D.; Seebach, D. Helv. Chim. Acta 1981, 64(5), pp 1552-1557.

[12] In the early stages of our work we chose to use the reaction illustrated as Figure 5, equation (a) over equation (b) because we were unsure of the stability of the alkoxyalkylzirconium intermediate.

[13] (a) Msayib, K. J.; Watt, C. I. F. Chem. Soc. Rev. 1992, 21(4), pp 237243. (b) Hancock, R. D. J. Chem. Educ. 1992, 69(8), pp 615-621.

[14] Tsukube, H.; Hori, K.; Inoue, T. Tetrahedron Lett. 1993, 34(42), pp 6749-6752. 
[15] Seebach et. al. found that their reagents (eq. (c)) were significantly more selective in thf than in diethyl ether (see reference 11). However, those reagents have proven to be orders of magnitude more selective in diethyl ether than zirconocene and base (eq. (a)) in thf. This suggests that the active intermediate in the latter reaction is different from that in the former, otherwise we would likely see greater selectivity in the latter case.

[16] Selectivities as high as $87.6: 1$, benzaldehyde over benzophenone, have been attained by adding the base to a zirconocene solution and then adding that mixture to the substrate solution (eq. (c)), Behzad Mohtashemi, unpublished results.

[17] I was able to fill in a few blanks, these appear in the experimental section, but most of this topic was supplied by Behzad Mohtashemi, unpublished results.

[18] Behzad Mohtashemi, unpublished results.

[19] This experiment was a repetition of a prior competition except that in that case the Grignard solution was at room temperature before addition, and the selectivity was 1.14:1, Daniel A. Straus, unpublished notes. Both experiments were performed with stoichiometric amounts of reagents, Grignard and each substrate. In this repeated experiment, both the Grignard and substrate solutions were brought to $0^{\circ} \mathrm{C}$ prior to combination.

[20] This reaction should be performed at lower temperature, as were eq. (a) and eq. (c), in an effori to improve yield and produce more reliable selectivity data.

[21] Ching, W-M.; Kallen, R. G. J. Am. Chem. Soc. 1978, 100(19), pp 6119-6124. Note: The authors calculate the rate constants for the reaction of hydrogen cyanide or cyanide with substituted benzaldehydes as follows: $4-\mathrm{CH}_{3} \mathrm{O}-=2.59 ; 4-\mathrm{CH}_{3}=1.88 ; 4-\mathrm{H}-=2.45 ; 4-\mathrm{Cl}-=4.89$; $3-\mathrm{Cl}, 4-\mathrm{Cl}-=4.39 ;$ and $4-\mathrm{NO}_{2}-=10.74 \times 10^{-4} \mathrm{~K}_{-1}, \mathrm{M}^{-2} \mathrm{~s}^{-1}$. 
[22] In the potassium tert-butoxide induced alkylation of benzaldehyde 6phenylfulvene is produced, with 2-furfuraldehyde, 6-(2-furfuryl)fulvene. These were deduced by CG and GCMS comparison in the former and GCMS comparison in the latter with an authentic sample prepared by the method of Little: Stone, K. J.; Little, R. D. J. Org. Chem. 1984, 49, 1849 (Reference [1]). The amount increases with reduced alkoxide base, Daniel A. Straus, unpublished notes.

[23] This result was confirmed by GC-MS, but the yield has not been optimized, Behzad Mohtashemi, unpublished results. My preliminary investigation produced $40 \%$ yield by GC using internal standard.

[24] Kikkawa, I.; Yorifuji, T. Synthesis 1980, p 877.

[25] Daniel A. Straus, unpublished results. 


\section{Appendix 1}

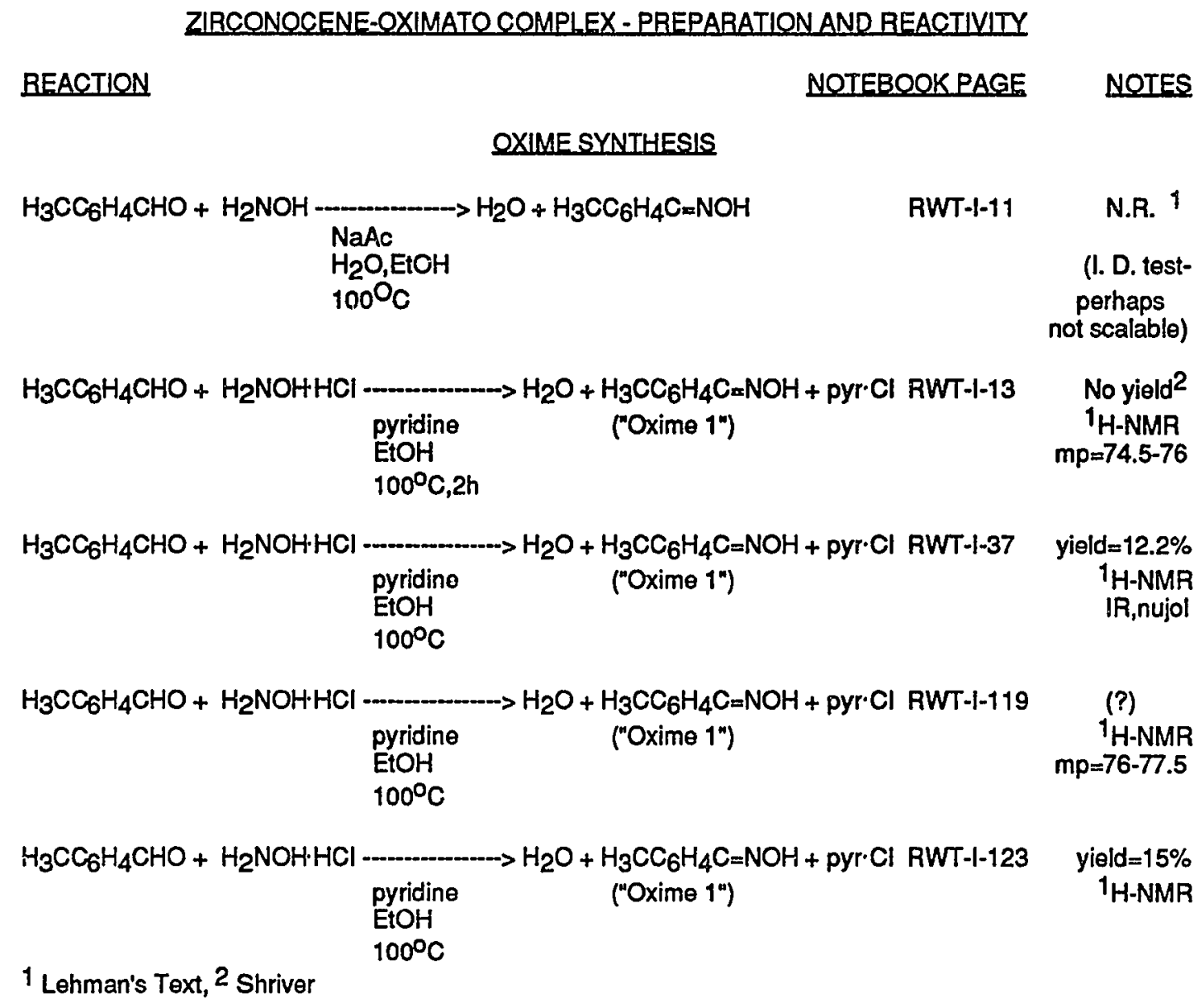

\section{OXIMATO SYNTHESIS}

\begin{tabular}{|c|c|c|c|c|}
\hline "Oxime 1" $+\mathrm{Cp}_{2} \mathrm{ZrHCl}$ & $\mathrm{C}_{6} \mathrm{D}_{6}$ & & RWT-I-17 & $\begin{array}{r}{ }^{1} \mathrm{H}-\mathrm{NMR} \\
\text { inconclusive }\end{array}$ \\
\hline "Oxime 1" + Cp2ZrN & $\mathrm{C}_{6} \mathrm{D}_{6}$ & $\begin{array}{l}\mathrm{Cp}_{2} \mathrm{Zr}(\mathrm{Me}) \mathrm{ON}=\mathrm{CHC}_{6} \mathrm{H}_{4} \mathrm{CH}_{3}+\mathrm{CH}_{4} \\
\text { ("Oximato 1") }\end{array}$ & RWT-I-21 & $\begin{array}{r}{ }^{1} \mathrm{H}-\mathrm{NMR} \\
60,90 \mathrm{MHz}\end{array}$ \\
\hline bxime 1" $+\mathrm{Cp}_{2} \mathrm{ZrM}{ }_{2}$ & $\mathrm{Et} 2 \mathrm{O}$ & $\begin{array}{l}\mathrm{CP}_{2} \mathrm{Zr}(\mathrm{Me}) \mathrm{ON}=\mathrm{CHC}_{6} \mathrm{H}_{4} \mathrm{CH}_{3}+\mathrm{CH}_{4} \\
\text { ("Oximato 1") }\end{array}$ & RWT-I-23 & $\begin{array}{r}{ }^{1} \mathrm{H}-\mathrm{NMR} \\
60 \mathrm{MHz}\end{array}$ \\
\hline xime $1 "+C_{p} Z r l$ & $\begin{array}{l}\text { Et2O } \\
\text { a) } \mathrm{RT}, 1 \mathrm{hr} \\
\text { b) }-10^{\circ} \mathrm{C}, \mathrm{ov} \\
\text { c) }-30^{\circ} \mathrm{C}\end{array}$ & $\begin{array}{l}\mathrm{Cp}_{2} \mathrm{Zr}(\mathrm{Me}) \mathrm{ON}=\mathrm{CHC}_{6} \mathrm{H}_{4} \mathrm{CH}+3+\mathrm{CH}_{4} \\
\text { ("Oximato 1") } \\
\text { lernight }\end{array}$ & RWT-1-33 & $\begin{array}{r}\text { 1H-NMR } \\
\text { IR,nujol } \\
\text { (RWT-I-35) }\end{array}$ \\
\hline
\end{tabular}


OXIMATO SYNTHESIS (CONTINUED)

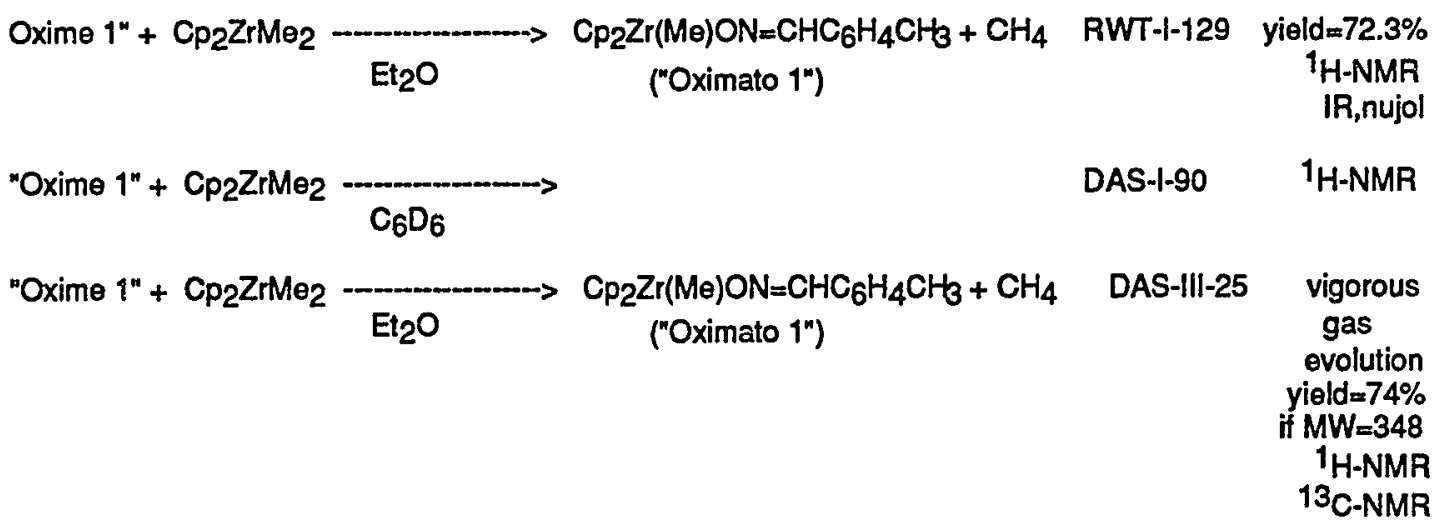

"Oximato 1" + $\mathrm{Cp}_{2} \mathrm{Zr}(\mathrm{Me}) \mathrm{Cl}$-.......... $\mathrm{Cp} 2 \mathrm{Zr}(\mathrm{Cl}) \mathrm{ON}=\mathrm{CH}(p-$ tol $)+$ impurity Diethylether ("Oximato $3^{n}$ )

RECRYSTALLIZE "OXIMATO 1" (RWT-I-133)

"Oxime 1" + Cp2 ZrHCl THF $\mathrm{Cp}_{2} \mathrm{Zr}(\mathrm{Cl}) \mathrm{ON}=\mathrm{CHC}_{6} \mathrm{H}_{4} \mathrm{CH}_{3} \cdot \mathrm{THF}$ ("Oximato $2^{n}$ )

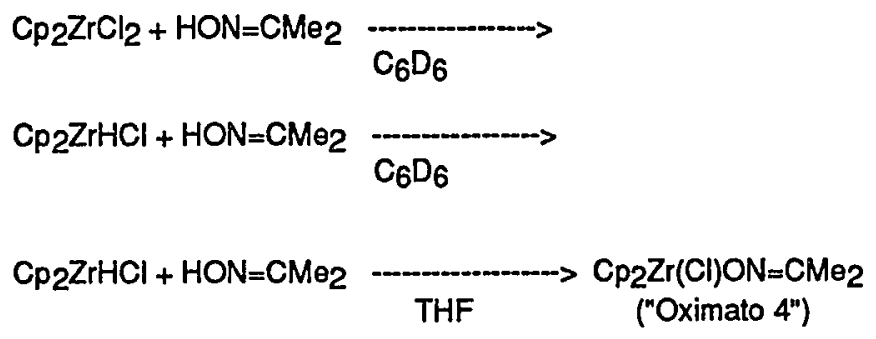

$\mathrm{Cp}_{2} \mathrm{Z} \mathrm{rHCl}+\mathrm{HON}=\mathrm{CMe}_{2}$

THF

DAS-III-31 vigorous gas evolution to clear,colorless solution ${ }^{1} \mathrm{H}$-NMR toluene for prep.?

DAS-III-21 crystals too small for X-ray

DAS-I-1C0 vigorous gas ovolution clear sol'n crystals ${ }^{1}$ H-NMR $\mathrm{CD}_{3} \mathrm{CN}$

DAS-1-96 solubility problem

DAS-1-97 gas evolved white paste' NMR imposs.

DAS-1-99 vigorous gas ovolution white ppt yield $=49 \%$ ACN for rxtl? 1H-NMR

DAS-l-102 yield $=59 \%$ if $M W=328$ 


\section{OXIMATO SYNTHESIS (CONTINUED)}

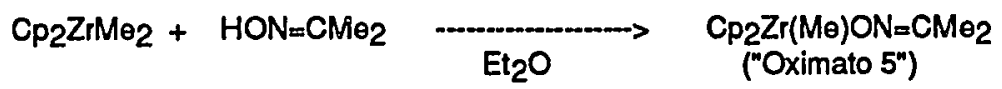

DAS- -105 yield $=74.4 \%$

if $M W=348$

$1_{H-N M R}$

\section{BEACTIVITY OF OXIMATO COMPLEXES.}

"Oximato 1" + Acetopheno
"Oximato 1" + $\mathrm{Cp}_{2} \mathrm{ZrHCl}$

$\mathrm{C}_{6} \mathrm{D}_{6}$

a) $R T, 1 \mathrm{hr}$

b) $100{ }^{\circ} \mathrm{C}$

c) $+\mathrm{CH}_{2} \mathrm{Cl}_{2}$

"Oximato 1" + Naiv(Si(Crig)ziz $-\underset{C_{6} D_{6}}{--.->}$

a) RT

b) heat

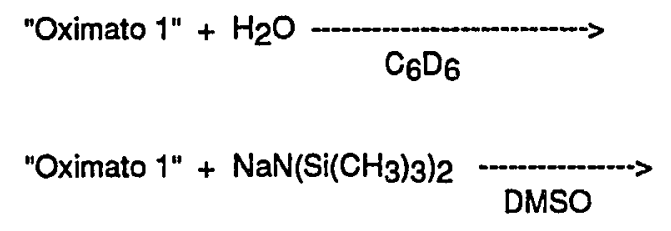

"Oximato 1" + $\mathrm{NaN}\left(\mathrm{Si}\left(\mathrm{CH}_{3}\right)_{3}\right)_{2} \frac{-}{-\mathrm{C}_{6} \mathrm{D}_{6}}$

"Oximato 1" $+\mathrm{KH}-\frac{18 \mathrm{Cr} 6}{\mathrm{THF}}$

"Oximato 2" + $\mathrm{NaN}\left(\mathrm{Si}\left(\mathrm{CH}_{3}\right)_{3}\right)_{2}$

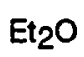

$20 \mathrm{~min}$

"Oximato 1" + $\mathrm{Cp}_{2} \mathrm{ZrHCl}$

$$
\mathrm{C}_{6} \mathrm{D}_{6}
$$

N. R. ?

RWT-1-27

next time try heating

RWT-I-31 a)bubbles, yellow sol'n, ppt. b)deep orange sol'n c) 1 H-NMR unchanged

RWT-1-29 bubbles orange ppt

1H.NMR messy
RWT-1-41 ${ }^{1}$ H-NMR rxn but messy
DAS-I-91 "blood red" on mixing $1_{\text {H-NMR }}$ upfield $\mathrm{Cp}$ ? no ligands?

DAS-1-92 clear intense yellow sol'n messy Cp's downfield phi, $\mathrm{CH}_{3}$ upfield

DAS-1-98 slow gas ovolution heating accelerates yellow paste on evap poor NMR

DAS-1-106 orange-yel solid 1 H-NMR

DAS-I-109 yellowish

1H-NMR 


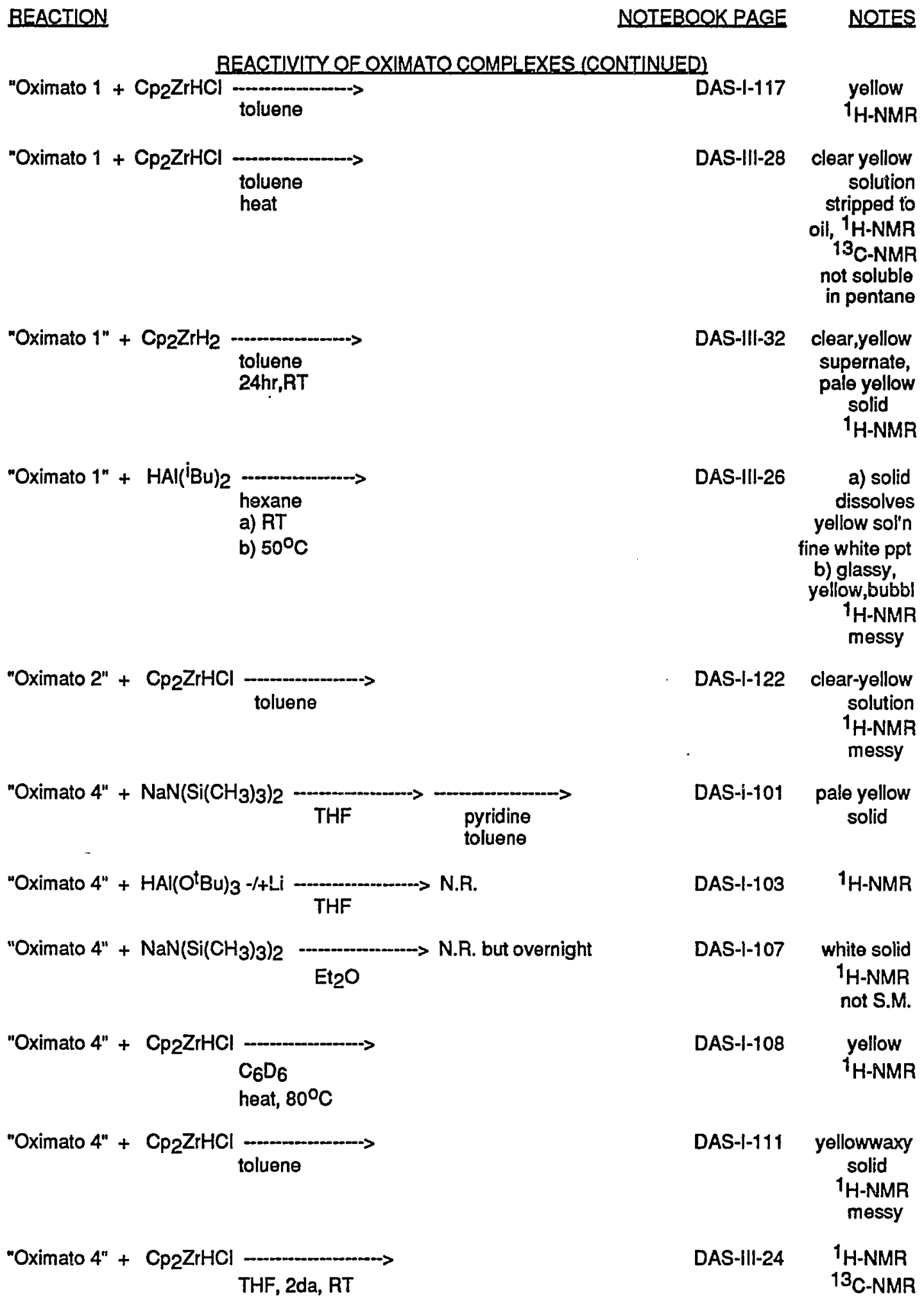




\section{APPENDIX 2}

\section{COMPETITION REACTIONS (Benzaldehyde vs "Compound")} ZIRCONOCENE/BASE REACTION

COMPOUND

A Benzophenone

D

E

$\mathbf{F}$

G

H o-Tolualdehyde

I

J

$\mathbf{K}$

Lp-Nitrobenzaldehyde :
$\mathrm{Et}_{2} \mathrm{O}$

THF

THF

18Crown6

SOLVENT IEMP

REAGENT EXCESS

$-30^{\circ} \mathrm{C}$

$0^{\circ} \mathrm{C}$

${ }^{\circ} \mathrm{C}$

THF $\quad 0^{\circ} \mathrm{C}$

12Crown4

THF

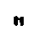

"1

*

n

n

" $0^{\circ} \mathrm{C}$

"

n

$n$

m

$-50^{\circ} \mathrm{C}$
(xs)LiOn-Bu

(xs)LiOn-Bu

(xs)LIOn-Bu

(xs)LiOn-Bu

$\sim 1 / 1 \quad(4.5)$

(xs) KOt-Bu

n

$1 / 1$ (4)

$1 / 1$ (4)

+ base 1st

$\sim 5 / 1(3.5)$

$10 / 1(5)$

PRODUCT\# NOTEBOOK

BATIO REFERENCE

YYIELD)

RWT-11-54

RWT-II-61

fulvene s

fulvenes?

RWT-II-64

fulvenes

RWT-II-66

$15.6: 1$

$(73.1 \%)$

RWT-II-76

$15.4: 1$

(40.9\%)

RWT-II-91

RWT-II-121
$18.97: 1$
$(72.3 \%)$
$10 / 1(4)$

$1: 1.61$

RWT-1I-94

$1.25: 1$

RWT-II-102

$1.03: 1$

(35.0\%)

RWT-II-110

$1.27: 1$ (70.85\%)

RWT-II-128

$\sim 10 / 1(4.5)$

$1: 1.2$ (25.6\%)

RWT-II-137

p-NO2phenylfulvene?

Notes: $\S$ Reagent excess is the ratio of each carbonyl substrate to equivalents of zirconium complex.

\# Product ratio is defined as [alcohol product from benzaldehyde]: [alcohol product from competing substrate]

- Yields are calculated by an internal standard method using p-xylene, biphenyl, or 4,4'-dimethylbiphenyl as necessary to avoid coelution with reaction products. 


\section{APPENDIX 3}

COMPETITION REACTIONS (Benzaldehyde vs "Compound") SEEBACH CONDITIONS

\begin{tabular}{|c|c|c|c|c|c|}
\hline COMPOUND & SQLVENT & IEMP & $\begin{array}{l}\text { REAGENT§ } \\
\text { EXCESS }\end{array}$ & $\frac{\text { PRODUCT }}{\text { BATIO }}$ & $\begin{array}{l}\text { NOTEBOOK } \\
\text { BEEERENCE }\end{array}$ \\
\hline A Acetophenone & $\mathrm{Et}_{2} \mathrm{O}$ & $-30^{\circ} \mathrm{C}$ & $1 / 1$ & $\begin{array}{r}57: 1 \\
(?)\end{array}$ & RWT-I-143 \\
\hline B Benzophenone & $\mathrm{Et2O}$ & $-30^{\circ} \mathrm{C}$ & $1 / 1$ & (?) & RWT-II--11 \\
\hline C & $n$ & $n$ & $\begin{array}{l}2.5 / 1(1.4) \\
(x s) \text { KO Bu }\end{array}$ & $\begin{array}{r}1042: 1 \\
(113 \%)\end{array}$ & RWT-II-146 \\
\hline D & $"$ & $0^{\circ} \mathrm{C}$ & $2.5 / 1$ & $\begin{array}{c}1773: 1 \\
(94 \%)\end{array}$ & RWT-Iil-15 \\
\hline $\mathbf{E}$ & $"$ & $"$ & $2.5 / 1$ & & RWT-III-57 \\
\hline $\mathbf{F}$ & $"$ & $0^{\circ} \mathrm{C}$ & $\stackrel{2 / 1}{"(\mathrm{Ot}-\mathrm{Bu})_{3} \mathrm{ZrMe} \mathrm{r}^{n \Psi}}$ & $\begin{array}{c}140: 1 \\
(17.8 \%)\end{array}$ & RWT-1II-67 \\
\hline $\mathbf{G}$ & $n$ & $0^{\circ} \mathrm{C}$ & $\begin{array}{c}2.5 / 1 \\
"(O t-B u)_{3} Z r M e^{n \Psi}\end{array}$ & $\begin{array}{l}410: 1 \\
(6.5 \%)\end{array}$ & RWT-III-76 \\
\hline H & $n$ & $0^{\circ} \mathrm{C}$ & $\begin{array}{c}2.6 / 1 \\
\left({ }^{\prime \prime}\right)^{y}+(x s) \mathrm{KO} t-\mathrm{Bu}\end{array}$ & $\begin{array}{c}(?) \\
(20.4 \%)\end{array}$ & RWT-III-71 \\
\hline I $p$-Tolualiehyde & $"$ & $-30^{\circ} \mathrm{C}$ & $1 / 1$ & $\begin{array}{r}1: 1 \\
(?)\end{array}$ & RWTT-11-34 \\
\hline$J p$-Anisaldehyde & $"$ & $"$ & $1 / 1$ & $\begin{array}{r}\sim 1: 1 \\
(?)\end{array}$ & RWT-11-39 \\
\hline K o-Tolualdehyde & $n$ & $0^{\circ} \mathrm{C}$ & $1 / 1$ & $\begin{array}{c}1.53: 1 \\
(?)\end{array}$ & RWT-II-104 \\
\hline $\mathbf{L}$ & $n$ & $-50^{\circ} \mathrm{C}$ & $10 / 1$ & $\begin{array}{l}1.27: 1 \\
(58.2 \%)\end{array}$ & RWT-III-133 \\
\hline Ai p-Nitrobenzaldehyde & n & $-50^{\circ} \mathrm{C}$ & $5 / 1$ & inconclusive & RWT-1I-143 \\
\hline N Mesitaldehyde & $"$ & $0^{\circ} \mathrm{C}$ & $\begin{array}{l}2.5 / 1(1.4) \\
\text { (xs)KOBBu }\end{array}$ & $\begin{array}{l}1.99: 1 \\
(69.9 \%)\end{array}$ & RWT-III-5 \\
\hline 0 & $"$ & n & $2.2 / 1$ & $\begin{array}{l}3.51: 1 \\
(131 \%)\end{array}$ & RWT-III-10 \\
\hline
\end{tabular}


Notes: $\S$ Reagent excess is the ratio of each carbonyl substrate to equivalents of zirconium complex.

\# Product ratio is defined as [alcohol product from benzaldehyde]: [alcohol product from competing substrate]

- Yields are calculated by an internal standard method using p-xylene, biphenyl, or 4,4'-dimethylbiphenyl as necessary to avoid coelution with reaction products.

¥ Tri-tert-butoxyzirconiumchloride has recently been purchased to produce trialkoxyzirconium methyl in situ in the Seebach reaction. This and methylpotassium reagent might produce interesting results. 